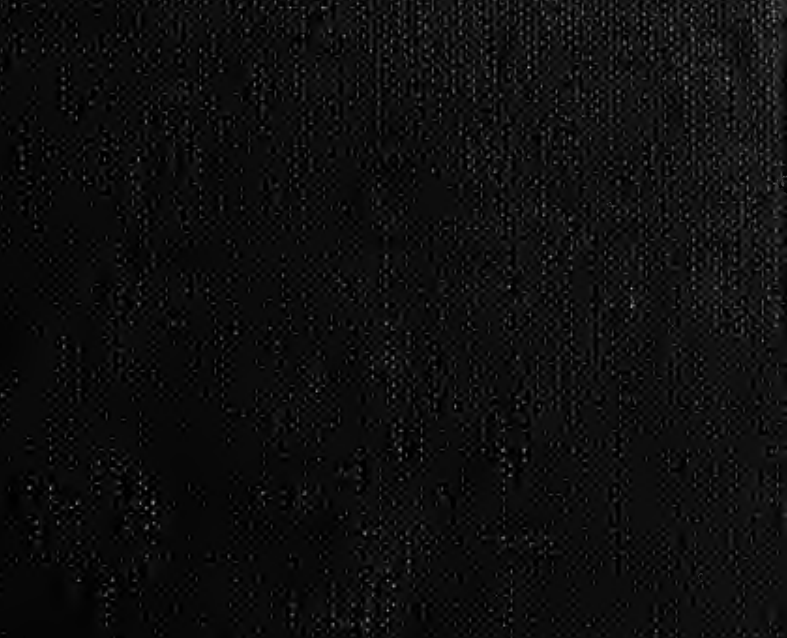

8.20 .8$.

3 


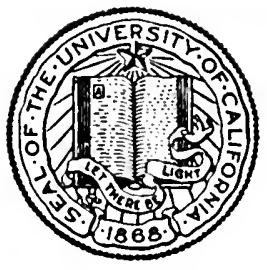

THE LIBRARY OF

THE UNIVERSITY OF CALIFORNIA LOS ANGELES 


$$
\text { ofteren t5. opecter }
$$




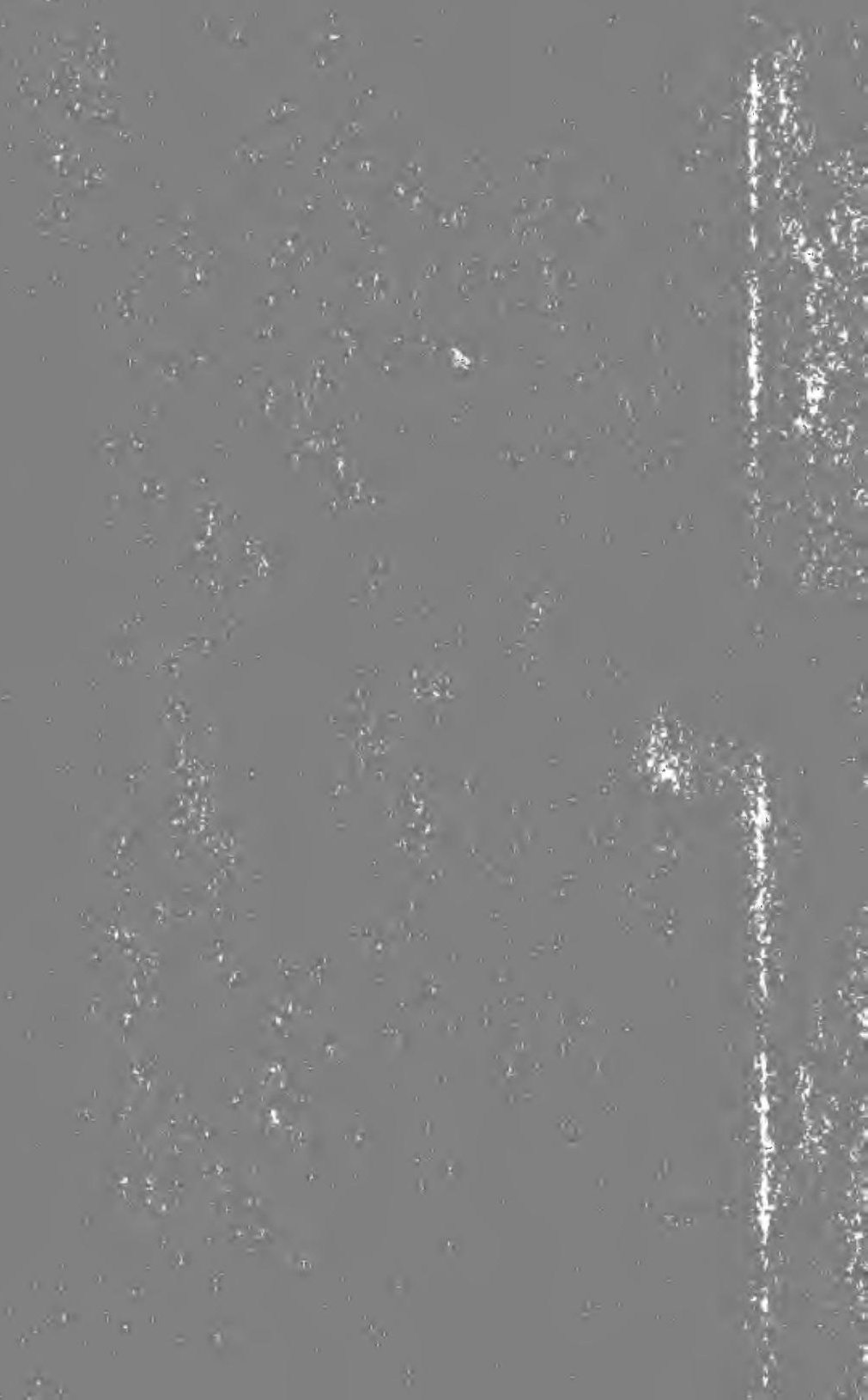




\section{THE PSYCHOLOGY OF SUBNORMAL CHILDREN}




\section{JBitef Course Feries in Education}

EDITED BY

PAUL MONROE, PH.D., LL.D.

BRIEF COURSE IN THE HISTORY OF EDUCATION

Paul Monroe, Director of School of Education, Teachers

College, Columbia University.

BRIEF COURSE IN THE TEACHING PROCESS

George D. Strayer, Ph.D., Professor of Educational Administration, Teachers College, Columbia University.

\section{THE PSYCHOLOGY OF CHILDHOOD}

Naomi Norsworthy, Ph.D., formerly Associate Professor of Educational Psychology, and MARY Theodora WhitLey, Pr.D., Assistant Professor of Education, Teachers College, Columbia University.

\section{DEMOCRACY AND EDUCATION}

John Dewey, Ph.D., LL.D., Professor of Philosophy, Columbia University.

\section{SCHOOL HYGIENE}

Fi.etciler B. Dresslar, Ph.D., Professor of Health Education, George Peabody College for Teachers, Nashville.

PRINCIPLES OF SOCIOLOGY WITH EDUCATIONAL APPLICATIONS

Frederick R. Clow, Ph.D., Teacher in the State Normal School, Oshkosh.

\section{THE PSYCHOLOGY OF SUBNORMAL CHILDREN}

Leta S. Hollingworth, Ph.D., Assistant Professor of Education, Teachers College, Columbia University.

\section{VOCATIONAL EDUCATION}

David Snedden, Ph.D., Professor of Education, Teachers College, Columbia University. 


\section{THE PSYCHOLOGY OF SUBNORMAL CHILDREN}

BY

LETA S. HOLLINGWORTH, Ph.D.

ASSISTANT PROFESSOR OF EDUCATION

TEACHERS COLLEGE; COLUMBIA UNIVERSTTY

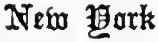

THE MACMILLAN COMPANY

1922

All rights reserved 
Copyright, 1920,

BY THE MACMILLAN COMPANY.

Set up and electrotyped. Published June, 1920.

J. S. Cushing Co. - Berwick \& Smith Co.

Norwood, Mass., U.S.A. 


$$
\begin{aligned}
& \text { Ed./Psych. } \\
& \text { Library } \\
& L B \\
& 1091 \\
& \text { H72 }
\end{aligned}
$$

THIS BOOK

IS DEDICATED TO

\section{ELIZABETH E. FARRELI}

$$
\text { A PIONEER }
$$

IN THE EDUCATIONAL FIELD

OF WHICH IT TREATS 


\section{Digitized by the Internet Archive in 2007 with funding from Microsoft Corporation}


"The influences of the environment are differential, the product varying not only in accord with the environmental force itself, but also in accord with the original nature upon which it operates. We may even expect that education will be doubly effective, once society recognizes the advantages given to some and denied to others by heredity. That men have different amounts of capacity does not imply any the less advantage from or need of wise investment."-EDWARd LeE Thorndike. 
.

\section{.}




\section{PREFACE}

WiTH the growth of the movement to establish special classes for children who are subnormal in intelligence there has grown the demand for teachers who are trained in the psychology and education of such children. It is my hope that this volume, which consists of lectures given for some years past in Teachers College, Columbia University, may in a measure serve the purpose of such teachers. It is addressed primarily to them, rather than to clinicians, for whom the majority of books on this subject have been hitherto especially prepared. The discussion is, therefore, confined largely to the educational psychology of mentally deficient children, with -relatively slight emphasis on methods of identification and diagnosis. The illustrative matter, also, relates to the achievement of defectives, rather than to their clinical features.

There has been a very conscientious effort to base the discussion soundly upon the results of psychological research, as set forth in the references appended. The lists of references are selected, not complete, except in the case of chapters on the psychology of development and learning. On these subjects the purpose has been to refer to all published experimental research bearing directly upon defectives. It is 
unfortunately true that upon many points of interest for pedagogy no scientific data are available, and we have still to rely upon expert opinion and common observation.

It has been my experience that students who have mastered fundamental courses in educational psychology, and in the essentials of biology, profit much more by study of the material herein contained than do those who have not had such previous training. However, the aim has been to present the facts with a minimum of technicality.

As I formulated the book, I became increasingly conscious of what I owe to my years of professional association, first with Dr. M. G. Schlapp, Director of The Clearing House for Mental Defectives, The PostGraduate Hospital, New York City, and later with Dr. Menas S. Gregory, Director of the Psychopathic and Alcoholic Services, Bellevue Hospital, New York City. Also, by way of that unconscious learning from each other which goes on among those long associated in clinical work, I have gained much from my colleagues at Bellevue Hospital, Dr. Melvin J. Taylor, Dr. Theron J. Vosburgh, Dr. E. J. Barnes, and Dr. Stephen P. Jewett.

My thanks are due to Dr. Paul Monroe for editorial supervision of my manuscript.

Leta S. Hollingworth.

Teachers College, Columbia University: 


\section{TABLE OF CON'TENTS}

\section{Preface}

CBAPTER

I. Individual Differences $\cdot$ •

Variability. Children differ greatly in mental capacity. Ratio of feeble-minded to very gifted. Feeble-mindedness as related to sex. Feeble-mindedness as related to race. Feeble-mindedness as related to the environment.

II. The Scientific Study of Mental Defectives .

Why study subnormal children? Proportion of defectives among delinquents. Among alcoholics. Among unmarried mothers. Among prostitutes. Among the unemployed. Among dependents. Cost of anti-social conduct of defectives. Mentally deficient children in the schools. The problems of retardation and elimination. Curriculum supposed to be at fault. Causes inherent in the children. Results of mental surveys. Mental deficiency and truancy. Disciplinary problems. Reasons for studying subnormal children very numerous.

III. The Definition of Mental Deficiency • •

Terminology. Early definitions. Various criteria of mental deficiency. The social-economic criterion. The pedagogical criterion. The medical criterion. The psychological criterion. The classification of mental defectives. "Constitutional inferiority."

IV. Identification

Identification of defectives of low grade. Recognition of milder degrees of subnormality. Necessity for establishing a scientific method of identification. 
Binet's measuring scalc.. The measuring scale of Yerkes, Bridges, and Hardwick. The Stanford Revision of the Binet-Simon Scale. Psychographic methods. Group tests. How a diagnosis is made. The teacher's duty. The school nurse's duty. The physician's duty. The psychologist's duty. The growth of psychological clinics in the United States. The future of the psychological clinic.

V. Are the Defective a Separate Species?

Former assumptions. The search for qualitative differences. Special systems of education devised on the basis of erroneous assumptions. Norsworthy's experiments. Binet's observations. Witmer's conclusions. Other evidence. Implications for education.

VI. "Arrested Development" . . . . .

What does "arrested development" mean? The limits of physical growth. The limits of mental growth. Mental contents of the feeble-minded compared with the mental contents of normal children of equal mental age. Do the defective progress normally to a certain point, and then suffer arrest? How long do the feeble-minded continue to develop mentally? True cases of arrested development. Summary of the facts concerning development.

VII. Are the Feeble-Minded Equally Feeble in All Respects?

Physique. Sensory capacity. Motor control. Instinct and emotion. Intellectual capacities. Is an individual defective uniformly feeble in all his abilities? Unevenness of abilities as shown by intelligence tests. The experiments of Ordahl and Ordahl. Variability in school attainments of children with identical mental ages. Idiots-savants. Implications for education. 
The correlation between physical traits and mental traits. Height and weight. Cranial measurements. Vital capacity. Motor ability. Variability in physical traits. Stigmata of degeneration. Mongolians. Microcephalics. Physical education. Birth rate and mortality.

IX. The Instincts and Emotions of the FeebleMINDED . . . . . . .

General consideration of instinct and emotion. The instinctive and emotional life of the mentally deficient. Analysis of crimes and misdemeanors. Legal responsibility. Moral imbeciles. The moral training of mental defectives.

\section{How do the Mentally Defective Learn? 170}

The learning processs. How do the feeble-minded compare with the normal of equal chronological age? How do the feeble-minded compare with normals of equal mental age? Transfer of training in normal and feeble-minded of equal mental age. The importance of mental age in learning. Mental age not the sole condition of learning. Summary of the psychology of learning in the case of subnormal children. Implications for education.

XI. Can the Mentally Deficient be Made Normal by aNy System of Education? . .

Is it possible to overcome mental deficiency? Can innate capacity for learning be increased? Fallacies based on inadequate experimentation. What can educational treatment do for subnormal children? The nature of improvement in the feeble-minded. Importance of early diagnosis. Ability to learn versus ability to grow. The first recorded experiment in the education of a defective. 
XiI. The Causes and the Prevention of Mental DEFICLENCY

Prevention of mental deficiency must be based on knowledge of its causes. Heredity and variation. Sample studies in the heredity of mental inferiority. Mental defect is inherited. The nature of heredity. Alleged and possible causes of deviation in the direction of subnormality. Alcoholism and other toxic conditions in the parents. Institutional life. Sensory defects. Dental caries and defects of the teeth. Tonsils and adenoids. Malnutrition. Hookworm and malaria. Physical defects in children of normal intelligence. Physical defects in children of very superior intelligence. Physical defects should be corrected for the sake of general health. The prevention of mental deficiency.

\section{Secondary Cases}

Small percentage of mental deficiency due to disease of the nervous system or injury to nervous tissue. Syphilis. Ductless glands. Abnormal growths in the brain. Hydrocephalus. Encephalitis and meningitis. Epilepsy. Infantile cerebral degeneration. Injury to the brain. These causes may act upon any degree of native intelligence. Mental deficiency due to accident and disease not hereditary. Not many secondary cases in public schools.

XIV. Nervous and Mental Disorders which may Complicate Mental Deficiency . • . 253

The subnormal subject to mental and nervous disorders which may affect children in general; not rendered immune by inferior intelligence. Speech defects. Chorea. Hysteria. Dementia Praecox. ManicDepressive Insanity. Other forms of mental and nervous disorder in mental defectives. 


\section{TABLE OF CONTENTS}

\section{Special Classes and Special Schools}

Why have special classes been established? History of special classes for subnormal children in the United States. Organization of special classes. Special schools. Training of teachers for special classes and special schools. Distribution of subnormal children in the grades. Relation between special classes and the psychological clinic. Follow-up work. 


\section{LIST OF ILLUSTRATIONS}

FIGURE

1. Normal distribution of $\mathbf{1 0 0 0}$ individuals, chosen at random, and measured in a given trait. (Schematic.)

2. Actual distribution of 1000 new-born male infants, chosen at random, and measured for length, in centimeters. (From Montague and Hollingworth. Reproduced by courtesy of The American Journal of Sociology.) . • . * • • .

3. Flight of birds, illustrating variability in speed and endurance. (Schematic.) . . . . .

4. Actual distribution of 905 school children, chosen at random, and measured for general intelligence. (From Terman. Reproduced from The Measurement of Intelligence, by permission of and special arrangement with Houghton Mifflin Company.) .

5. Distribution by age of 1000 mental defectives, 568 males and 432 females, presented consecutively for diagnosis; showing inequality of social and economic pressure upon the two sexes. (From Hollingworth. Reproduced by courtesy of William Wood and Company.) • • • • .

6. Showing schematically the erroneous conception of the division between normal and defective, and between normal and genius . . . . .

Curves showing the normal increases in height, in growing children, year by year. (From Baldwin. Reproduced by courtesy of Prof. Bird T. Baldwin.)

8. Curves showing the normal increases in ability to perform the pictorial completion test, year by year, in growing children. (From Pintner and Anderson. Reproduced from The Pictorial Completion Test, by special arrangement with Warwick and York.) . 
FIOURE

9. Ball-and-Field. Reduced one half from standard size. (From the Stanford Revision of the Binet-Simon Scale for Measuring Intelligence. Reproduced by courtesy of Houghton Mifflin Company.)

10. Various degrees of adequacy in response to Ball-andField test, by adults of various degrees of intelligence .

11. Typical record of a defective child's performance on the Stanford-Binet. Showing unevenness of abilities.

12. Psychograph of a feeble-minded adult, showing unevenness of abilities

13. Curves showing the height and weight of feebleminded inmates of American institutions, as compared with normals, age for age. (From Goddard. Reproduced by courtesy of The Journal of Nervous and Mental Disease.)

14. Curves showing the course of learning in a defective child, and in a normal child, of equal birthday age. (From Strong. Reproduced by courtesy of The Psychological Bulletin.) .

15. Curves showing the course of learning in defectives and in normal children, of equal mental age. (From Woodrow. Reproduced by courtesy of The Journal of Educational Psychology.)

16. Writing of feeble-minded individuals, as compared with that of normal children, of equal mental age .

17. Drawings of a house, comparing a feeble-minded adult with a normal child of equal mental age

18. Drawings of a man, comparing a feeble-minded adult with a normal child of equal mental age. .

19. Responses of a feeble-minded man, illustrating the fact that specific training is powerless to raise the level of general intelligence

20. Heredity chart, from the family of "Sam Sixty." (From Kostir. Reproduced by courtesy of The Ohio Board of Administration.) . . . . 215 
21. Facsimile of a letter written by a feeble-minded child with chorea . $. \quad . \quad . \quad . \quad . \quad .258$

22. Motor test and handwriting of a normal child, compared with the motor test and handwriting of a child suffering from chorea . . . . . 260

23. Facsimile of a letter written by a child in the manic phase of manic-depressive insanity . . . . 264

24. Drawing by a child in the manic phase of manic-depressive insanity . $. \quad . \quad . \quad . \quad .265$ 
-

. 


\section{THE PSYCHOLOGY OF SUBNORMAL CHILDREN}

\section{CHAPTER I}

\section{INDIVIDUAL DIFFERENCES}

This volume discusses the psychology and educational treatment of intellectually subnormal children. What concept have we of subnormality in children? What is a subnormal child? To speak of subnormal children implies at once the existence of normal or average children, for to be subnormal one must be so with respect to some norm or standard. Thus thought will be clarified by devoting a little time to a consideration of normality. What is a normal or standard child?

Variability. In psychological research we find that if a large number of individuals, selected at random, are measured or appraised in any given trait, either mental or physical, about half of them will fall within certain very narrow limits; while the remaining half will distribute themselves about equally on either side. Furthermore, the farther we go from the confines of the middle fifty percent in either direction, the fewer become the individuals who fall there. 


\section{PSYCHOLOGY OF SUBNORMAL CHILDREN}

So that when we have finished measuring a thousand persons, and have tabulated and platted the measurements, we find that we have a curve approximately like this:

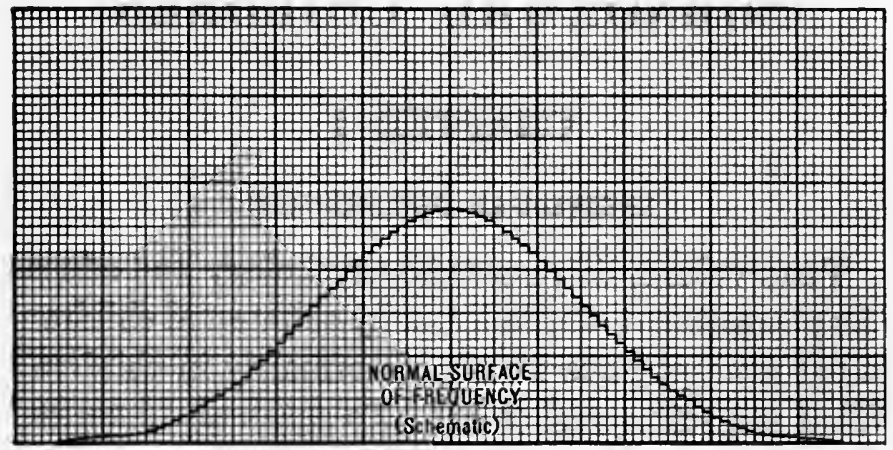

FIg. 1. - Normal distribution of 1000 individuals, chosen at random, and measured in a given mental or physical trait. (Schematic).

A concrete illustration will make this entirely clear. It is easier to think of this matter in terms of physical traits at first, because we can easily verify for ourselves the statement that human beings differ widely from each other in physical traits. No two human beings look exactly alike. Therefore, suppose we measure one thousand new-born infants in length, taking the measurement to a centimeter. We shall obtain a table like that on the following page.

About half of the infants measure between 49 and 52 centimeters, with all the remainder tapering off on either side toward two extremes. As the infants become shorter they also become fewer, until we 
find that only one infant is as short as 38 centimeters. And similarly, as the infants become longer they also become fewer, until at the length 62 centimeters we find only one infant. If we plat a distribution curve showing these facts graphically, it looks like this:

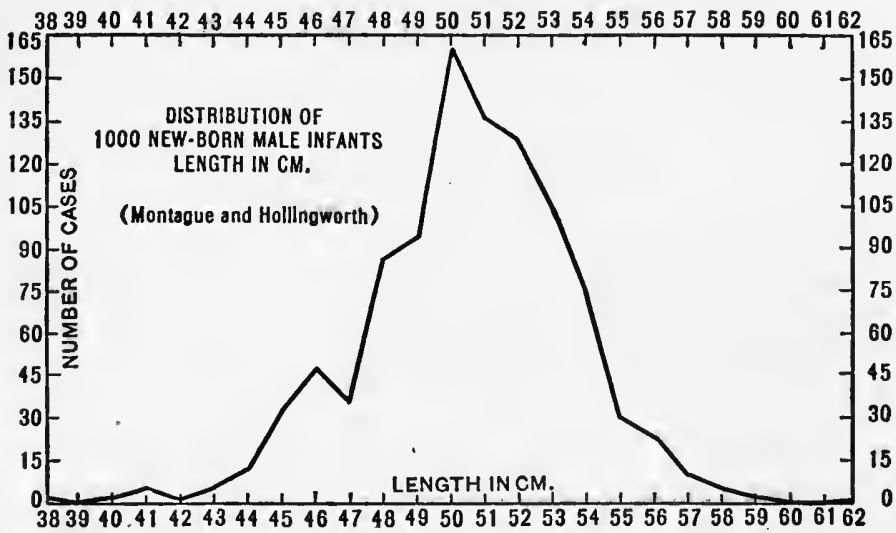

Fig. 2. - Actual distribution of 1000 new-born male infants, chosen at random, and measured for length in centimeters. (From Montague and Hollingworth. Reproduced by courtesy of The American Journal of Sociology.)

Length (in Centimeters) of Infants at Birth

\begin{tabular}{c|c||c|c|c|c}
\hline \hline Centimeters & Frequency & Centimeters & Frequencr & Centimeters & Frequenct \\
\cline { 2 - 4 } 38 & 1 & 47 & 40 & 56 & 24 \\
39 & 0 & 48 & 87 & 57 & 10 \\
40 & 1 & 49 & 96 & 58 & 5 \\
41 & 5 & 50 & 158 & 59 & 2 \\
42 & 2 & 51 & 136 & 60 & 0 \\
43 & 5 & 52 & 130 & 61 & 0 \\
44 & 10 & 53 & 103 & 62 & 1 \\
45 & 32 & 54 & 75 & & \\
46 & 47 & 55 & 30 & & \\
\hline
\end{tabular}


The same scientific law is illustrated in the flight of large flocks of certain kinds of homing birds. Notice a flock of birds going south in autumn. The flock looks like this:

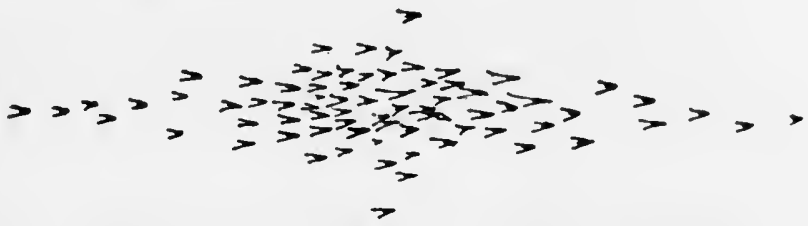

FIG. 3. - Flight of birds, illustrating variability in speed and endurance. (Schematic.)

This is, of course, simply the curve of distribution. The birds are not all equally swift, and are distributed by the test of their flight with respect to speed and endurance. About half of them are what would be called average in speed and endurance. They fly massed in the center, approximately together. But some are swifter; and one is swifter than any of his fellows, and leads the flock. On the other hand, some are slower than the average; and one or two are so slow that they scarcely can keep the others in sight at all.

Those forming the central mass are the standard or normal birds. Those ranging on each end toward the two extremes are the exceptional birds. Normality, by definition, is what the greatest number of individuals can do. The birds who fly far behind might be designated the subnormal birds.

It is noticeable, too, that no two birds are exactly 
alike in ability to fly. If we could measure this ability to a millimeter, we should find them all differing more or less among themselves in distance from their goal.

These phenomena hold throughout organic nature, and the study of them is called the study of individual differences. When the traits involved are mental, we speak of the psychology of individual differences. It is one of the marvelous facts about human beings that of all the millions in the world no two are exactly alike in any given trait, save occasionally by chance. Not even twins are exactly alike. In twins who very closely resemble each other, mentally and physically, differences will appear if they are seen together. Human beings differ widely in physical characteristics, but they differ far more in mental traits. These myriad dissimilarities are mainly due to the operation of the relatively unknown laws of heredity and variation, upon which biologists and psychologists are at present spending much of their research time.

Children Vary Greatly in Mental Capacity. The interesting fact for us is that children do vary greatly in mental traits; that they differ widely in intellectual ability, by nature; and that a small proportion of them are extremely different from the average or norm. Those who deviate from the norm in the direction of inferiority, we call the subnormal children. They are to be the objects of special study here. 
It is true that a child may be subnormal in any one of many different respects. He may be below the average in emotional control, or in moral sense, or in a special function such as adding, subtracting, spelling, reading, or music. This volume does not attempt to treat fully all these various kinds of subnormality. About some of them very little is known. The discussion here is limited primarily to subnormality in general intelligence. We shall study the psychology of the feeble-minded and the dull, for whom special classes have been established now in many school systems.

Dr. Terman has shown in his recent monograph how children are distributed with respect to general intelligence. The curve shows the same laws as those shown in physical traits. The majority of children cluster around a median point in mental ability. By gradual degrees they approach the idiot at the low extreme, and the genius at the high extreme. The curve is as shown in Figure 4.

Wherever we find a large unselected group of children, such as is represented in a public school system in the West or Middle West in the United States, where all the children except a few idiots and a few physical invalids are in school, this is what we find. If we measure the general intelligence of all the school children, we obtain Terman's curve of distribution. Most of the children are normal (average), for normal in the psychological sense means, by 
definition, what the majority can do. About two percent of them will fall so low on the curve that we call them feeble-minded. Just above them, and continuous with them in mental ability, are the dull and inferior, who in turn merge with the normal. At the other extreme, about two percent of the children will

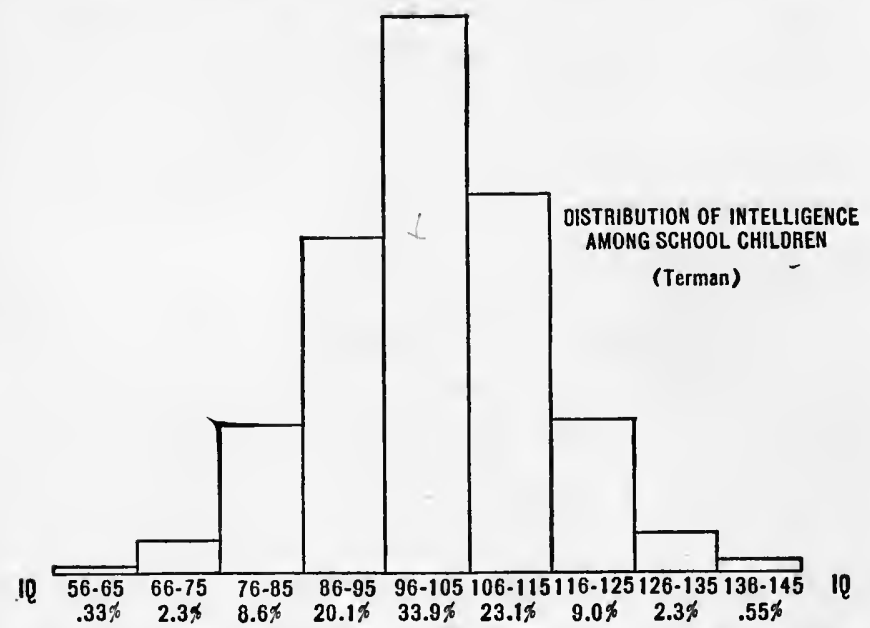

FIg. 4. - Actual distribution of 905 school children, choson at random and measured for general intelligence. (From Terman. Reproduced from The Measurement of Intelligence, by permission of, and special arrangement with, Houghton Mifflin Company.)

fall so far above the average that they can progress through school approximately twice as fast as can the average child.

Let us note again what was said previously, - that children differ far more in mental traits than they do in physical traits. The tallest child of a given age is not more than twice as tall as the shortest child, 
among ten thousand. The longest infant in a thousand is not quite twice as long as the shortest infant. But the most intelligent child among ten thousand is many times as capable as is the dullest. It is possible to find children whose intelligence is approximately zero, - vegetative idiots; and to find, on the other hand, children whose intelligence measures 180 or more, as compared with the average of 100 . Two children, one boy and one girl, of more than 180 intelligence quotient have been found in recent years in the Horace Mann School. Miss Coy furnishes us with an account of the school career of a girl whose intelligence quotient is given as 167 . Thus in mental traits there is great variability.

A Few More Will Be Found among the FeebleMinded than among the Very Gifted. It is true that if we included not only school children in our measurement of the juvenile population, but all children born into the community under consideration, we should find our curve slightly weighted at the lower end. This would be the case because disease and accident can operate to reduce a mentality that was potentially normal or superior. But we know of no external influence that can operate to raise a low or mediocre mentality to higher levels. A small percentage of feeble-mindedness is caused by pathological conditions which affect the nervous system. This matter will be discussed more fully in a subsequent chapter. For the present we shall merely state 
that the great majority of subnormal children result just as the mediocre and the superior result, from the operation of the laws of heredity and variation. Our concern is with those unfortunate deviates, who fall at the extreme lower end of the distribution curve for greneral intelligence.

Feeble-Mindedness as Related to Sex. It has sometimes been stated that there are more feebleminded boys than feeble-minded girls. This statement has been based on erroneous inferences, from the statistics of institutions for the detention of the feeble-minded. These statistics nearly always show that there are more males than females among inmates. The following figures, taken from Dr. Kuhlmann's researches, are fair samples:

1. Results of 1915 Questionnaire, returned from seven states:

In Institutions for the Feeble-Minded

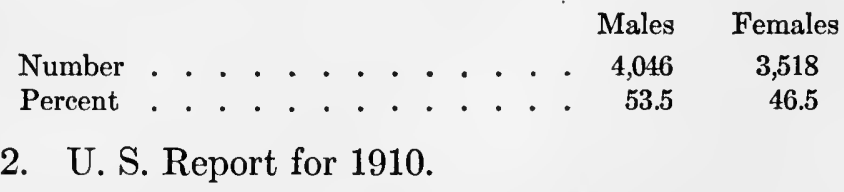

In Institutions for the Feeble-Minded

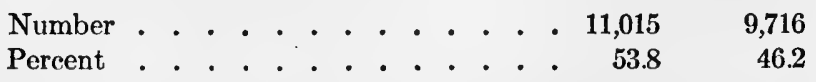

It is true that institutional statistics almost invariably show more males than females detained as feeble-minded. It would, however, be unscientific 
to conclude from such data that there are more feeble-minded males in the population at large; that more feeble-minded males are born. Institutional statistics may be merely an index of the degree to which it is easier for one sex to survive outside of institutions, than it is for the other.

That such is indeed the case is well shown by a research made at the Clearing House for Mental Defectives, in New York City, in 1913. One thousand consecutive cases of intellectual defect were taken from the files of this institution. In all cases the chronological age and the intellectual status (mental age) were carefully noted. Of the 1000 individuals thus tabulated, 568 were males and 432 were females. Of individuals brought for diagnosis before they were sixteen years old, 490 were males and 273 were females. Of individuals brought after they were sixteen years old, 78 were males and 159 were females. Of individuals over thirty years of age there were three times as many females as males. These facts are shown graphically in Figure 5.

The research also showed that the males brought to this clinic for diagnosis and commitment were of distinctly higher mental status, age for age, than were the females. The figures proved, for instance, that a girl or woman with a mental age of six years survives outside of institutions about as well as does a boy or man with a mental age of ten or eleven years. 
The reason for this state of affairs is not far to seek. To interpret the facts we have but to reflect on our social organization. Women and girls as a class do not follow competitive careers. The work of

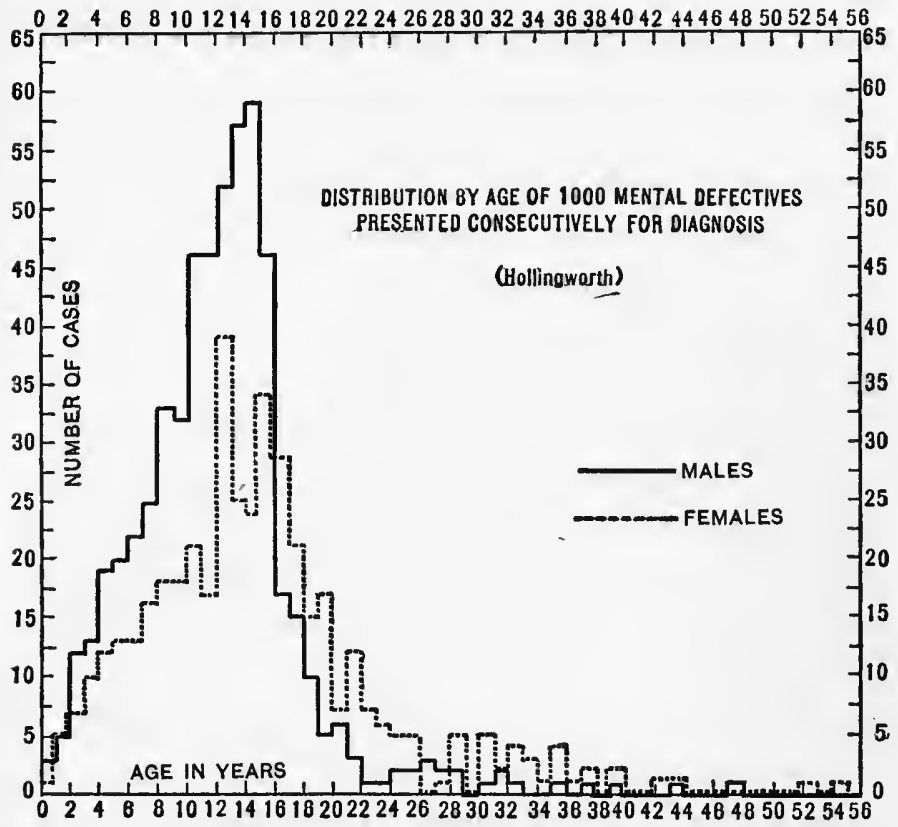

Frg. 5. - Distribution by age of 1000 mental defectives, 568 males and 432 females, presented consecutively for diagnosis ; showing inequality of social and economic pressure upon the two sexes. (From Hollingworth. Reproduced by courtesy of William Wood and Company.)

the majority is in the house, domestic service and child-bearing, performed in isolation, and not in competition with others for a wage. Moreover, in our society, sex as such may be a commercial asset to 
girls and women, opening to them ways in which they may survive without much regard to intellectual status. The various psychological studies of prostitutes make this fact clear beyond a doubt.

Men, on the other hand, form a highly competitive class, working in rivalry with each other for a wage. The boy who cannot compete becomes an object of concern, is brought to the clinic, and is directed toward an appropriate institution. The girl who cannot compete is not so often recognized as defective, since it is not unnatural for her to drop into the noncompetitive life of the home, where she can "take care of " small children, peel potatoes, scrub, and perform other routine household tasks. If physically passable, as is often the case, she may marry, thus fastening herself to economic support. Indeed, it is not at all uncommon for the ignorant parents of a feeble-minded girl to object strenuously to her commitment, on the grounds that she already has "a nice fellow," and will soon marry. Social and economic pressure bears very unequally upon the sexes in the matter of commitment to institutions for the feeble-minded.

The reports made by inspectors of ungraded classes also nearly always show more boys than girls in such classes. For example, in a recent survey of the ungraded classes of the Bronx, in New York City, there were found 258 boys and 103 girls on the register. The inspector, however, does not fall into the error 
of concluding that this means more feeble-minded boys than girls in the schools at large. She says, "The fact that more boys than girls are found in these ungraded classes permits of explanation other than that of greater variability in males. One of these is based on the fact that boys have greater freedom, are less restrained than girls. Because of this, they come into conflict with their school environment. This maladjustment makes it imperative that some notice be given to them, and some explanation sought."

Dr. Sylvester makes the same general observation, in discussing the fact that more boys than girls are found in ungraded classes in Philadelphia. He says, "Sex distribution is of little importance. For reasons not of interest here, a relatively small number of girls are placed in the special backward classes. It is a matter of observation confirmed by these results (in mental tests), that the girls of these classes, as a group, are more backward than the boys. ... Obviously the girls of a mental grade corresponding to the brighter boys in the backward classes were left in the regular classes."

Dr. Terman found that when pupils are measured at random, in a wholly objective way, by means of mental tests, there is no sex difference in numbers of feeble-minded identified.

The conclusion, therefore, is that there are as many feeble-minded girls as boys in the schools, but 
that the former are not so frequently selected for ungraded classes, where subjective judgment enters at all into the choice. The subjective standard of what constitutes normal intelligence is apparently lower for girls than it is for boys.

Feeble-Mindedness as Related to Race. The few investigations which have been made in the matter of race differences in intelligence have indicated that, on the whole, Indian and negro children have a somewhat lower average intelligence than do white children. This would mean, then, that a greater proportion of negro or Indian children would be far behind the norms in mixed communities, than would be the case with white children. A greater percentage of negroes and Indians would find their way into the ungraded classes, where the norms of performance are determined or partially determined by whites. White children of various nationalities seem to be very much alike in respect to the proportion of feeble-minded among them. Mental tests seem, on the whole, to give about the same results when used on English, German, Russian, and Italian children. A great many more comparative studies of races will be necessary before absolutely conclusive statements can be made on the subject. It may be that a comparison of the black race and the white race, based on negroes found in the United States, is misleading, for we cannot be sure that their ancestors formed a wholly unselected sampling of negroes. 
Possibly those who could be caught and led into slavery were on the average more stupid than those who were not caught. If this were true, a comparison between the white race and the black race, based on negroes found in the United States, would be as misleading as a comparison of native Americans with Italians or Portuguese found in the United States.

Feeble-Mindedness as Related to the Environment. It is quite true that we find inferior children originating most often in inferior homes. The majority of the feeble-minded come from families with inferior incomes, living in an inferior environment. It is very easy to misinterpret this state of affairs, and to infer that the low-grade environment is the cause of the children's inferiority. It has even been suggested that we should obtain norms for the various social classes, as though all could not be related to one norm for the population chosen at random. If carried out to its logical conclusion, this would mean that by measuring the inmates of schools for the feeble-minded, we might obtain a norm which would be applicable to such inmates, on the basis of which they could then be classified as "normal"!

The most reasonable interpretation of the relationship which is found between feeble-mindedness and low-grade environment is that the former is the cause of the latter. Feeble-minded parents produce feebleminded children, and they also maintain inferior homes. 


\section{ReFerences}

1. Hollingworth, L. S., The Frequency of Amentia as Related to Sex. Medical Record. Oct., 1913.

2. Kuhlmann, F., The Part Played by the State Institutions in the Care of the Feeble-Minded. Journal of Psycho-Asthenics. Sept. and Dec., 1916.

3. Montague, H., and Hollingworth, L. S., The Comparative Variability of the Sexes at Birth. American Journal of Sociology. Nov., 1914.

4. Morse, J., A Comparison of White and Colored Children Measured by the Binet-Simon Scale of Intelligence. Popular Science Monthly. 1914.

5. Phillips, B. A., The Binet Tests Applied to Colored Children. Psychological Clinic. 1914.

6. Report on the Mental Examination of Certain Pupils in the Thomas Indian School, Iroquois, N. Y. Eugenies and Social Welfare Bulletin No. XI. Bureau of Analysis and Investigation, State Board of Charities. Albany, N. Y.

7. Reports on Special Classes. Nineteenth Annual Report. Sex Distribution of Children in Ungraded Classes in the Bronx. Department of Education. New York City, 1916-17.

8. Rowe, E. C., Five Hundred and Forty-Seven White, and Two Hundred and Sixty-Eight Indian Children Tested by the Binet-Simon Tests. Pedagogical Seminary. 1914.

9. Strong, A. C., Three Hundred and Fifty White and Colored Children Measured by the Binet-Simon Measuring Scale of Intelligence. Pedagogical Seminary. 1913.

10. Sunne, D., A Comparative Study of White and Negro Children. Journal of Applied Psychology. 1917.

11. Sylvester, R., The Form Board. Psychological Monographs. Volume XV, No. 4. Sept., 1913.

12. Terman, L. M., Sex Differences. The Relation of Intelligence to Social Status. (Stanford Revision and Extension of the Binet-Simon Scale for Measuring Intelligence.) Warwick and York. Baltimore. 1917.

13. Thorndike, E. L., Individuality. Houghton Mifflin Company. New York. 1911.

14. Whipple, G. M., Classes for Gifted Children. Public School Publishing Co.. Bloomington, Ill. 1919. 


\section{CHAPTER II}

THE SCIENTIFIC STUDY OF MENTAL DEFECTIVES

What Reasons Have Educators and Society at Large for Studying Subnormal Children? Let us reflect for a moment upon the significance of such children for the social life of their day, and for the future history of civilization. We have our distribution curve, representing, let us say, the intelligence of all adults at any given time. We have the average, the majority of mankind, working along and conserving the traditions of the race. They live with average ability and in average happiness. They present no special problem. They determine the normal life of their time by sheer force of numbers. They tend neither to degenerate, nor to advance markedly beyond traditions.

At the extremely low end of our curve we have the undesirable and unfortunate deviates, the dull, the subnormal. They constitute a great burden, economically and socially. They tend to draw the whole mass of mankind downward. This influence works in a great variety of ways. By intermarriage with the more intelligent, the subnormals tend to degrade all the social body. By marrying or cohabiting 
among themselves they produce a numerous offspring, and increase the financial burden on public and private charity. Psychologists working in penal institutions and courts have shown conclusively that crime and delinquency of all kinds are closely related to mental subnormality. Alcoholism is closely bound up with mental deficiency, many feebleminded persons being chronic drunkards. Disease easily originates among the unintelligent, and is spread broadcast by them. The problem of the unmarried mother is to be understood more clearly in the light of mental inferiority. Since subnormal children grow up into subnormal adults, there is certainly sufficient reason here for studying them.

The Proportion of Mentally Deficient among Delinquents Is Very Great. In California, where the problem of subnormality has been studied by psychologists and educators with special care, it is stated that on the most conservative reckoning, more than twenty-five percent of the inmates of reform schools are feeble-minded; that the proportion is fully as high among those brought into the juvenile courts; and that a fourth, at least, of the convicts in the prison of St. Quentin are either defective or just above definite deficiency. In New York, psychologists give the percentage of feeble-minded in reformatories and prisons as approximately twenty-five percent. In the Bedford Reformatory for Women about a fourth of the inmates were found to be feeble- 
minded; in Auburn Prison the same proportion; and in the Westchester County Penitentiary the percentage rises to one third.

In Illinois, the figures are about the same. It would be merely wearisome to multiply statistics. As psychological investigation progresses, the problem is shown to be nation-wide; indeed, world-wide. There is no longer any question of the fact that delinquency and mental subnormality are causally related.

Alcoholics Are Often Mentally Deficient. The problem of chronic alcoholism, which has always been such a burden on society, is much more clearly seen when viewed in the light of psychological data. Dr. V. V. Anderson found that of one hundred drunken women a large proportion were not of normal mentality. Dr. H. H. Goddard has laid stress on feeble-mindedness as a cause of alcoholism. The present writer has seen how great a part low intelligence plays in filling the alcoholic wards of Bellevue Hospital, in New York City. To study subnormal children is therefore to study, in some measure, the problem of alcoholism.

There Are Many Feeble-Minded Women among Unmarried Mothers. Dr. Jean Weidensall has reported the percentage of mental defectives among an unselected series of the unmarried mothers, from the obstetrical service of the Cincinnati General Hospital. The mental examination of these women 
showed that between 54 percent and 58 percent of them were definitely feeble-minded. "From 40 to 45 percent of the unmarried mothers are almost without question so low-grade mentally as to make life under institution care the only happy one for themselves, and the most economical and the only safe arrangement for society." The findings of Dr. Grace Fernald in California are in harmony with these results. The illegitimate child is very frequently the offspring of a feeble-minded mother.

Many Prostitutes Are Feeble-Minded. Studies made at Bedford Reformatory, in New York, by the New York Probation and Protective Association, at the Magdalen Home in New York City, and in other places prove that there are many mentally defective prostitutes. The proportion among the girls who are detained in these institutions does not, of course, fairly represent the proportion of feeble-minded among prostitutes in general, for only the more stupid are likely to be apprehended. The brightest are not available for mental examination. Nevertheless, it is quite evident that prostitution gains hundreds of recruits annually from the numbers of the intellectually subnormal.

Chronic Unemployment Is Often Due to Mental Deficiency. Tests of one hundred and fifty migrating, unemployed men, commonly called "hoboes," who passed through Palo Alto, California, in the spring of 1915, gave a proportion of feeble-minded- 
ness as high as that found among convicts. Of unemployed men who came for shelter to the Municipal Lodging House in New York City during the winter of 1914, one in every eight was shown by mental tests to be definitely feeble-minded. No record was kept of the number who tested just above the border-line, but the number must have been very great. One of the commonest complaints made of feeble-minded individuals, in reply to the question, "Why do you bring him here?" is, "He cannot hold a job."

The Cost of All This Anti-Social Conduct Is Very Heavy. Dr. Terman estimates that feebleminded criminals and misdemeanants cost California annually about $\$ 2,000,000$. "When there is added to this the loss accruing from the part played by feeble-mindedness in alcoholism, pauperism, prostitution, and disease, it is reasonable to conclude that the mentally defective inhabitants of California entail a burden upon the state in excess of $\$ 5,000,000$ a year."

The State Commission of Prisons of New York estimates that it costs $\$ 1,000$ to detain, indict, try, and dispose of the average felon. In the year 1917, 2,279 felons were received into the State prisons, costing the public treasury $\$ 2,279,000$. Of these individuals eighty-seven percent had served previous terms. By their release into the community, and their return to their former habits, the State had to spend about $\$ 2,000,000$ to dispose of them again. 
Each time this great group of repeaters has to be retried, the same great amount of money must be expended again.

What California and New York spend is not more than has to be spent by other states. The burden is, however, not only financial. Misery and disease are generated by the mentally defective. Normal persons are often the victims of their crimes. Normal persons are contaminated by the diseases which they carry. Nothing can be more certain than that low-grade intelligence constitutes one of the heaviest social burdens with which we have to reckon.

Nearly All of the Mentally Defective Pass, as Children, through the Schools. Under our compulsory school laws all except the lowest grade of feebleminded come under the supervision of the teachers. The defective paupers, criminals, unmarried mothers, alcoholics, prostitutes, hoboes all have school histories. When these histories are elicited, it is found that they were the chronically "left back," the truants, the disciplinary problems. Typically they drift through school as repeaters, till at the age of sixteen years they have reached the 5 th or 6 th grade. They then drop out, being no longer within the limits of compulsory school age. Young adults, who have passed through school since ungraded classes have been established, sometimes have a history of having attended these classes. All subnormal individuals should be identified and studied while yet they are 
children, in order that they may be trained in useful specific habits up to the limits of capacity; and in order that those who are incapable of any social adjustment may be protected from miserable and delinquent careers. We must discover the subnormal child, who is potentially a social menace.

Dr. Glueck, of Sing Sing Prison, reproaches educators for their failure to identify and study those defective children who later, as adults, became inmates there. He says:

"Whatever justification there may have been for the indifference displayed toward the many deviations from average normal behavior, which so many of these individuals manifested in their parental homes, surely the failure to appreciate these indications of a pathological state during their contact with the public school cannot be easily condoned.... At any rate from the biologist's point of view, education should have for its object primarily the fitting of the individual for proper living, and in this respect our school system has singularly failed, as far as these cases are concerned. Not that we believe that any large number of these ninety-eight defectives could have been restored to normality, but we do insist that in a great many instances they gave highly suggestive, if not unmistakable, evidence during their school life of being incapable of proper adjustment under ordinary conditions of life, and that some provision should have been made for placing them in a more appropriate environment.

"Aside from the fact that nine never reached beyond the third grade, that five never reached beyond the fourth grade, and that twelve never reached beyond the fifth grade, many traits came to light which should have been properly evaluated. Thus, backwardness and inability to learn, which necessitated repetition of classes on one or more occasions, was manifested in thirty-four instances; excessive truancy in twenty-one instances; incorrigibility in five; extremely irregular attendance in eight; inability to get along socially in five; extreme dislike for studies in eleven; one case terminated in expulsion, and a number of them had to be 
transferred to reformatory institutions direct from school. In four instances school attendance was begun after the age of ten had been reached.

"If there has been no opportunity thus far to demonstrate clearly the beneficent results of a rational administration of problems of juvenile maladjustment, because a rational approach to this problem has been in vogue only during very recent years, the facts brought out in this study ought to emphasize sufficiently the extreme danger involved in an indifferent approach to such problems."

Dr. George Ordahl, psychologist of the Sonoma State Home in California, lays great stress on the desirability of a system of studying children "which would insure the detection, in the first ten years of life, of children who are certain to become wards of the state later in life, and who, if not detected at this early period, will reproduce their kind and otherwise become a burden to society."

For About Ten Years Educators Have Been Studying Retardation in the Schools. In 1909 Dr. Leonard P. Ayres made an elaborate study of educational retardation in the public schools of this country. He found an astonishingly large percentage of pupils below normal in school status. Hundreds of children were failing to make a grade a year. In every school system studied there were found to be many children older for their grades than they should have been. In his report Ayres said:

"These children constitute serious problems for the teachers. They are misfits in the classes, require special attention, and render more difficult the work with other children." 
Sixteen percent of the children in the systems studied were "repeaters," that is, were doing the work of the grade for the second or third time.

"This means that in the country as a whole, about one-sixth of all the children are repeating, and we are annually spending about $\$ 27,000,000$ in this wasteful process in our cities alone."

Many Educators Inferred That This Great Amount of Retardation Was Due to Faults in the Curriculum. As soon as the statistics of retardation and elimination, which were collected all over the country after Ayres' study was published, became known among educators, the search for the causes of the condition began. In this search the curriculum was first attacked. It was believed that if a new curriculum could be devised and established, retardation and climination would cease to be school problems. This approach was, however, not very fruitful in results, except where the device of the differentiated curriculum was tried. So long as a single curriculum was offered for all pupils, retardation and elimination continued to be problems. No curriculum has ever been. found that will eliminate these problems, if it is applied impartially to all children attending school. The desired result was achieved only when different curricula were applied to different pupils.

The Causes of Retardation and Elimination Are Usually Inherent in the Children Themselves. While the curriculum was being examined and overhauled, studies of the mental, physical and social 
condition of school children were undertaken. These revealed to what an extent retardation and elimination are due to the condition of the children, rather than to the course of study itself. They showed why only the differentiated curriculum is effective in solving these problems.

The causes of educational retardation are various. Some of the children fail of promotion because they have been out for months or a year through accident or severe illness. Others are old for their grade because they made a late entrance into school. Others are handicapped by some defect of the special senses. Others are lazy or mischievous. Still others suffer from chronic physical ailments, such as tuberculosis, hookworm, or anaemia, which interfere with normal. school progress. Speech defects hold a certain number back. Some are neurotic, or insane, or suffer from epilepsy. Some fail in only one special kind of work, such as spelling, arithmetic, or reading. But the most important single factor in chronic failure in school work is weakness in general intelligence, usually termed mental deficiency or feeble-mindedness.

In the last decade, since Goddard translated the work of Binet, and introduced the use of his measuring scale at Vineland, psychological examination has shown over and over again that about two percent of school children are so weak mentally as to be inherently incapable of profiting by the work of the regu- 
lar grades. These would be classified as definitely feeble-minded. Just a little higher on the scale we have the very dull, the inferior, the stupid, who also tend to fall behind the grade. These children fail because they are by original nature incapable of doing what the average child can do. They will fail to achieve a satisfactory rating in the pursuit of any curriculum which is adapted to the abilities of the majority.

Educators Should Examine the Results of Various Mental Surveys. Among the first of these surveys was that by Dr. Goddard. He measured two thousand school children by a standardized test, and found that about two percent of them fell so far below the norms for the group that it was unreasonable to suppose that they could even approximately compete with their fellows in school pursuits. Dr. Terman in his examination of one thousand unselected school children arrived at substantially the same result. Subsequent surveys, when scientifically conducted, have verified this conclusion repeatedly. Surveys have been made, it is true, which found less than one percent feeble-minded, but these are the work of untrained examiners, who modified the standard tests in such a way as to render them useless for the purpose, or who improvised methods of examination, with no understanding of the fundamental principles involved. The commonest error of amateur investigators is that they unconsciously 
modify the methods of psychological examination in such a way as materially to lower the norms of performance, and thus to include as normal many feebleminded children. Where the scientific methods of identification have been understood and used, the result has been that about two percent of school children are so far below the average as to be considered definitely feeble-minded.

It should be added that when selected groups are examined, the two percent for the school population chosen at random does not remain fixed. Dr. Pyle, for example, has found that in the rural schools of Missouri the percentage is greater than this. In public schools which are located in high-class residential districts in cities, the percentage is smaller. The two percent holds only for unselected school children.

Mental Deficiency Leads to Truancy. Under our compulsory school laws every child between certain specified ages, usually six to fourteen years, must be in school if physically and mentally able to attend. So far as mentality is concerned, the practical effect of the law is that all children above the grade of idiot come to school. Thus there are many who are feebleminded, who are by nature forever incapable of attaining to the level of performance set by the majority as the standard, in attendance upon the public schools. Furthermore, it is in many schools a custom, and in others a formal rule, that no child may be held back in the same grade more than two years. 
It is obvious that such laws and rules result in the misplacement of thousands of children, so far as their mental ability is concerned. Except where special classes have already been provided, children are placed in school on the basis of chronology rather than on the basis of psychology. Dr. Terman, for instance, found nine-year mentality scattered from the first grade to the seventh grade, and twelveyear mentality scattered from the third grade to the eighth grade inclusive! Such findings prove that, in general, the date of birth of a child is a very potent factor in determining his school status. Terman further found that dull children tend to be graded above their true intellectual level, while bright children tend to be graded below the point where they are really capable of functioning.

From these facts it is small wonder that mental deficiency and truancy are closely related phenomena. The deficient child, graded two or three years above the level where he is able to function, understands little or nothing of what is presented in the classroom. In addition to this source of maladjustment, it often is the case that such a child is placed with much younger children, even though still above his level, - as, for example, a thirteen-year-old, with a mental age of seven years, in the fourth grade. From this inappropriate and uncongenial environment the child very naturally desires to escape. The logical outcome is truancy. 
In an analysis of the causes of truancy in New York City, Miss Irwin concluded that in 43 percent of the cases which were studied the truant was definitely not of normal intellectual capacity. In 8 percent the normality of the truants was questionable. In only 49 percent of cases were the truants definitely of normal intelligence.

In elaborating the results of her study this investigator says:

"One falls into the habit of regarding truancy as the outcropping of sin or vice, as something abnormal and unnatural. Those who know the meaning and value of education speak as though the instinct to get up in the morning, to take hat and books and start for school, was as natural an instinct in a boy as the instinct to seek food and warmth in a young puppy. As a matter of fact, this getting up at a regular time, starting for a regular place where he will be confined, disciplined and made to work, and to do this day after day, is a highly evolved activity and the result of training upon a being capable of assuming responsibility. When we have a boy who is feeble-minded and incapable of assuming responsibility, and a home that is defective and incapable of training to regularity, it is the great wonder that a boy ever goes to school at all... The one recommendation that can strongly be made as a result of this study is that a thorough and competent psychological and physical examination be made of every case reported for truancy, and that those cases found to be mentally defective shall not be given punitive treatment as truants, but removed from the jurisdiction of the compulsory attendance department entirely and educated in the schools or in institutions as feeble-minded children. This would decrease the number of cases to be handled, and inmensely increase the possibilities of success in the handling of the normal cases by the attendance officers and truant schools."

Two typical cases may be cited from this report. The general picture which they present will be fa- 
miliar to every teacher of experience in the regular grades of the elementary school.

Case No. I is William H-. He is 14 years 10 months old, and his mental age is found to be that of a child of 9 years 4 months. He is in the $5 \mathrm{~B}$ grade in school. Thus he is over three years behind the age-grade norms in school, and is nevertheless graded above his real intellectual capacity. A mentality of 9 years 4 months is capable of performing the work of grade $4 \mathrm{~A}$ in New York City. It is probable that William understands very little of what is presented in the schoolroom. He receives low marks, fails chronically, and has naturally no incentive to attend school. His intellectual feebleness is illustrated by the fact that he says he is going to high school and college, and at the same time says that the reason he does not attend school now is that "school is too hard." William is the seventh of ten children, nine of whom are living. His family is very poor and inefficient.

Case No. II is John A-, aged 13 years 2 months. His mental age is 9 years 2 months, and he is graded in 5B. Thus although behind the norm in school status, he is, nevertheless, higher than he should be in the school. His mental level does not permit him to follow the work of grade 5B, where average 11-yearolds are found. He is now in a special D class for conduct. The problem in school discipline is that he steals, is a truant, and is generally troublesome in 
school. He has a brother, also a truant included in this study, who is 11 years 7 months old, with a mental level of 7 years 6 months.

The Mentally Defective Child Is Frequently a Disciplinary Problem. Studies of juvenile delinquents have established the fact that anti-social behavior is very often explained by the fact that the child is not as able as are average children to perceive social situations, to realize remote consequences, and to profit by instruction. A large percentage of incorrigibles are feeble-minded.

Dr. Goddard in his book, The Criminal Imbecile, has presented in detail three cases of serious crimes perpetrated by mental defectives of high grade, who had never been recognized for what they really were. These cases are carefully analyzed from the psychological point of view, and show how crime originates when the intellect is too inferior to act as a deterrent. Dr. Healy in his Individual Delinquent also provides us with case studies of children and adolescents, who became delinquent on the basis of low intelligence.

The best statistics we have on the subject of the feeble-minded child as a disciplinary problem, aside from the case of truancy, come from the children's courts and from reformatories. Dr. Ordahl is among those who have presented data on this point. He made psychological examinations of minor delinquents selected at random in the Juvenile Court 
of San José in 1916, and found 45 percent of those examined feeble-minded. Included in this study were twelve girls and twenty-one boys. "The offenses charged against the boys are eight cases of truancy, five of stealing, two of larceny, one of forgery, one of begging on the street, one of stabbing, while two are incorrigible and one has been brought to the attention of the court because he has not been able to progress at school.

"Of the twelve delinquent girls five were guilty of active immorality, four were in grave danger of becoming so because of their impulsive tendencies in that direction, while two have been brought to the attention of the court because of too slow progress in school."

Dr. Kelley studied inmates of a state reformatory for boys in Texas, with the result that 20 percent were classified by him as definitely feeble-minded. He adds that "probably at least fifty percent of delinquents are totally incapable of being taught to look after themselves in an environment as unfavorable as the one from which they came."

The psychologists of the Preston School of Industry, at Ione, California, find between 30 and 35 percent of the boys committed there for delinquencies to be definitely feeble-minded, and classify a large proportion, in addition, as of border-line intelligence. A very small minority of their cases are described as of fully normal ability. The offenses committed by 
these subnormal boys were murder, assault, sex crimes, burglary, robbery, automobile thefts, forgery, incorrigibility, petty stealing, and vagrancy.

The report of the Psychopathic Clinic connected with the Juvenile Court in New York City shows a similar state of affairs. Large numbers of the children examined on this clinic are of subnormal intelligence. In the year 1915 a study was made of 463 children, who were sent from the Juvenile Courts of New York City to The Clearing House for Mental Defectives, for mental examination. Many forms of mental deviation were found among these children, but the most frequent form of deviation was intellectual deficiency. About half of them were so inferior as to be definitely classifiable as feeble-minded, while a great many more were of "border-line" intelligence. These children presented disciplinary problems of kinds which will be indicated by the charges on which they were arraigned: theft and accomplice in burglary, truancy, sexual misbehavior, general incorrigibility, disorderly conduct (cursing, throwing stones, etc.), fighting, assault, associating with vile and vicious persons, murder and attempted murder, vagrancy, intoxication, arson, begging, peddling without a license, destroying property, taking and procuring drugs, violating child labor laws, and being " an intolerable nuisance."

It is necessary to say a word here as to just what inferences we may draw from the statistics of reform- 
atories and juvenile courts. We find that a very large percentage of children examined in these places are feeble-minded. Is it permissible to conclude that the same proportion holds for all delinquents? The answer is, No; for we are dealing here with a selected group of delinquents, - those who were caught. We are dealing with those who have been unsuccessful in delinquency, and among these we shall expect to find a larger percentage of the stupid than we should find among unselected misdemeanants.

Bearing all these facts in mind, we know nevertheless that a very large proportion of delinquency among both children and adults is due to intellectual deficiency. Thus the study of subnormal children will contribute in a very important way to the solution of the disciplinary problems of the school, which have always taken so much of the time and strength of teachers.

The Reasons for Studying Subnormal Children Are, Therefore, Very Numerous. Such study is inseparably bound up with the educational problems of retardation, elimination, truancy, and delinquency. It is inseparably connected with the social problems of crime, alcoholism, illegitimacy, prostitution, unemployment, and pauperism. The identification of the subnormal while they are children, and the wise adjustment of them to the social and economic life of the community is a task which 
school systems must in the future undertake in much greater measure than they do at present.

\section{REFERENCES}

1. Ayres, L. P., Laggards in Our Schools. Russell Sage Foundation. New York. 1909.

2. California State Board of Charities and Corrections. Surveys in Mental Deviation. Sacramento. 1918.

3. Crafts, L. W., Bibliography of Feeble-Mindedness in its Social Aspects. Journal of Psycho-Asthenics. Monograph Supplement. 1917.

4. Glueck, B., A Study of 608 Admissions to Sing Sing Prison. Mental Hygiene. Jan., 1918.

5. Irwin, E. A., Truancy. Public Education Association. New York. 1915.

6. Johnson, G. R., Unemployment and Feeble-Mindediness. Journal of Delinquency. March, 1917.

7. Kelley, T. L., Mental Aspects of Delinquency. University of Texas Bulletin, No. 1713. Austin. 1917.

8. Murphy, J. P., Illegitimacy and Feeble-Mindedness. Mental Hygiene. Oct., 1917.

9. Montague, H., Report of the Psychopathic Clinic of the Children's Court. New York. 1918.

10. Ordahl, G., Mental Defectives and the Juvenile Court. Journal of Delinquency. Jan., 1917.

11. Paddon, M. E., A Study of Fifty Feeble-Minded Prostitutes. Journal of Delinquency. Jan., 1918.

12. Poull, L., The Mental Status of Truants. Ungraded. Oct., 1919.

13. Pyle, W. H., and Collings, P. E., The Mental and Physical Development of Rural Children. School and Society. Nov. 2, 1918.

14. Report of the State Commission of Prisons. Albany, New York. 1918.

15. Report of the Portland Vice Commission. Portland, Oregon. 1912.

16. Schlapp, M. G., and Hollingworth, L. S., The Mentally Defective as Cases in the Courts of New York City. Medical Record. Feb., 1915. 


\section{SCIENTIFIC STUDY OF MENTAL DEFECTIVES 37}

17. Stenquist, J. L., Thorndike, E. L., and Trabue, M. R., The Intellectual Status of Children Who Are Public Charges. Archives of Psychology. 1915.

18. Toops, H. A., and Pintner, R., Mentality in its Relation to Elimination from School. School and Society. April, 1918.

19. Weidensall, J., The Mentality of the Unmarried Mother. National Conference of Social Work. No. 124. Chicago. 1917.

20. Williams, J. H., Exceptional Children in the Schools of Santa Ana, California. Whittier State School. California. 1918. 


\section{CHAPTER III}

THE DEFINITION OF MENTAL DEFICIENCY

Terminology. Many different words are used to designate those who are subnormal in intelligence. Mental defectives, aments, the feeble-minded, the mentally deficient, the very inferior, the subnormal are all terms in common use to-day. All are used to designate those members of the human species who fall into the lowest two or three percent on the scale of distribution for intelligence. All are used in this discussion, being employed interchangeably, as they are synonymous.

Many other terms have also been used, which are not employed here, because their application is very inexact or ambiguous. Such terms are "exceptional children," "atypical children," "backward children," "abnormal children," " retarded children." Some of these terms are very useful in situations requiring tact, in which too great bluntness would be offensive to human sentiment, and have been invented for just this purpose. However, in a scientific treatise on the subject ambiguity and vagueness are out of place. It is true certainly that children who are subnormal intellectually are "exceptional" 
and are "atypical," but these words describe equally well the insane, the very gifted, those afflicted with special disabilities, and any and all who deviate in any respect from the usual. "Abnormal" is open to the same objection, with the added objection that it carries with it the idea of a pathological disturbance. "Backward" and "retarded" vaguely and erroneously imply that the condition is one which will disappear with time, that the child is temporarily behind in his development, but may be expected to "catch up" eventually. In a scientific treatise all euphemisms are inappropriate.

Even those terms which are here employed to designate the intellectually subnormal, - mental defectives, aments, the feeble-minded, the mentally deficient, the very inferior, the subnormal, - are less exact than we could wish. "Mental" and " mind," for instance, are properly terms which include much more than the intelligence. Thus, strictly speaking, one who is deficient in emotion or in volition may be referred to as "mentally deficient" or "mentally defective," though he be of normal intelligence.

This struggle for definite and satisfactory terms is the bane of all who undertake to discuss a part of a continuous distribution, which is not marked off by any distinct feature. What is to define the difference between the individuals to be included in the discussion, and the individuals just barely not to be included in the discussion? The fact is that no such 
definition is possible, except on arbitrary and artificial grounds. When the present volume has been studied through, it will be apparent that the only entirely satisfactory practice would be to speak of individuals simply in terms of the IQ (intelligence quotient), without introducing words which convey the idea of a distinct entity.

Nevertheless, when words are currently in use to communicate certain ideas, it is not permissible to ignore or change them suddenly. Therefore, the words in common use which are least ambiguous, are here employed to designate those who are very far below the norms in general intelligence. These terms are mental defectives, aments, the feebleminded, the mentally deficient, the very inferior, and the subnormal.

Early Definitions of Mental Deficiency. In the first chapter of this book we set out to answer the question, What is a subnormal child? In other words, What constitutes mental deficiency? It will be of interest to consider some of the early definitions of feeble-mindedness or "idiocy," as it was called. These definitions will show us the confusion of thought which formerly existed in respect to the matter, as well as what were the concepts of mental deficiency historically held.

Lord Coke, an ancient jurist, says, "An idiot, or natural born fool, is one who from his nativity, by perpetual infirmity, is non compos mentis." old 
English Law defines an idiot as a person of non-sane memory. "It is sufficient to find him so if he has not any use of reason; as if he cannot count 20 pence, or if he has not understanding to tell his age, or who is his father or mother." Blackstone says, "An idiot, or natural born fool, is one that hath no understanding from his nativity, and is therefore by law presumed never likely to attain any."

These are all legal definitions, founded on the practical necessity of determining responsibility for crime, or capacity for undertaking the administration of property. By the time property was firmly established, and crime was punished by court procedure, it was recognized that there are persons so deficient in general ability that they ought not to be punished for their sins as others should be, and that they cannot manage their property. Thus a legal definition had to be formulated. These legal definitions included, as we now know, only the lowest grade of mental defectives.

As we have early legal definitions, so we have early medical definitions. Sylvius Delboe ${ }^{1}$ writes, "Even the condition of many stupid men is to be designated sickness, whereby they are not able to reason nor to recognize cause and effect." Willis ${ }^{2}$ declared that "Idiocy and stupidity depend on a lack of judgment and intelligence, the actual rational mind being not concerned; the brain is the seat of the sickness, which

1 Opera Merliea, 1677.

2 De Anima Brutorum, 1678. 
rests on a lack of imagination and memory, the seat of which is in the brain. The imagination is located in the corpus callosum, or the white substance; the memory in the cortical substance. So if imbecility or stupidity arises, the cause is in the brain region involved, or in the animal spirits, or in both."

Furthermore, there is the ecclesiastical definition of mental deficiency, whereby it is looked upon as the work of spirits. Heinroth ${ }^{1}$ wrote, "Where Satan is there is weakness, darkness, hatred and destruction everywhere. An evil spirit abides, therefore, in the mentally deranged; they are the truly possessed." According to other ecclesiastical versions, the idiot was blessed, and under the care of good spirits.

As early as 1834 the psychological definition appeared. Herbart" said, "Idiocy and imbecility, which alone of all the mental disorders appears to be inborn, and which - as the opposite extreme of genius, is general weakness of the mind, - does not differ so much in quality as in degree, and may go so far that the man almost resembles a plant, but as such grows and is healthy."

The Various Modern Criteria of Mental Deficiency. In more recent years definitions of mental deficiency have been based on social and economic success; on school progress; on physical traits; and on psychological tests. We may for convenience

1 Lehrbuch der Störungen des Seelenlebens, 1818.

2 Lehrbuch der Psychologic, 2nd edition, 1834. 
refer therefore to (1) the social-economic criterion, (2) the pedagogical criterion, (3) the medical criterion, and (4) the psychological criterion.

The Social-Economic Criterion. The Royal Commission of Great Britain, which investigated the question of mental deficiency in 1904, adopted a definition of mental deficiency which was based wholly on economic and social adjustment. This was as follows:

"A feeble-minded person is one who is capable of earning a living under favorable circumstances, but is incapable, from mental defect existing from birth, or from an early age, $(a)$ of competing on equal terms with his normal fellows; or $(b)$ of managing himself and his affairs with ordinary prudence."

Following this standard, the Mental Deficiency Act of 1913 in England classified mental defectives thus. (The highest grade, called in this country morons, are termed in England "the feebleminded.")

"The feeble-minded are persons in whose case there exists from birth or from an early age mental defectiveness not amounting to imbecility, yet so pronounced that they require care, supervision, and control for their own protection or for the protection of others, or, in the case of children, that they by reason of such defectiveness, appear to be permanently incapable of receiving proper benefit from the instruction in ordinary schools.

"Imbeciles are persons in whose case there exists from birth or from an early age mental defectiveness not amounting to idiocy, yet so pronounced that they are incapable of managing themselves or their affairs, or, in the case of children, of being taught to do so.

"Idiots are persons so deeply defective in mind from birth, or from an early age, as to be unable to guard themselves against common physical dangers." 
The chief objection to social-economic adaptability as the final criterion of mental deficiency is that it does not apply equally to all individuals under all circumstances. It is always a relative, never an absolute standard. Judged by it, an individual who is normal in a simple rural community might be feeble-minded in the complex environment of the city; a woman of a certain mental capacity might easily pass as normal, while a man of the same intellectual quality would be considered an imbecile; the heir to wealth might seem to be of ordinary intelligence, whereas a penniless individual of the same caliber might not be able to maintain himself in the social milieu.

A scientific definition of mental deficiency will be one which will apply to the individual no matter what the external circumstances which surround him, and regardless of sex. Let us examine other criteria which have been used or proposed.

The Pedagogical Criterion. Certain communities have passed rulings that every child who is three or more years behind the grade proper to his years shall be examined psychologically, and if found to be intellectually deficient, shall be transferred to a special class. Two decades ago, before psychology had advanced to a point where it could be applied to the problem, the pedagogical criterion alone was applied to determine whether or not a child should be placed in a special class. Let us see why it is that the ped- 
agogical criterion of failure to progress in school is not in itself sufficient.

If we were to rely upon the fact that a child is three or more years retarded in school status, and upon this only, what kinds of mistakes would be made? We have already emphasized the fact that children are retarded in school for a great variety of reasons, of which lack of general intelligence is but one. If we defined a feeble-minded child as one who is three or more years retarded in school status, we should include improperly within our definition many who are physically ill, many who have had the misfortune to be out of school for various reasons, many who suffer from sensory defects, many who have some special disability in a school subject such as reading or arithmetic, many with severe speech defects, and many insane, neurotic, and epileptic children. All of these conditions may lead to serious retardation in school status, though general intelligence may be normal. Also there would be included children who are deteriorating mentally from organic diseases of the nervous system, and who must be differentiated carefully from those whose defect is original, as the course of their subsequent development is very different. The pedagogical criterion alone is thus highly unsatisfactory.

The Medical Criterion. There have been various attempts by medical men to formulate definitions of mental deficiency. Voisin says: "The idiot is an in- 
dividual whose intellectual, sensory and motor faculties are not developed, or are abnormally developed in a defective manner or are arrested in their evolution before or some years after birth, to a degree which they can not overcome in consequence of chronic lesions of the brain." Ireland's definition is as follows: "Idiocy is mental deficiency or extreme stupidity, depending upon mal-nutrition or disease of the nervous centers, occurring either before birth or before the evolution of the mental faculties in childhood." Bourneville says, "Idiocy consists of the arrested development, either congenital or acquired, of the intellectual, moral and emotional faculties, which may or may not be accompanied by motor difficulties and perversions of instinct."

In general, medical definitions have been based on the assumption that mental deficiency is analogous to physical disease in its nature, and have sought to describe in the defective person some symptom or condition that would differentiate him clearly from the normal. There is also noticeable a tendency to define in terms of a hypothetical underlying physiological cause. Combined with this we find recognition of the importance of social, economic, and scholastic behavior. In general, we may say that the medical criterion is largely the social-economic criterion, with a special emphasis on the description of clinical features, or of stigmata, if any are present. In fact, the medical profession has interested itself 
chiefly in the so-called secondary conditions, which Dr. Tredgold describes at length, and with the clinical varieties of idiocy and imbecility, such as cretinism, mongolianism, hydrocephalus, microcephalus, syphilitic amentia, and epileptic amentia. Dr. Tredgold's excellent treatise is devoted almost exclusively to these conditions, though it is true that a very small proportion of the feeble-minded are included under them.

In formulating a definition of mental deficiency, Dr. Tredgold, who is the most authoritative of modern medical writers on the subject, says, "The condition is a psychological one, although the criterion is a social one, and we may accordingly define amentia as a state of restricted potentiality for, or arrest of, cerebral development, in consequence of which the person affected is incapable at maturity of so adapting himself to his environment or to the requirements of the community as to maintain existence independently of external support."

The chief objections to the medical criterion, and to its application in diagnosing mental deficiency, are well stated by Binet, the French psychologist, thus:

"Each one according to his own fancy, fixes the boundary line separating these states. It is in regard to the facts that the doctors disagree. In looking closely, one can see that the confusion comes principally from a fault in the method of examination. When an alienist finds himself in the presence of a child of inferior intelligence, he does not examine him by bringing out each of the symptoms which the child manifests, and by interpreting all symptoms and classifying them; he contents himself 
with taking a subjective impression as a whole, of his subject, and of making his diagnosis by instinct. We do not think we are going too far in saying that at the present time very few physicians would be able to cite with absolute precision the objective and invariable sign, or signs, by which they distinguish the degrees of inferior mentality."

Concerning these objections Binet further says, "We have abundant proof of this in the strikingly divergent medical diagnoses made only a few days apart by different alienists upon the same patient."

The inadequacies of the medical criterion arise naturally from the fact that those formulating it have been trained in the diagnosis and treatment of physical disorder, and when confronted with a mental condition can reason only from analogy with what they have learned of physical states. The medical curriculum does not, in the United States at least, include instruction in psychology.

The Psychological Criterion. It is unnecessary to comment further upon the confusions of thought arising out of attempts to apply the criteria which we have described. In 1904 it was decided to segregate for special instruction all of the mentally defective children in the schools of Paris. The professional advice of Alfred Binet, Professor of Psychology in the University of Paris, was sought. Upon the request of the appointed Commission, Binet undertook to provide a psychological criterion of mental deficiency, upon the basis of which the children could be scientifically selected. 
The diagnosis of feeble-mindedness evidently rests upon the determination of intellectual status, in the first place. No matter what may be the educational, social, or economic maladjustments of the individual, no matter what may be the number of his physical stigmata or his clinical features, if his general intelligence is normal, he is not feeble-minded. Thus the first problem in the psychological determination of mental deficiency was the problem of measuring general intelligence.

It would take us too far afield from the immediate purposes of this book to discuss the technicalities involved in this problem of measuring intelligence. Binet and other psychologists had for many years been working upon mental tests. It occurred to Binet to formulate a series of tests, in a manner which will be more fully described in a subsequent chapter. By his method Binet succeeded in obtaining a quantitative measure of general intelligence, which would apply to all native school children, of normal sensory capacity. The unit of measurement was "mental age," which has now come to be a familiar term among educators.

Thus was the psychological criterion of mental deficiency for the first time established. It is necessary, however, to take further steps, since there is a difference between feeble-mindedness and dementia, which is not always revealed by the measurement of intelligence alone. Demented persons also register 
low in intellectual status, but their condition differs essentially from that of the feeble-minded in origin, in outcome, and in treatment.

To one skilled in the practice of abnormal psycholcogy, the differential diagnosis between dementia and feeble-mindedness is usually not difficult. The past history of the individual is of fundamental importance, as are neurological and physical symptoms. Qualitative differences also appear in the direct examination of the intelligence, as Binet, and later Pressey, have demonstrated in their experimental work with dements.

In any scientific study of the psychology of subnormal children it is necessary to keep such distinctions clearly in mind. Persons who have made no study of the subject do not usually distinguish between feeble-mindedness and other kinds of mental deviation. They speak of an imbecile as "a crazy boy," and say of an insane man, "So-and-so is becoming feeble-minded." They refer indiscriminately to all abnormal persons as "silly," " out of their heads," "half-witted," and "weak-minded." Teachers, however, must bear in mind that there are distinctions; that a feeble-minded child is one who never had a normal mental capacity, whereas an insane or demented child is one who has at a former time been gifted with greater mental capacity than that which characterizes him subsequently. The feeble-minded child is a proper subject for educational treatment. 
His condition can be improved by instruction, whereas demented and insane children are usually not to be considered for retention in public school classes.

The psychological criteria having been established, definitions of mental deficiency began to be formulated on a psychological basis. The somewhat awkward definition based on the earlier work with graded intelligence tests was substantially as follows: Children who show a mental retardation of two or more years, below and including the chronological age of 9 years; and three or more years of mental retardation above the chronological age of 9 years; and adults who grade at or below a mental age of 12 years, and who are not demented, are to be considered technically defective.

Since the work of Terman and his collaborators, another definition is now replacing this unwieldy one. This is based on the use of the intelligence quotient (to be explained in a subsequent chapter), and upon the percentage of the total range of intellect, which is found by measurement to include all who fall below a given status. The final definition is, to be exact, based on a combination of psychological measurement and social fact. The result of the research of the past decade is that individuals who grade below $70 \mathrm{IQ}$ are never found to be capable of satisfactory independent adjustment to school or to social environment. They cannot even approximate the 
performance of their fellows. Dr. Terman found that two percent of his unselected school children graded at or below 73 IQ. If we include in our estimate the idiots and very low grade imbeciles, who would have been found among a thousand unselected children (though not among a thousand unselected school children), we should have about two percent of mental defectives. This is what we should expect on the basis of all the known facts about individual differences. We should expect that about two percent of all individuals belonging to our species would vary so far from the average, as to be unfitted to meet the ordinary exigencies of iife.

We are now tending toward this definition: a feeble-minded person is one who has originally an intelligence quotient of 70 percent or less, and whose status falls in the lowest two percent of human intellect.

The Classification of Mental Defectives. Much confusion of thought has also existed in past times in the matter of classifying the feeble-minded. At first the feeble-minded were not differentiated at all, all defectives being referred to indiscriminately as idiots. Then it was noticed by those observing them, that all defectives were not equally defective, and various attempts to group them into two or three categories were made. Such classifications have been attempted on the basis of speech, of physiological condition, of sensori-motor activities, and on the amount and kind 
of care needed. Thus Esquirol, a medical writer, has classified the defective into (1) those using short phrases; (2) those using monosyllables; and (3) those making inarticulate sounds. Another classification according to speech was by Howe: (1) simpletons, those using simple sentences; (2) fools, those using simple words; and (3) idiots, those using simple sounds.

Seguin classified according to what he conceived to be the physiological condition, into (1) profound idiocy, the central nervous system affected; and (2) superficial idiocy, the terminal organs affected.

Barr attempted a classification on the basis of kind and amount of care needed: (1) asylum care, profound idiots, superficial idiots, and idio-imbeciles; (2) custodial life, moral imbeciles; (3) apprenticeship and colony life, imbeciles; (4) trained for a place in the world, backward or mentally feeble.

At the present time the feeble-minded are classified on a psychological basis as idiots, imbeciles, and morons. The words refer to the mental status of the individual. In terms of the $\mathrm{IQ}$, idiots grade roughly from 0 to 20 , imbeciles from 20 to 40 , and morons from 40 to 70 . Imbeciles and morons are in turn subdivided into low-grade, mid-grade, and highgrade. Thus we often hear the term "high-grade imbecile," "low-grade moron," etc.

These terms are in general use to-day, but it would really be far better and more scientific if we were to 
cease from using them, as they create artificial distinctions in the popular mind. It would be better to speak of persons of weak intellect simply in terms of their IQ. Thus, in practice, we should speak of a defective child as having an intelligence quotient of 50 , or 58 , or 67 , instead of labelling him imbecile or moron, as we now do. If it were accepted usage to refer to children simply in terms of the intelligence quotient, we should clear up those difficulties of parents who go about from clinic to clinic, finding that their child is called a high-grade imbecile in one place, and a low-grade moron in another; and trying to find out exactly what constitutes the difference between them, and which the child really is. It is often impossible to classify a child as one or the other. $\mathrm{He}$ may have an intelligence just on the border-line between the two, and can thus be classified as one or another equally well. For there is, of course, no valid distinction between a high-grade imbecile and a low-grade moron; between an idiot and a low-grade imbecile. The use of such words leads to the notion that there must be some entity which can invariably be identified as imbecility, as different qualitatively from moronity, and from idiocy. This is, of course, not so. Thus it would be preferable to speak of subnormal children merely in terms of their intelligence quotients.

"Constitutional Inferiority." Now, above 70 and below 80 or 85 on the scale of intellect fall those per- 
sons whom we call in clinical practice "the borderliners," "the dull," "the inferiors." They are not technically classifiable as feeble-minded, yet they are distinctly below the average in capacity. There are great numbers of these children, for we must always bear in mind that as we go up toward the norm, or average, the numbers increase very rapidly. Throughout our discussion it is necessary to bear in mind the shape of the curve of distribution.

The Psychological Criterion Is Now the Most Widely Accepted. Mental deficiency is now generally recognized as a psychological condition. It is to be identified and classified by psychological methods. That this is so is recognized by the best modern medical writers, as well as by the educators and psychologists, to whose researches we owe the advance that has been made in our knowledge of defective children in recent years. As Tredgold says, "The condition is a psychological one," and the treatment is therefore essentially educational. Before systematic education is begun, however, it is necessary to be certain that general health is as good as it is possible to make it. This statement, of course, holds true of all children. We shall not dwell upon details of medical and surgical treatment here, since, to quote Tredgold again, "the principles are the same in these as in ordinary children." Science knows of no special medical or surgical treatment for mental deficiency, except in secondary cases to be described in a subsequent chapter of this discussion. 


\section{REFERENCES}

1. Doll, E. A., Clinical Studies in Feeble-Mindedness. R. Badger. Boston. 1917.

2. Kuhlmann, F., What Constitutes Feeble-Mindedness? Journal of Psycho-Asthenics. 1915.

3. Pintner, R., and Paterson, D. G., Psychological Basis for Diagnosis of Feeble-Mindedness. Journal of Criminal Law and Criminology. May, 1916.

4. Tredgold, A. F., Mental Deficiency. William Wood and Company. New York. 1915. 


\section{CHAPTER IV}

\section{IDENTIFICATION}

Identification of Defectives of Low Grade. It has always been easy for psychologists, physicians, and teachers to recognize idiots and low-grade imbeciles as subnormal. They have always been identified also by the populace at large, and have been described in popular terms as "half-witted," "halfbaked," " daft," " foolish," "silly," "simple," " childish," or "young for their age." It is interesting too, in the light of modern psychology, to note how people in general have naïvely described the defective in terms of tests of knowing and doing. "Doesn't know enough to come in out of the rain"; " doesn't know beans "; " doesn't know straight up "; "can't even pound sand in a hole"; these are some of the expressions used to convey an idea of the mental condition of defective persons.

In the modern psychological method of measuring intelligence we find tests involving orientation (right, left), tests involving knowledge of what to do when it rains ("What's the thing to do if it is raining when you start to school?"), tests involving the recognition of objects of common experience, like beans, 
(knife, key, penny, watch, pencil). The psychological method of identifying the subnormal is in a sense a scientific elaboration of these naïve methods of identification, just as the modern chemical laboratory is an outgrowth of folk-observations of the effects of certain ingredients upon others in combination.

The subnormal who can be identified as such by naïve methods are, however, only the very low grade, who are destined never to attain a mental age of over about six years. To return for a moment to our simple folk-tests, - a mentality of over six years does know beans, does know what to do in case of rain, does know straight up, and can pound sand in a hole. Thus naive observation was and is inadequate for the recognition of all' grades of mental defect above this low level. The majority of the defective escape detection by the populace at large.

Recognition of Milder Degrees of Subnormality. Defectives higher in the scale than those destined to the ultimate level of five or six years were formerly not recognized for what they are. Their education proceeded by the birch-rod, dunce-cap method. All teachers are familiar with old wood-cuts showing colonial schoolrooms, with the children sitting around the master, on wooden benches. Everyone will recall the inevitable dunce, sitting in the corner with his dunce-cap on. In the light of what we now know, we may venture the guess that under those colonial dunce-caps lurked many an IQ of 70 or less. 
However, in those days no one was thought of as feeble-minded who could learn to write his name, read simple words, and "do sums." Those whom we now call morons and high-grade imbeciles were then regarded as "lazy," "bad," " ne'er-do-well," but as normal intellectually. Not psychological diagnosis, but corporal punishment, was the accepted procedure with regard to them. The defect was to be overcome by forcing the child to kneel on the sharp edge of a triangular rod, by application of the birch, and by the dunce-cap.

The colonial dunce, isolated in his corner, represents the rude beginnings of the modern special class. Only we no longer beat and torture him. We select him by psychological methods, and place him with his peers, under the care of a teacher especially trained to understand him, where he can learn those things which are suited to his capacities. But how is he to be selected with accuracy and justice, since to common observation the nature and extent of his defects are not apparent? The answer to this question involves a discussion of the psychological methods of measuring intelligence. No exhaustive or technical exposition of these methods can, however, be undertaken here, as the subject is sufficiently broad at the present time to require several volumes for its adequate treatment. Since teachers are not to be responsible for the correct identification of defectives, but only for the proper training of them, this 
discussion will be limited to a brief general description of the methods of identification now in use.

The Necessity for Establishing a Scientific Method of Identification. It is not enough to obtain the personal judgment of those who are acquainted with a child, as to what his mental quality may be, any more than it is enough to ask them what may be his height, his weight, or the size of his feet. It is a matter of common knowledge that wide errors are made in judging height and weight, even by very intelligent persons. No stock raiser would trust the personal judgment of a buyer to determine the weight of his stock at the market. No householder would trust the personal judgment of a grocer as to what constitutes a pound of rice or tea. The great fallibility of subjective judgments is recognized by the presence of scales in every market, and of yardsticks in every dry-goods store. Judgments of mental capacity are subject to much greater errors than are judgments of such qualities as height, weight, length, area, loudness, tint, and pitch. Yet human beings are willing to rely on personal judgment of mental traits, each of us priding himself that he is " a good judge of human nature," and believing himself to be gifted with some mysterious power of gauging mental qualities accurately!

In the specific case of teachers' judgments of their pupils several special fallacies enter in to produce wide errors. These will be recognized by nearly 
every teacher as soon as they are pointed out. In the first place, teachers tend naturally to judge intelligence on the basis of success in school work, especially success in reading and arithmetic. This leads them into many errors, for success in school work depends on a number of factors, only one of which is intelligence. A bright child who has a special disability in reading or arithmetic, who is deaf or astigmatic, who is physically ill, may be rated low in school work, because all of these factors may reduce his efficiency. Also, a very young child who is doing work of a certain quality in a certain grade, may be rated as of equal intelligence with a much older child who is doing the same quality of work in the same grade.

There is a universal tendency among teachers to neglect the factor of age when judging the innate intelligence of pupils. It has been repeatedly shown that feeble-minded children are judged as normal by teachers under whom they are doing average work in a grade for which they are four or five years too old, by the age-grade norms. In the same way it has been shown that teachers judge as average children doing average work in a grade for which they are too young, by the age-grade norms.

An additional source of error is that the pupil is judged by appearance, manner, and dress, all of which may or may not be related to the child's intelligence. A dull child, who is well dressed, handsome, and well 
trained in manners may be rated higher in some instances than a bright child who is ugly, or boisterous, or in rags.

It is apparent that it is necessary to have a means, first, of singling out intelligence from all the other factors which complicate efficiency in school work, and secondly, of measuring intelligence objectively, so that the personal equation may be eliminated as completely as possible.

Binet's Measuring Scale. We have already noted the fact that when in 1904 Binet was called upon to advise the educational authorities in Paris as to the segregation of the mentally defective children in the schools, he was obliged to reply that there existed at that time no scientific method of selection. Only the very lowest grades could be recognized with certainty, and these constitute a small part of the problem in the public schools.

For more than fifteen years Binet had worked in the psychological laboratory with mental tests, and in the analysis of mental processes. He knew fully the psychological factors which enter into subjective judgments to render them unreliable, and he knew also the scientific principles which underlie the formulation of objective criteria in psychological experimentation. Finally he succeeded in arranging a series of mental tests, some of which were so simple that three-year-olds could respond adequately to them, while others were sufficiently difficult to try 
the abilities of adults, with many intermediate degrees of difficulty.

Psychologists had worked for more than twenty years with mental tests, and psychiatrists dealing with the insane had attempted to devise some method of approaching their patients by means of tests, before Binet undertook the formulation of his scale. These previous efforts had been unfruitful, because no one had combined the two basic ideas upon which Binet's scale was constructed. A few investigators had arranged tests in series, but had done it on the basis of " expert opinion." The investigator guessed which tests would be significant, and applied them according to his personal opinion. Other investigators realized that the value and significance of a test cannot be determined by guessing, and had tried out mental tests objectively, but had not hit upon the idea of constructing norms on the basis of mental age.

Binet made his arrangement of tests not on the basis of his own judgment of what would be easy and what would be difficult, but on the basis of objective experiment. Many tests were tried on children of all ages. In the course of this experimentation certain tests were rejected, others were devised, and finally each test selected was assigned a place in the scale, on the basis of the actual performance of the children themselves. In its first rough form the scale consisted merely of thirty tests arranged in an ap- 
proximate order of difficulty. This was published in 1905. Three years later the scale was again presented, this time with the tests standardized in terms of mental age. Those tests which the average threeyear-old can meet successfully were grouped under three years; those which the average four-year-old can meet successfully were grouped under four years, and so forth. Thus each test came to have a certain objective value, expressible in terms of the average intelligence of children of a given birthday age.

In 1911 Binet published a second revision of his scale, but his work was soon thereafter interrupted by death, and he was prevented from perfecting his idea. However, his published researches had been read by psychologists all over the civilized world, and others at once took up the task of perfecting and extending his scale. In the United States revisions of the scale were published by Dr. Goddard, Dr. Kuhlmann, Drs. Yerkes, Bridges, and Hardwick, and Dr. Terman. The two former performed the service of translating the scale, and of making minor adaptations to suit American children. The others have extended and revised the scale, and have introduced certain features of scoring which require comment here.

The Measuring Scale of Yerkes, Bridges, and Hardwick. In 1915 Yerkes, Bridges, and Hardwick published their measuring scale, revising to a considerable extent the tests of Binet by eliminating some 
and introducing others of their own devising. The chief feature of this scale was, however, the use of a new method of scoring, the method of scoring by points instead of by years of mental age. Each test is assigned a value in points, according to this method, and the maximum number of points which it is possible to make is known. The score of a child thus consists of the number of points he can make.

It is thought by many competent psychologists that the method of scoring by points has advantages over the method of scoring by years of mental age, and that future developments in mental diagnosis will proceed in this direction. However, it is necessary to notice that in order to render the results intelligible in relation to the case of a given child, the points must always be translated back again into terms of mental age. It is necessary to know what is the normal number of points for four-year-olds, for five-year-olds, and so forth. The advantage of a scale having points as units is that by means of it curves of mental growth may be determined, in a way which is impossible by the use of scales in which the unit is years or months of mental age. For the identification of the defective children in any given community, at any given time, neither method has any advantage over the other, except that scores in terms of mental age are more easily communicated to those interested in the child's welfare, who are not professional psychologists. 
Yerkes, Bridges, and Hardwick also introduced the intelligence coefficient, which is the figure obtained by dividing the number of points obtained in an examination, by the number of points obtained on the average. For example, if a child of eight years obtains a score of 20 points, whereas the average score of children of that age is 39 points, the intelligence coefficient of the child under consideration is 51 . Such a measure had been suggested earlier, but had not been used in practice.

The Stanford Revision of the Binet-Simon Measuring Scale. The Stanford Scale is so named because the labor on it was done at Stanford University. It is the work of Dr. Terman and his collaborators. Binet's scale in its original form was crude in many respects. It was standardized on only a few children, and those few were not wholly unselected. It did not measure intelligence above the eleven-year level. Directions for giving the tests were not standardized, and inasmuch as the directions in giving a test constitute a very important part of the test itself, this led to unreliable results. Binet did not provide any method for comparing the intellectual quality of a younger child with that of an older child. Obviously "two years retarded" means different things at different ages. A three-year-old who is two years retarded is a low grade defective, whereas a thirteen-year-old who is two years below the norms is merely dull. Thus some method of expressing the 
intellectual quality as well as the intellectual status praesens is highly desirable.

The Stanford Scale remedies these defects of the original Binet Scale more nearly than does any other now available. It is standardized on a large number of children, selected as nearly as possible at random. It measures intelligence up to and including adult (so far as the average and the subnormal are concerned). Directions for giving the tests have been carefully standardized. Finally, the intelligence quotient is introduced as the expression of intellectual quality, with mental age as the expression of the intellectual status praesens.

A few further remarks concerning the intelligence quotient are necessary, in order that teachers may have a clear comprehension of this term, which is coming into such wide use, and which is so significant for their understanding of their pupils. The intelligence quotient, referred to in this book and generally as the IQ, is simply the ratio of actual age to mental age, the quotient obtained by dividing the latter by the former. For example, if a child eight years and no months old, measures at a mental age of ten years and two months on the scale, his IQ is 127 . If a child of the same age measures eight years and no months, his IQ is 100 . If another child of the same age measures four years no months, his IQ is 50 . In grading children for school work, the intellectual status praesens, the mental age, is the important 
consideration. In looking forward to determine what their future prospects may be, the important consideration is the IQ. (Its significance is obviously the same as the intelligence coefficient of Yerkes, Bridges, and Hardwick.)

Does the IQ tell us exactly what a child will be intellectually ten years hence? Or does the IQ change from year to year? We cannot answer this question positively now. No one has ever re-measured the same children year after year from early childhood to maturity. Such re-measurements as we have indicate that the IQ remains constant for the middle 50 percent of children; that the average child gains just a year in mental age each year he lives, until maturity is attained. In the case of subnormal children the indication is that the IQ becomes slightly lower as development proceeds. They fall gradually farther and farther behind the norms as time goes on. In the case of superior children no data have been made available, but from tests repeated on very superior children in the Horace Mann School the present writer believes that they become farther and farther removed from the norms in the direction of superiority as they develop, and that the IQ becomes gradually higher and higher, ${ }^{1}$ as the IQ of the inferior becomes lower and lower.

In all this there is, unfortunately, no encourage-

1 This surmise is confirmed by Dr. Terman in his recent work, The Intelligence of School Children. He notes the same tendency. 
ment to believe that the IQ of a defective child may change for the better as he grows older. To those that have, more shall be given; while from those that have little, even the little that they have shall be taken away. Nature does not hold by the law of compensation, however much we might wish that she would.

Psychographic Methods. There is noticeable at present a movement toward the analysis of mental make-up, by the method of measuring the individual in various kinds of mental work, and by casting up the result for each test separately. Such a method yields a psychographic picture of the individual, showing in what kinds of work he is least capable, and in what kinds of work he is most capable, as well as revealing his general intelligence level. This method was proposed some years ago by William Stern, and has been developed somewhat by psychologists. Its full development and application are, however, matters for the future.

Group Tests. A serious difficulty in the use of a measuring scale such as those just described is that it can be applied to but one individual at a time. To sift out all the defectives from among ten thousand school children by giving each an individual examination is an exceedingly expensive process. When the psychologists in national service were confronted with the necessity of identifying the mentally deficient among the soldiers during the recent war, it was 
clear that an individual examination could not be given to each of the thousands of men who presented themselves for duty. In this situation group tests were devised, which could be given to many men at the same time. Those who fell far below the norms in these group tests were then selected for individual examination.

The same method is applicable to school children, and in future we shall undoubtedly see group tests regularly in use as a preliminary means of identifying the subnormal.

After the foregoing discussion a need may be felt for some brief and simple definition of a mental test. What is a mental test? The definition is most appropriately formulated in terms of behavioristic psychology, on the tenets of which mental tests are founded. A mental test is a standard situation, which provokes a response capable of qualitative or quantitative interpretation. At present mental tests have been devised only for intelligence. Other aspects of mental life cannot yet be tested.

How a Diagnosis Is Made. A diagnosis of mental deficiency is never made on the basis of an intelligence examination alone. Intelligence tests are strictly limited in their function to the determination of intelligence level at the time of examination. By their use alone all forms of mental incompetence would be confused. The temporary mental inadequacy of the manic-depressive, the deterioration of 
the paretic, the inaccessibility of the dementia praecox, and many other forms of mental disorder may be mistaken for feeble-mindedness on the basis of an intelligence test alone. Intelligence scales give no information as to the underlying causes of the incompetence which they reveal. Thus much additional information must be sought. No diagnosis can be made without a developmental history, a family history, a school history, a neurological examination, a sensory examination, and in some cases data even beyond these.

In school systems which afford medical inspection, school nurse, and a psychological clinic several individuals contribute to the diagnosis of a given case. Those participating may be the teacher, the physician, the school nurse (or visiting teacher), and the psychologist. Not many communities are thus adequately equipped at present. Newark, New Jersey, may be mentioned as a model. In that city the Division of Medical Inspection in the schools maintains a psychological clinic, through which children suspected of mental deficiency pass, to be examined for the special schools. The teacher reports on the school work and the conduct of the child. The school nurse visits the home, and collects information about family and personal history. The physician makes a report on the health of the child. This information comes finally to the psychologist, who is in charge of the psychological clinic. He confers 
further if necessary with teacher, nurse, or physician, and makes the diagnosis on the evidence from his direct examination of the child, plus all the additional information which he receives. This plan was formulated and carried into execution by Dr. George J. Holmes, Supervisor of Medical Inspection in the schools of Newark. Other cities such as St. Louis, Cleveland, Los Angeles, Cincinnati, are similarly well equipped. Still other communities are partially equipped to care for the identification of subnormal children.

The Teacher's Part in Identification. The teacher's or supervisor's function is primarily and chiefly to organize and carry on the proper training of the children. However, in doing this he or she becomes aware of certain data which are of much interest in identification. In cases where group tests are not used, the teacher of the regular elementary grades is expected to note and report upon children who show symptoms of mental deficiency, and who are to be examined. The teacher or supervisor should observe the pupils, to report upon their work and conduct, and to consult with the psychologist on progress made under training.

The School Nurse's Duty. The school nurse, or visiting teacher, goes to the home, and tries to assist the parents in following out recommendations made for the welfare of the child. Frequently it becomes her function to collect data on family and personal 
history, and to keep in touch with the family situation in general.

The Physician's Duty. The school physician should ascertain the physical condition of the mentally subnormal children, just as he ascertains the condition of all the other children in the school. $\mathrm{He}$ should report upon the general health of the child, with special reference to diseases such as syphilis, which are known to affect the nervous system. The medical inspection of subnormal children follows the same lines as the medical inspection of average and superior children. As Tredgold says, of medical and surgical treatment, "the principles are the same in these as in ordinary children." If any physical disability is present, it should be corrected, if it is corrigible. It is the function of the physician to determine the presence or absence of physical disorder, to prescribe treatment, and to report upon such conditions to the psychological clinic.

The Psychologist's Duty. The responsibility of the final diagnosis of mental deficiency rests upon the psychologist, or psychiatrist, who has been especially trained for his work in normal and abnormal psychology, and in neurology. It is his duty to make the mental examination. He should coördinate and interpret the various kinds of information, in coöperation with all others concerned, and should determine the mental status and quality of the child. His verdict will imply a certain kind of training for the child, 
which depends in turn upon those who have the organization and conduct of education under their charge.

The Growth of Psychological Clinics in the United States. Over twenty years have elapsed since Dr. Lightner Witmer established the first psychological clinic in the United States, at the University of Pennsylvania. Dr. Witmer has told how this happened. A teacher came to the psychological laboratory, where Dr. Witmer was in charge, seeking help for a puipil who could not spell. "Her assumption was that psychology should be able to discover the cause of this deficiency and advise the means of removing it." Dr. Witmer applied himself to the problem, which the teacher thus set for him. At that time psychology had never attempted to discover the causes of chronic bad spelling, or the remedies for it. It appeared to Dr. Witmer that if psychology were worth anything to him or to others, it should be able to assist the efforts of the teacher in a retarded case of this kind.

Working out his methods of examination as he went, Dr. Witmer made a thorough study of this child, who was a fourteen-year-old boy. It was discovered that the important factor in the boy's difficulty was an eye defect. After this defect had been corrected the teacher and the psychologist worked together, to instruct the boy, "as though he were a mere beginner in the art of spelling and reading." 
Other teachers approached this laboratory, and thus it came about that the first psychological clinic in this country was established as a result of the earnest demand of teachers for help in the solution of educational problems. It is in response to their increasing demands that psychological clinics have appeared all over the United States within the past decade.

The clinic at the University of Pennsylvania was established in the year 1896. In 1909 the demand for its services had become so great that regular daily clinics were instituted. All kinds of mental and moral deviation are handled, as is true of psychological clinics the country over. Mental deficiency is but one of the psychological problems which arise in the schools, though it is one of the largest problems.

Following the precedent of the University of Pennsylvania, many departments of psychology and education in universities have established psychological clinics. Sometimes they are called educational clinics, or psycho-educational clinics. As examples may be mentioned the Psychological Clinic at the State University of Ohio, the Psychological Clinic at the University of Indiana, the Educational Clinic at the College of the City of New York, the Psychological Clinic at the University of Texas, the Psychological Clinic at the University of Pittsburgh, and the Psychological Clinic at the University of Southern California. 
In other instances the educational officers of a city or state have established a psychological clinic as a part of the public school system. Examples of this are found in the Psycho-Educational Clinic in St. Louis, the Psycho-Educational Clinic in Newark, the Psychological Clinic in Oakland, the Psychological Clinic in Los Angeles, the Vocation Bureau in Cincinnati, the Psychological Clinic in Cleveland, the Department of Child Study in Chicago, and numerous others.

In small towns and in rural districts the psychological work is best administered by the state, as is now done in Wisconsin, New Jersey, New York, and other states.

The Future of the Psychological Clinic. As the movement for special classes grows, the psychological clinic will grow with it. Individualized instruction calls for the scientific recognition of individual differences, which is the service that the psychologist has been trained to render.

It is sometimes objected that the clinic will be an added expense, which a given community cannot afford to shoulder. It must be remembered, however, that the community in that case continues to incur the expense of repetition in the grades, of truant officers, and of adolescents who are turned out of school at the age of fifteen or sixteen years, untrained, though hundreds of dollars have been spent in presenting unsuitable material which they could not 
grasp. Ayres' figures showed that repeaters in the grades cost millions of dollars annually, all this money being spent in teaching over again material which cannot in many cases be grasped at all. In the long run the judgment of a community is bound to be that money invested in a psychological clinic is more useful than money invested in repetition, truancy, and industrial helplessness.

\section{REFERENCES}

1. Army Mental Tests. Office of The Surgeon General, Washington. 1918.

2. Binet, A., and Simon, Th., The Development of Intelligence in Children. Trans. by E. Kite. The Training School. Vineland, N. J. 1916.

3. Goddard, H. H., The Research Department: What it is, What it is Doing, and What it Hopes to Do. The Training School. Vineland, N. J. 1914.

4. Holmes, A., The Conservation of the Child. Lippincott Company. Philadelphia. 1912.

5. Otis, A. S., Group Intelligence Scale. World Book Company. New York. 1919.

6. Pintner, R., The Mental Survey. D. Appleton and Company. New York. 1918.

7. Pressey, S. L. and Pressey, L. W., A Group Point Scale for Measuring General Intelligence. Journal of Applied Psychology. Sept., 1918.

8. Stern, W., Psychological Methods of Testing Intelligence. Warwick and York. Baltimore. 1917.

9. Terman, L. M., The Measurement of Intelligence. Houghton Mifflin Company. New York. 1916.

10. Terman, L. M., Research in Mental Deviation among Children. Laboratory of The Buckel Foundation. Stanford University. Bulletin No. 2. 1915.

11. Wallin, J. E. W., Problems in Sub-Normality. The World Book Company. Yonkers, New York. 1917. 


\section{PSYCHOLOGY OF SUBNORMAL CHILDREN}

12. Whipple, G. M., Manual of Mental and Physical Tests. Warwick and York. Baltimore. 1917.

13. Yerkes, R. M., Bridges, J. W., and Hardwick, R., A Point Scale for Measuring Mental Ability. Warwick and York. Baltimore. 1915. 


\section{CHAPTER V}

ARE THE DEFECTIVE A SEPARATE SPECIES?

Since the treatment of the feeble-minded must be primarily educational, it is necessary that the teachers who have charge of them should be informed of all the known facts about their mental condition. One of the first questions to be investigated by experimental psychologists interested in the training of mentally deficient children was this: Do the feeble-minded form a distinct species intellectually?

It Was Formerly Assumed as a Matter of Course that the Feeble-Minded Belonged to a Distinct Mental Species. Herbart's theory advanced so long ago, that the feeble-minded form simply the opposite extreme from genius, and differ from the normal only in degree, made relatively little impression upon current thought. It was supposed generally that the feebleminded were divided from the normal by a sharp line of demarcation, on the one side of which stood all who were not feeble-minded, while on the other side stood all who were so afflicted, - the so-called idiots. According to this view, there was also another line of demarcation, separating the normal people from the 
geniuses, who like the feeble-minded formed a separate species. Thus the conception of the matter which formerly obtained might be graphically represented in this way:

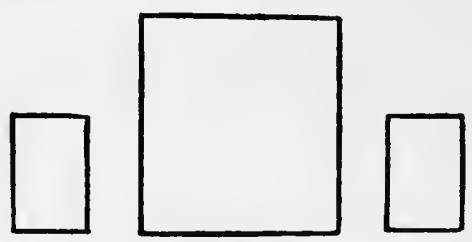

Fig. 6. - Showing schematically the erroneous conception of the division between normal and defective, and between normal and genius.

There were, according to this view of the distribution of intellect, the " idiots," who were all like each other in some essential characteristics, but entirely unlike normal persons in these particulars. Then there were the " normal " persons, who were mentally all equal to one another, but different from the "idiots" and from the "geniuses" in certain definite and essential traits. Finally there were the "geniuses," who all shared some mysterious essence or quality, which was, however, totally absent in " normal" or "ordinary" human beings.

It will be seen at once that such a view would have certain implications for pedagogy. If the mentally deficient child belongs to a species which differs in kind from ordinary children, he will have to be instructed by methods and in matters which differ in kind from the methods and matters of the ordinary school. 
The Search for a Qualitative Difference between the Feeble-Minded and the Normal. The belief that the mental defective is of a different kind from the normal is reflected over and over again in the literature of the subject. There has been, however, no agreement as to what might constitute this difference; as to what might be present in (or absent from) the mental constitution of the feeble-minded, which was not present in (or absent from) the mental constitution of ordinary persons.

At one time it was supposed that the "idiot" was imbued with a supernatural power, and that this quality separated him distinctly from the ordinary children. The babblings of the feeble-minded were thus heeded with the greatest respect, as being messages from the supernatural. It is even reported that Tycho Brahe, an astronomer of the Middle Ages, kept an idiot in his observatory, and hoped by means of his inarticulate mutterings to learn the secrets of science. Houses in which idiotic children were born were thought to be marked by the divinity. This attitude of superstitious veneration is reported to survive even yet in certain oriental countries.

Later there appears in connection with the medical conception of mental deficiency the idea that feeblemindedness is a pathological condition, due to some underlying pathological cause, but for the operation of which the individual in question would have been normal. The feeble-minded, according to this view, 
would be separated definitely from the normal in the same way that the sick are separated from the well. This conception of mental deficiency as a disease arises naturally among physicians, since they tend, in accordance with psychological law, to reason from analogy with what has come within their experience. Physicians are trained to recognize and treat physical disease. An individual either has or has not typhoid fever, for example. Reasoning from analogy with such organic abnormalities, men came to speak of the feeble-minded as "having imbecility" or being " affected by idiocy," as though these things were disease entities.

Examples of this tendency to regard the feebleminded as a separate species are freely scattered through the literature. For instance in the writings of Tuke the following appears: "As the scale of imbeciles ascends, it is found that the condition is evidenced not so much by low obtuseness as by irregularity of intellectual developments. This seems to make the difference between the extreme stupidity of the lowest of the healthy, and the highest form of the morbidly depraved type. . . The two conditions do not merge gradually into each other." Again, in a Report on Physical and Mental Affections of Children published in London, we find the following: "We have, then, in the ascending scale from imbecility upwards, this irregularity of mental conformation, and then again separated as by a clear line the 
uniformity of dullness of a low class of the healthy type. . . . Belonging, so to speak, to a separate series is the lowest of the healthy - the dullard."

There has also been a protracted effort to formulate a qualitative difference between the mentally deficient and the normal in terms of psychology. It has been said that the essential difference consists in "a want of psychic force." Thus originates the term "weak-minded," with vague ideas of analogy with physical weakness. An interesting illustration of this point of view was shown in the case of an imbecile, who was recently referred to the writer by a dentist. The dentist refused to administer gas to this obviously "weak-minded" girl until he had in hand a statement signed by a psychologist to the effect that the "weak" mind was not liable thus to be wholly extinguished. ${ }^{1}$

Still another theory has had it that there is in the feeble-minded person an "absolute defect," an absolute lack of something which is always found in normal persons. As to what this "absolute defect" might be, there has been much disagreement. The feeble-minded have been variously said to lack " judgment," "reasoning power," " understanding," "the power to learn." Even Binet in his earlier researches concluded that there must be some real difference of kind, which could be used as a touchstone

${ }^{1}$ This precaution would not have seemed irrelevant, however, had this girl been found to be a glandular case. Anesthetios are dangerous in some such cases. 
to distinguish the defective from ordinary children. In his work entitled Mentally Defective Children, Binet says: "A second and totally different theory is tenable, and this one appears to us to be much nearer the truth. It is that a defective child does not resemble in any way a normal one whose development has been retarded or arrested. He is inferior, not in degree, but in kind. . . . An unequal and imperfect development is his specific characteristic. These inequalities of development may vary to any degree in different subjects. They always produce a want of equilibrium, and this want is the differentiating attribute of the defective child." After further research, Binet completely revised this conclusion, as we shall see.

Various Special Systems of Education Were Devised on the Assumption that Mentally Defective Children Differ in Kind from Ordinary Children. The best known of these is, perhaps, the "physiological method" of Seguin, to whom belongs the honor of having formulated the first complete system of education for defective children. His plan was founded on the now antiquated faculty psychology. He believed that general improvement could be brought about by training in specific tasks; that mind could be divided into separate entities, called variously 'the attention,' 'the sense-perceptions,' ' the will,' ' the memory,' and the like; and that each of these could be strengthened by special exercise, as 
a muscle may be strengthened by lifting dumbbells, so that it will lift any kind of objects equally well.

For the day in which he lived, Seguin's ideas were, however, remarkably advanced. Another feature of his method was the "education of muscles." He hoped to develop ideas of movement and achievement in the idiot, by putting him through various planned exercises. The form-board, now used as a mental test, was originally devised by Seguin as an educational instrument, for training idiots in perception of form and size. In short, Seguin believed that the feeble-minded would profit from the application of a different kind of training from that given to ordinary children. It remained for Montessori, whose methods are very similar to those of Seguin, to demonstrate that normal children are amenable to the same devices which were found effective with deficient children.

In the practical demonstration of his methods, Seguin founded the famous school which bears his name, and which has grown in usefulness with the growth of interest in, and scientific knowledge about, the mentally defective.

Norsworthy's Experiments. Dr. Norsworthy was the first to investigate this question by the methods of experimental psychology. Her results were published in the year 1906. It so happened that during the very years in which she was 
carrying out her experiments, Binet and Simon were also working experimentally with defective children, though not with this particular question so clearly formulated as the purpose of their investigation.

Dr. Norsworthy measured a number of feebleminded children, in a variety of mental traits, and likewise a number of ordinary school children in the same traits. She found that in all traits measured the performance of the former was continuous with the performance of the latter. In other words, the feeble-minded did not fall into a class by themselves, but joined with the normal, forming the very fag-end of the curve of distribution. The conclusions of this careful research are stated by the investigator thus:

"Idiots seem not to form a separate class or species, as far as intellectual traits are concerned, but are included as part of a large distribution. A group of individuals forming a separate species in any trait would be a group clustering about a central point, and lying in the main outside the distribution of normal individuals in that trait." This latter result Norsworthy did not obtain.

Binet's Observations. As we have already stated, Binet at a relatively early period in his study of the feeble-minded stated that they seemed to him to differ in kind from normals. But after prolonged psychological experimentation he revised this idea, and came independently to the same conclusion as 
that reached by Norsworthy. In the volume entitled The Intelligence of the Feeble-Minded, Binet writes on this question as follows:

“... Is it possible to cite known mental faculties which belong to normals and are not found among defectives? Formerly this was believed, and certain authors believe it still; but this is because they have submitted their subjects to incomplete observations. Let us make an enumeration. Is the defective radically incapable of attention? Evidently not. We have proved, even with idiots, that they give undeniable evidences of attention. ... Is it that memory is lacking? Not that either. We have noted many instances of prolonged memory among them. . . . Are they strangers to the notion of number? This has been believed, because they employ at random the names of numbers which they do not understand; but some precise tests have shown us that they have a distinct consciousness of plurality even when they cannot name it. Is it then critical sense, judgment that they lack? Certainly judgment often fails them; or rather they can be placed in certain conditions where it would require a particular degree of judgment for them to be equal to the situation, and they cannot attain it. But in other cases they certainly show some judgment, for instance when Albert refuses to be the dupe of suggestion. We may thus pass in review all our faculties, and determine that not one is entirely lacking in them...They always have them in some degree...The arsenal of their intellect is equipped with all the weapons.

"Another means of arriving at the same conclusion consists in repeating an experiment that had been attempted by them but in which they had failed: let that experiment be simplified by replacing it with another of the same nature but easier, and the defective immediately takes his revenge. A certain movement cannot be accomplished in ten seconds; he does it in twenty seconds. He cannot repeat four figures; but he can repeat two. He does not understand a certain sentence; but he comprehends another that is shorter and less complicated. He fails in a 'game of patience' formed of ten pieces; he succeeds if the number of pieces is only three. Sometimes it is not easy to simplify a test; but every time that it is reduced sufficiently, one can be certain that the defective will be able to succeed. 
"This truth, verified repeatedly, frees us from the necessity of undertaking an investigation whose result can be foreseen.... Thus there is no need of asking whether an imbecile has any æsthetic sense. He will always have at least a trace. Show him two figures, one pretty, the other ugly, and he will be able to make a distinction between them if you carry the degree of deformity far enough.

"All this leads to the conclusion that the difference between the defective and the normal is not produced by the absence of a particular faculty, and alienists who in their definitions have seemed to imply the contrary have deceived themselves."

Witmer's Conclusions. Witmer is in harmony with the conclusion reached by Norsworthy and by Binet, as is shown in a statement made by him in 1907. As a result of his examination of children in the psychological laboratory, Witmer says, "I would not have it thought that the method of clinical psychology is limited necessarily to mentally and morally retarded children. These children are not, properly speaking, abnormal, nor is the condition of many of them to be designated as in any way pathological. They deviate from the average of children only in being at a lower stage of individual development."

Other Evidence that the Feeble-Minded Differ from Normals Only in Degree. The best evidence we have that the feeble-minded are different from ordinary persons not in kind, but only in degree, comes from psychological experiments like those of Norsworthy and Binet. All similar experiments made since their work was published have confirmed their result. Besides, these researches, and as a conse- 
quence of them, other facts have come to light in recent years, which formerly were unknown, and which contribute materially to our understanding of this question. For example, before the graded scales for the measurement of intelligence were devised, the moron was unknown. All who could learn to read and write with some degree of skill, and who had no stigmata of degeneration, were considered to belong to the "normals." Such a child might be characterized as lazy, bad, ne'er-do-well, careless, shiftless, but not as feeble-minded. This failure to perceive the true condition of the great number of defectives whom we now call morons, of course, contributed to the view of the idiot and imbecile as a scparate species. The morons, who bridge the span between the dull and the imbecile, were not perceived for what they are. The moron is not perceived in any true or useful sense even to-day, except where the meaning of mental measurement is understood. The mental survey and the mental clinic have, however, revealed him, and have shown where he stands on the continuous curve of intellect, which includes all human beings.

We may appeal also to statistics. If it be true that the feeble-minded form but the lower end of the normal distribution curve, we shall expect their frequency to decrease as the degree of their defect becomes greater. In other words, we shall expect to find fewer imbeciles than morons, and fewer idiots 
than imbeciles; for within the same species, the frequency decreases as individuals are removed farther and farther from the norm.

All statistics of the subject show that there are in fact fewer imbeciles than morons, and fewer idiots than imbeciles. The figures of the Royal Commission of Great Britain may serve as a sample. This Commission, using the social-economic criterion of mental deficiency, found in the districts surveyed by them, 585 idiots, 1007 imbeciles, and 9728 feebleminded (morons). This is just what we should expect to find if the feeble-minded are.continuous with the normal in mental ability.

It is a familiar fact to clinicians that there are scores of individuals who will be classified about equally often as idiot or imbecile, as moron or "inferior," by persons of equal competence in diagnosis, when the method of mental measurement is not used. This fact is in itself an indication of the continuity of normal with moron, of moron with imbecile, and of imbecile with idiot, since there is no differentiating symptom whereby these "border-line" cases can be classified. The very existence of " border-line " cases in itself suggests that all belong to the same mental species.

Implications for Education. This fact that the feeble-minded are different from average children not in kind, but in degree only, is of fundamental importance for education; for it follows that no mys- 
terious or unique matter or method is necessarily required in the task of training them. They can learn the same things that other children learn, up to the limits of their capacity. We need not look about for unique "physiological methods," "linguistic methods," or "medico-pedagogical methods," nor may we hope for any special results from them. The feeble-minded differ from ordinary children only in amount of ability, not in the kind of abilities which they possess.

A feeble-minded child, of whatever chronological age, if he has a mental level of seven years, is capable of acquiring the information that is acquirable by the average seven-year-old child. A feeble-minded child, of whatever chronological age, can do the work of the average second grade in public school, if his mental age is as much as seven years. He may be taught by the methods and with the materials suitable to children of about the age where he grades mentally. Feeble-minded children of high grade may be taught even the subjects given in the fourth, fifth and sixth grades of the public school, provided only that they remain in school till they are adult, and have reached their ultimate mental level. As no one is technically called feeble-minded whose ultimate intellectual level is over twelve years, none of the feeble-minded will be able to perform school work above the sixth grade, no matter how long they remain in school. Thus it is a question whether it is 
expedient to spend the school years of the defective in the performance of conventional school work, even though he is capable of grasping it up to a certain point.

It is not the province of psychology, however, to dictate or to state the curriculum which shall be established for the feeble-minded. This is a matter that must be decided on the basis of social aims. From the viewpoint of social expediency, which always implies also the welfare of the individual, it may be that the feeble-minded should be trained in manual labors only, and that no time should be spent in teaching them to perform the fundamental operations in arithmetic. Or it may be that social expediency demands that all of the feeble-minded who can learn to "read, write, and cipher" be taught to do so.

As a matter of fact, educators have not yet reached a final decision as to the curriculum which may most profitably constitute the education of the defective. The task of psychology in any event is to tell what the defective can do, in case society decides that it is best that this or that should be undertaken. And therefore we say, as Binet said, "The arsenal of their intellect is equipped with all the weapons," only the "weapons" are poor, inferior, not very dependable.

\section{REFERENCES}

1. Binet, A., and Simon, Th., The Intelligence of the FeebleMinded. Trans. by E. Kite. The Training School. Vineland, N. J. 1916. 
2. Goddard, H. H., Two Thousand Normal Children Tested by the Binet Measuring Scale of Intelligence. Pedagogical Seminary. 1911.

3. Kelly, R. L., Psychophysical Tests of Normal and Abnormal Children. Psychological Review. 1903.

4. Norsworthy, N., The Psychology of Mentally Deficient Children. Archives of Psychology. 1906.

5. Seguin, E., Idiocy and Its Treatment by the Physiological Method. First published in 1864. Reprinted by Teachers College, Columbia University. 1907.

6. Terman, L. M., The Distribution of Intelligence. (Stanford Revision and Extension of the Binet-Simon Scale for Measuring Intelligence.) Warwick and York. Baltimore. 1917.

7. Witmer, L., Clinical Psychology. The Psychological Clinic. March, 1907. 


\section{CHAPTER VI \\ “ARRESTED DEVELOPMENT"}

What Does Arrested Development Mean? Can this term be applied to describe the condition of the feeble-minded in any true scientific or psychological sense? It is true that in speaking of the subnormal, the term " arrested development" has been very frequently used. We may cite such examples as the following: "A general arrest of development involving all the psychic functions; three degrees are usually recognized: idiocy, imbecility, and feeble-mindedness." 1 "Atrophy of attention is, therefore, the most important symptom of arrest of psychic development." " "Imbecility as described here is regarded as the final expression of the 'degeneration' of the stock. It is a spontaneous arrest of mental development due to inherent factors." 3 . . .

Now, if the words " arrested development" are to be used in describing the psychology of the feebleminded, it is necessary to define them clearly, as

1 R. de Fursac. Manual of Psychiatry. Trans. by A. J. Rosanoff. J. Wiley and Sons. New York. 1913.

2 P. Sollier. Psychologie de l'idiot et de l'imbecile. F. Alcan. Paris. 1901.

${ }^{3}$ E. F. Ballard. An Epitome of Mental Disorders. P. Blakiston's Son and Company. Philadelphia. 1917. 
they may not have the same meaning to all persons using them.

The Limits of Physical Growth in Human Beings. Everyone is familiar with the fact that physical development ceases in human beings with the attainment of adulthood. At the end of the period of adolescence we say of the individual that he "has his growth." In this matter, as in all others, there are considerable individual differences. Some attain full physical growth relatively early in the teens; while others continue to grow a little after the age of twenty years. Teachers are usually familiar with curves of physical growth, like those in Figure 7, which show the average increase of height in growing children, year by year. As children approach the later teens the curve of physical growth rises more and more slowly, until finally it turns on the level, rising no further, and the children "have their growth." It is true that as years pass there are further increments of weight in human beings. These increments are not, however, due to growth, but to deposits of fat in the tissues.

It is not known exactly at what age the average curve for physical growth ceases to rise, because it is very difficult to follow adolescents after they leave high school, which is, on the average, at eighteen years. It will be seen that there is very little development after the average age of sixteen years. It is probable that, on the average, growth (proliferation and en- 
largement of body cells) has ceased entirely by the age of twenty years.

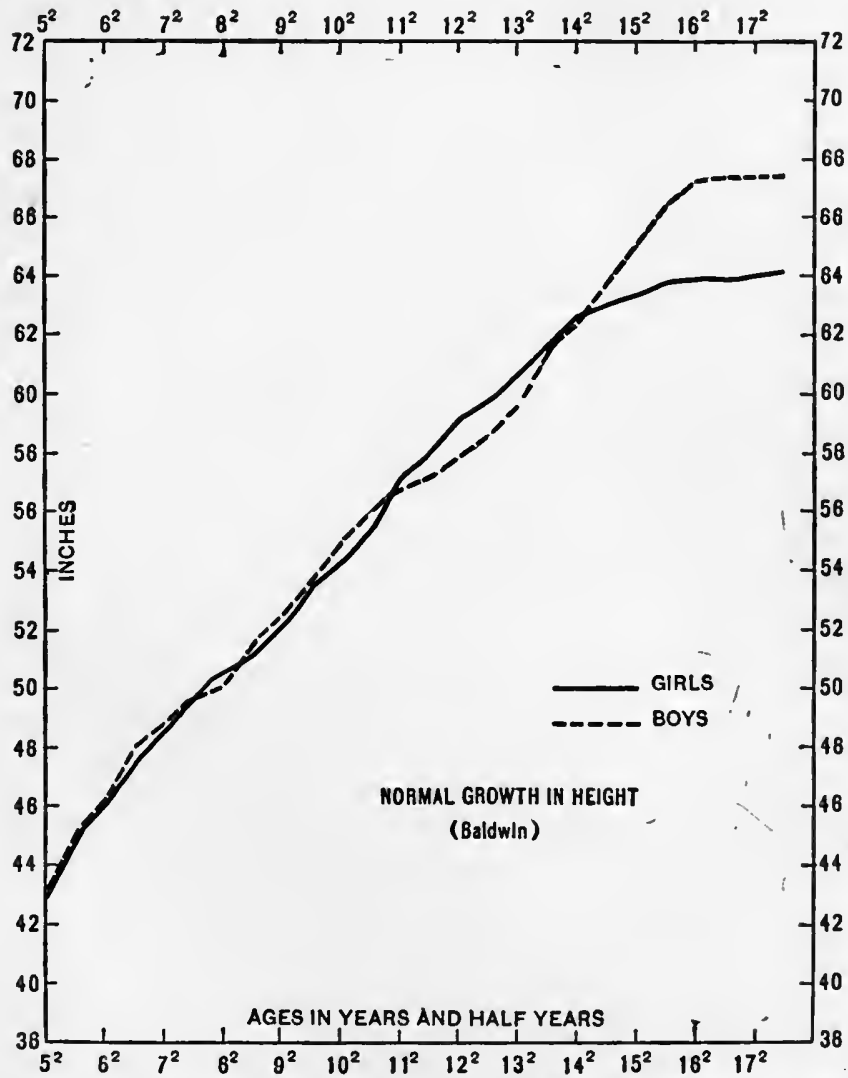

Fig. 7. - Curves showing the normal increases in height, in growing children, year by year. (From Baldwin. Reproduced by courtesy of Prof. Bird T. Baldwin.)

The Limits of Mental Growth. The facts of physical development have been called to attention, in 
order to clarify the understanding of certain facts of mental growth, which are less familiar. We are accustomed to think of human beings as "having their growth" physically by the end of adolescence, but persons in general have very vague and erroneous ideas about the limits of mental growth. When asked unexpectedly, "When do human beings cease to grow mentally?" the members of a graduate class in psychology gave a great variety of replies. Several upon reflection said they had no idea; others said that human beings never cease to grow mentally; others gave forty years as the limit; others, thirty-five years; others, thirty. There was much confusion as to the interpretation of the words " mental growth," many identifying the term with learning and education.

This state of affairs in a graduate class in psychology is not surprising, because the attempt to establish the limits of mental growth is a very recent enterprise of experimental psychology. By mental. growth is meant that gradual increase of capacity: for learning, which comes as a result of the develop-: ment of the nervous system, apart from all training.: The nervous system, which is the physiological basis of mental life, does not continue to grow indefinitely. Like all other tissues of the body, it "gets its growth." Since it is impossible for psychologists to observe and measure directly the course of growth of the nervous system in living children, they measure 
it indirectly by measuring behavior. Behavior is measured by means of mental tests, as already described in the chapter on this subject.

When mental growth is thus measured, we find, as in the case of physical growth, that the curve rises rapidly at first, and gradually approaches a level, above which it finally ceases to rise further, as shown in Figure 8. It cannot be stated at present just when mental growth ceases, on the average. (There are, of course, individual differences.) Dr. Terman was unable to obtain any rise in performance in general intelligence tests after the age of sixteen years. More recently, the mental tests in the army seem to indicate that the limits of mental growth are reached, on the average, between thirteen and fourteen years. - These observations are in substantial agreement with such measurements of brain weight as neurologists have been able to make. It appears that the brain reaches its maximum weight at approximately the age of thirteen years, on the average.

Although we are not as yet justified in stating on the basis of experimental evidence exactly the age when mental growth ceases on the average, we are justified in stating that it most probably lies between thirteen and twenty years. Thus development is normally "arrested" in all human beings between these limits. Such advantage as the average fortyfive-year-old has over the average twenty-year-old in the management of affairs consists in additional 


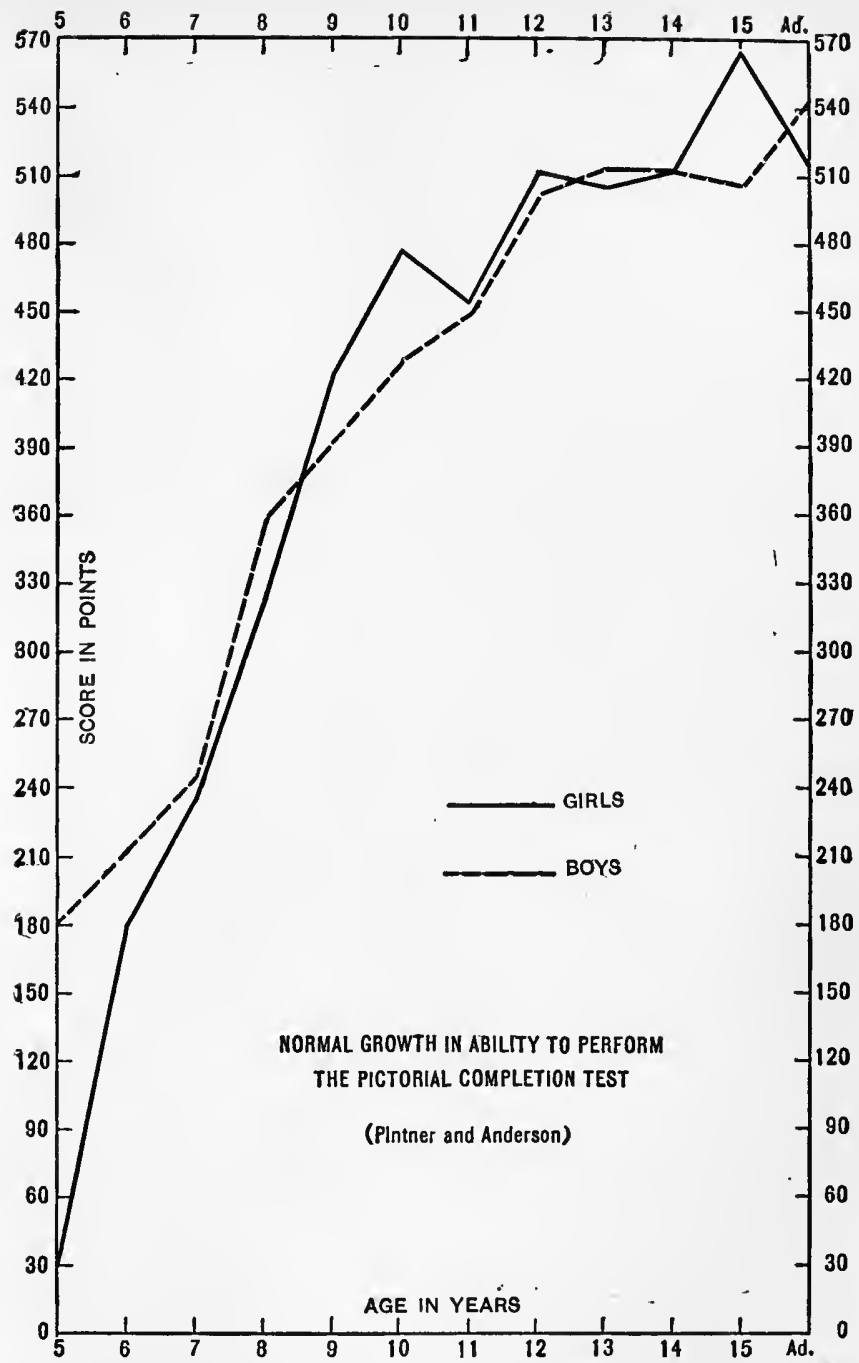

Fia. 8. - Curves showing the normal increases in ability to perform the pictorial completion test, year by year, in growing children. (From Pintner and Anderson. Reproduced from The Pictorial Completion Test, by special arrangement with Warwick and York.) 
knowledge, experience, and helpful specific habits, not in additional capacity for learning new things, which are equally unfamiliar to both.

In this sense the feeble-minded individual who is adult may be called a case of "arrested development," just as every other adult may be referred to as "arrested." It is to be feared, however, that the term is used in the case of the feeble-minded with a connotation quite different from this. It is used in a sense which would imply that those using it believe that the defective child follows the usual course of development up to a certain level, and then stops there; so that psychologically he remains thereafter in the mental state of a child of that age at which the alleged "arrest" took place. This use of the words "arrested development" implies a preformed idea of a completed being, toward which the organism was tending, and toward which it actually tended till a certain point in its course, when it stopped and remained forever uncompleted. So one often hears such phrases as "never developed mentally after the age of five years," "stopped growing intellectually at eight," and the like.

Now, if the defective is a case of " arrested development" in this sense psychologists would expect to find, in the first place, that the defective of whatever age is a duplicate of the normal child of his mental level, in respect to mental traits; in the second place, they would expect to find that defectives show 
normal progress up to the point at which the alleged "arrest" takes place; and in the third place, they would expect to find that mental growth ceases altogether at the age of arrest, and does not continue up to the age of later adolescence, as in the case of other children. If these conditions cannot be verified by research, the term "arrested development" has no significance, and cannot be applied.

Are the Mental Traits of the Feeble-Minded the Same as Those of Normal Children of Equal Mental Level? The psychological methods of mental measurement make it possible to work out quite exactly the comparison between the intellectual condition of defectives and of normal children of the various ages, which correspond to their mental ages. This question at present affords a fruitful field for research. There are certain specific habits and pieces of information which form a part of the mental contents of an adolescent or adult defective whose mental age is seven years, which do not form a part of the mental contents of normal seven-year-old children, simply because the former have lived many years at the seven-year level, while no normal child ever lives more than a few months at a mental age of seven years. If the normal child of seven could by some miracle remain normal and seven for ten or fifteen years, he also would acquire such habits and information, no doubt; but as it is he does not acquire them. It is furthermore true that the instincts 
undergo development in adolescent and adult defectives, which they have not undergone in normal seven-year-olds. This also produces differences in the mental traits of the two groups.

It remains for experimental psychology to work out in detail the comparison between defectives and normal children of various mental ages. Similarity in mental age may mean simply similarity of capacity for learning, similarity of capacity for comprehending the environment, with similarity in few other respects.

Do Defectives Progress Normally to a Certain Point, and Then Suffer Arrest? With respect to the second point of interest, i.e. does normal progress take place up to the stage at which the alleged arrest occurs? we must state that such is not the case. The histories of feeble-minded and dull children typically show that they are inferior and below par from the beginning. There is a very close relationship between lateness of walking and talking and inferiority of intelligence, as later ascertained. The same is true of all the important processes of development, - dentition, sitting up, creeping, grasping, learning to be clean in personal habits. The subnormal child is behind the average from the beginning of his career. $\mathrm{He}$ is inferior from his birth, and suffers no arrest of a development which was progressing normally. This is true of all but the small group of cases where deficiency is due to disease, which will be discussed later. 
A few developmental histories, chosen at random from among defective children, will serve as concrete illustrations of this point. R. H., a child twelve years old, measures seven years two months on the scale of intelligence. His intelligence quotient is therefore 60 . He did not begin to walk until he was two years old, and did not talk until he was four years old. He has always been backward in school status. F. McB., a girl fourteen years old, measures nine years four months on the scale of intelligence. Her aunts report that she was always "slow to get on," though her mother, who is also feeble-minded, noticed nothing wrong with her. Her school record from the age of six years is one of chronic retardation. At her present age she has attained the sixth grade, where she is incapable of doing the work. If measurements could have been made of the mental development of these children from birth they would undoubtedly have shown curves rising constantly, but more slowly than the average curve.

Tredgold states that in his experience he has met with a very few cases in which he could elicit no facts showing slowness of development in the earliest years of life, and in which the deficiency seemed really to have manifested itself first after childhood was somewhat advanced. It is probable, however, that psychological measurement would have shown the inferiority to have been present from birth. 
Parents of defectives often do not notice anything unusual about the development of their offspring, in the first place, because few parents are well informed as to what constitutes the course of normal development, and in the second place, because parents see their children as they wish them to be, rather than as they are. In the case of defectives an additional source of unreliability in parental statements enters, namely, the fact that the parents of defectives are often themselves defective, and are as incapable of giving information about the development of their children, as they are incapable of giving information about things in general. Also it is true that the milder the degree of deficiency, the more nearly does the individual approximate the course of normal development; so that common observation might never find anything noticeable in the development of morons and border-line cases.

The unhappy parents of subnormal children, casting about for a cause of the condition which shall be extrinsic, and not referable to heredity, are prone to mistake this infantile backwardness for the cause of the later noticed intellectual weakness. They sometimes say, "Of course you must consider the fact that so-and-so did not sit up or cut a tooth till he was over a year old, and of course that caused him to be backward." But infantile subnormality is not the cause of subsequent inferiority. It is part and parcel with it. The intellectual feebleness of the defec- 
tive adult is merely a continuation of his infantile backwardness. Those who are destined to go through life with subnormal intelligence begin to show the fact at an early age.

How Long Do the Feeble-minded Continue to Develop Mentally? Do the defective cease to grow mentally at a relatively early age? Or do they go on like others, developing until adolescence is reached or passed?

Measurements repeated for several years at Training Schools ${ }^{1}$ show that feeble-minded children continue to grow mentally until well advanced in adolescence. They develop very slowly, as compared

${ }^{1}$ In response to a request for information on this point, the following letter was received from Dr. F. Kuhlmann, Director of Research at The Minnesota School for Feeble-Minded:

"We have been making the re-examinations of our inmates every two years since 1910, with the exclusion of the cases with mentality below three, and any chronological age over twenty. I have planned to continue these re-examinations for a ten-year period before working up the results. We made one or two preliminary tabulations a few years ago, and it seems that the general results will probably be as follows:

"On the whole the IQ for a given case remains constant, with a slight tendency on the average to decrease after the ages of about nine and ten. To this general rule there are quite a number of individual exceptions. A good many cases deteriorate, for whom the IQ will then drop very suddenly, and this may be at any age. In a smaller number of cases the IQ increases with age, very markedly in rare instances, more or less frequently in a degree which may be a'ccounted for possibly by an increasing familiarity with the mental tests through repeated examinations. Also there seems to be the tendency for the mental ages to increase very slightly beyond the chronological ages of fifteen or sixteen." 
with normal children, gaining only a few months in a year. Toward the end of the period of growth the rise in the curve is barely perceptible, so that the intelligence quotient (relation of mental age to actual age) becomes slightly lower as time elapses. Nevertheless, growth does not cease entirely until childhood has passed.

Thus we can never say of a feeble-minded child that the limit of development has been certainly reached, until the years of adolescence. The feebleminded grow mentally more slowly than the average, and they never attain the average status, which marks the final limits of growth, but they continue their meager development until childhood is passed. They do not cease to grow mentally at five years, or at six years, or at any other year in early childhood, though it is probable that the age of final cessation of growth will be found to be the earlier the more inferior the child.

True Cases of Arrested Development. It has already been stated that a small percentage of mental deficiency is produced by some external factor, acting upon a child who but for this misfortune would have been of average or superior mentality. Suppose a child of four years, testing normal on the scale of intelligence, to suffer fracture of the skull, with injury to the brain; or suppose a child of three years, of superior intelligence, to develop encephalitis (inflammation of the brain). Such a child recovering 
from his illness might never develop mentally beyond the point at which his misfortune overtook him. Doubtless such a case could truly be described as " arrested development," though there might be uncertainty of real applicability even here.

Summary of the Facts. The term " arrested development" cannot be used to describe the condition of the feeble-minded in any true scientific, psychological sense (except possibly in the few cases which are the result of accident or disease). It is a meaningless expression, because the feeble-minded develop as all other human beings do, throughout the years of childhood, although they develop more slowly than normal children do, and never attain the status which is attained by the normal population at the final limits of growth. They are just as truly completed when adult as are other human beings, but they are inferior in mental capacity.

\section{REFERENCES}

1. Baldwin, B. T., A Measuring Scale for Physical Growth and Physiological Age. Fifteenth Year Book. Part I. National Society for the Study of Education. 1916.

2. Binet, A., and Simon, Th., The Development of Intelligence in Children. Translated by E. Kite. The Training School. Vineland, N. J. 1916.

3. Bolton, T. L., The Growth of Memory in School Children. American Journal of Psychology. 1892.

4. Donaldson, H. H., The Growth of the Brain. Charles Scribner's Sons. New York. 1895.

5. Goddard, H. H., Psychology of the Normal and Sub-Normal. Dodd, Mead and Company. New York. 1919. 


\section{PSYCHOLOGY OF SUBNORMAL CHILDREN}

6. Hollingworth, H. L., Mental. Ability and Chronological Age in Adults. Psychology of Functional Neuroses. (In Press.)

7. Ladd, G. T., and Woodworth, R. S., Elements of Physiological Psychology. The Macmillan Company. New York. 1911.

8. Pintner, R., and Anderson, M., The Pictorial Completion Test. Warwick and York. Baltimore. 1917.

9. Reynolds, M. M., A Study of the Heredity of Some Mentally Superior Children. Master's Essay. Columbia University. 1917.

10. Terman, L. M., The Rate of Growth and the Validity of the IQ. (Stanford Revision and Extension of the Binet-Simon Scale for Measuring Intelligence.) Warwick and York. Baltimore. 1917.

11. Terman. L. M., The Intelligence of School Children. Houghton Mifflin Company. Boston. 1919.

12. Town, C. H., A Study of Speech Development in 285 Idiots and Imbeciles. Psychological Clinic. 1913. 


\section{CHAPTER VII}

ARE THE FEEBLE-MINDED EQUALLY FEEBLE IN ALL ABILITIES?

ANoTHer question that presents itself as soon as the teacher begins her task of training subnormal children is this: Are they equally feeble in all respects? Or do they show more or less decided unevenness in intellectual development? We say, "The mind is feeble," but we must inquire into the matter much more analytically than this, if our interest is in teaching these minds. We know that average children are by no means equally capable in all situations. Shall we expect that subnormal children will also have their special strengths and their special weaknesses?

This question may be taken up from two standpoints. First: are the subnormals as a group more capable in certain traits than in others, when compared with normal children? Second: is an individual defective equally weak in all of his individual capacities?

Physique. Since the physical traits of the feebleminded are to be discussed in detail in a subsequent chapter, it will be necessary merely to note here the 
fact that physically they approach the norms. If a thousand mentally subnormal individuals are measured and compared with a thousand mentally normal individuals in any given physical trait, - weight, height, cranial circumference, and the like, - the amount of overlapping between the groups will be very great. Many of the mentally subnormal equal and surpass many of the mentally normal in these measurements.

Sensory Capacity. The power of making sensory discriminations has frequently been stated to be far less acute in the mentally deficient than in the intellectually normal. It is true that in the very low grades of deficiency, among idiots, there is often extreme defect of taste, and even perversion of taste. (By defect is meant that the capacity is diminished, while perversion means that the individual actually seeks and enjoys those things which in average persons are abhorrent to the senses.) Many idiots will eat and drink anything that falls within reach. Their only response to psychological tests often is that they try to eat the materials provided. They will chew quinine, soap, or sugar, all with equal enjoyment, and without giving any sign that they distinguish among the substances. Some show actual preference for filth.

Similarly, with the sense of smell. Some idiots will smell of the most disgusting odors without discomfited behavior. Many can even sniff ammonia, 
which in normal persons produces a reflex movement away from it, without apparent inconvenience.

Such sensory defects are noticeable, however, only among the idiots. As the intelligence approaches ${ }^{\circ}$ normal, the response to sensory stimuli approaches normal also. It is very difficult to make scientific tests of sensory capacity, because such tests involve the ability to comprehend and follow simple directions, which at once involves the intelligence. It is almost impossible to make satisfactory tests of vision and hearing, for example, in feeble-minded school children, because the examiner can scarcely be sure whether the child really does not see or hear what is presented, or whether he simply fails to report on it through lack of intelligence.

The general conclusion to be drawn from the experiments which have been made on the sensory capacities of mentally defective children is that they are not far removed from the norms in such capacities. If sensory tests could be devised which involved no comprehension or ability to report on the part of the child, we should probably find that the curves for the feeble-minded overlap to a very great extent the curves for children chosen at random.

In other words, the failure of the feeble-minded child to learn the lessons which his comrades master with ease is not due to the fact that his sense organs are less acute. The difficulty lies not in the sense organs, but in the ability to interpret and organize 


\section{PSYCHOLOGY OF SUBNORMAL CHILDREN}

the sensations which he has. He fails to learn to read, not because his retina is insensitive to black and white, but because he lacks the intellectual development which is prerequisite to the interpretation of the black marks which he sees. He fails to learn grammar, not because he cannot hear the sound of the teacher's voice, but because he is incapable of comprehending and organizing as part of his mental life, the remarks which she makes.

The fact, then, seems to be that the feeble-minded approach near to the norms in sensory acuity. This conclusion must not be interpreted to mean that sensory defects are never found among feeble-minded children. The feeble-minded, like the normal and superior, are subject to defects of the special senses. They may suffer from defective vision, from partial deafness, or from any other sensory defect which afflicts persons at large. Wherever such defects are found they should, of course, be corrected if they are corrigible.

Motor Control. In tests of motor control, as in tests of sensory acuity, we meet the difficulty of eliminating intelligence as a factor in the performance of the feeble-minded. Motor tests also involve the ability to comprehend. However, in spite of this difficulty, we have at our disposal for study several experimental studies of the motor equipment of mentally defective children.

In strength of grip, and speed of voluntary move- 
ment, the feeble-minded are inferior to children chosen at random. Mead found that feeble-minded adolescents, who were farm laborers in their institution, were decidedly inferior in grip to college students unused to manual work. Ordahl and Ordahl ascribe this inferiority in motor tests to "lack of energy and capacity for voluntary effort on the part of the feeble-minded," who though possessing good muscles are unable to exert force in the nervous control of them. Norsworthy believed that the necessity for comprehending exactly what is wanted interferes with the showing of the feeble-minded in tests of motor control; that if this factor could be eliminated, they would approach very closely to the norms.

Among defectives of the lowest grade a great variety of motor anomalies occur. Idiots sometimes spend hours going through series of purposeless movements. These may involve one set of muscles, or may involve the whole body. A swaying motion, backward and forward, is often seen. The idiot may occupy himself with the so-called "polar bear" movement, stepping a few paces forward and then moving back. Slapping his own face; pulling at one or both ears; grasping intermittently at a wisp of hair; stamping one foot suddenly at intervals; grimacing and nodding; these are a few of the motor phenomena which are met in idiots. The psychology of these peculiar motor habits, sometimes called 
tics, is little understood. Binet believed that these tics are explainable, in part, in the same way as those of certain blind persons. They are motor tendencies which might arise in anyone, but normal persons arrest and suppress them, because they are seen to be unsuitable. The idiot does not perceive his own actions; or if he does perceive that he is moving, has not intelligence enough to realize that such movements are not socially approved. Of course, some of the tics are doubtless reflex in character, and hence cannot be controlled.

Children showing these phenomena of movement are usually below the level of admission to the public schools. It is in the institutions, where idiots are collected, that we see them. However, occasionally a feeble-minded child of higher grade shows peculiar motor habits, such as grunting, tapping with his foot, moving a quantity of saliva about in his mouth, chewing various parts of his anatomy. The same mild phenomena occur among children of all degrees of intelligence.

The general conclusion from the studies of motor control in the feeble-minded is, then, that they are inferior to children chosen at random. But, although inferior on the average, they approach much nearer the norms in motor ability than they do in intellectual ability. This conclusion has definite implications for pedagogy. For example, the imbecile does not fail to write because his hand is not able 
to hold and guide a pen, though this may enter as a contributing difficulty. The chief factor in his failure is the lack of intellectual development which would enable him to perceive meaning and relationship in the symbols presented to him for learning.

Another important implication for pedagogy is that the feeble-minded will be best able to perform those services which call chiefly for motor response. This has been recognized in the curriculum, which has been gradually worked out for mentally deficient children. The manual arts are stressed. It is usually a matter for astonished comment on the part of visitors to institutions for the feeble-minded that such children as are detained there are capable of sewing, cutting, cooking, weaving, and cabinet-making. These are all processes which call largely for motor response, and when the motor habit has once been organized in the nervous system, it makes very little demand upon the intellect. Feeble-minded children who can never learn to read, are often capable of efficient knitting, weaving, and cleaning, because they approach nearer to the norms in motor ability than they do in intellectual ability. They are better able to deal with things, than with ideas.

From these generalizations it will not be inferred that every feeble-minded child, without exception, is most capable in manual processes. Occasionally we find a defective who is weaker in motor control 
than he is in the intellectual processes. Such cases are, however, rare.

The Intellectual Capacities. Turning now to the intellectual equipment, it has been found by all investigators that it is in this respect that the feebleminded are farthest from the norms. It is, indeed, upon marked deviation from the norm in this particular that the diagnosis of mental deficiency primarily rests. Many attempts have been made to formulate a satisfactory definition of intelligence. Binet's definition emphasized three phases of behavior: (1) the ability to take and maintain a given mental set; (2) the capacity to make adaptations for the purpose of attaining a desired end; and (3) the power of autocriticism. Stern defines intelligence as " the general capacity to adjust thinking to new requirements: it is general adaptability to new problems and conditions of life." Witmer writes: "I have defined intelligence as the ability of an individual to solve what for him is a new problem. A problem must be solved, and it must be new."

It is difficult to arrive at an entirely satisfactory definition of intelligence, - one that will include all of the essential elements, and will exclude all of the inessential and irrelevant elements. But certainly the ability to adapt behavior to the successful attainment of desired ends is a symptom of intelligence. This involves sensitivity to all the subtle elements in situations. In respect to such sensitivity and such 
power of adaptation, the feeble-minded are far from the norms. This point can best be understood by means of a few concrete illustrations, based on one of Terman's tests of intelligence. The following situation was presented to a number of normal adults and to a number of feeble-minded adults:

"Let us suppose that your baseball had been lost in this round field. You have no idea what part of the field it is in. You don't know what direction it came from, how it got there, or with what force it came. All you know is that the ball is lost somewhere in the field. Now take this pencil and mark out a path to show me how you would hunt for the ball so as to be sure not to miss it. Begin at the gate, and show me what path you would take."

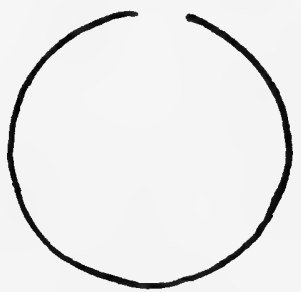

FIg. 9. - Ball-and-Field. Reduced one-half from standard size. (From The Stanford Revision of the Binet-Simon Scale for Measuring Intelligence.)

In Figure 10 we have the responses of normal and of feeble-minded to this situation. One of the most common errors of the latter consists in responding to but one or two elements in the situation. Some respond only to the element "ball "; others only to the element " mark out a path"; others of a higher degree of capacity respond to all the elements, but in a relatively clumsy and inefficient way. Without 
exception these persons, both normal and feebleminded, were content, each with his plan. The re-
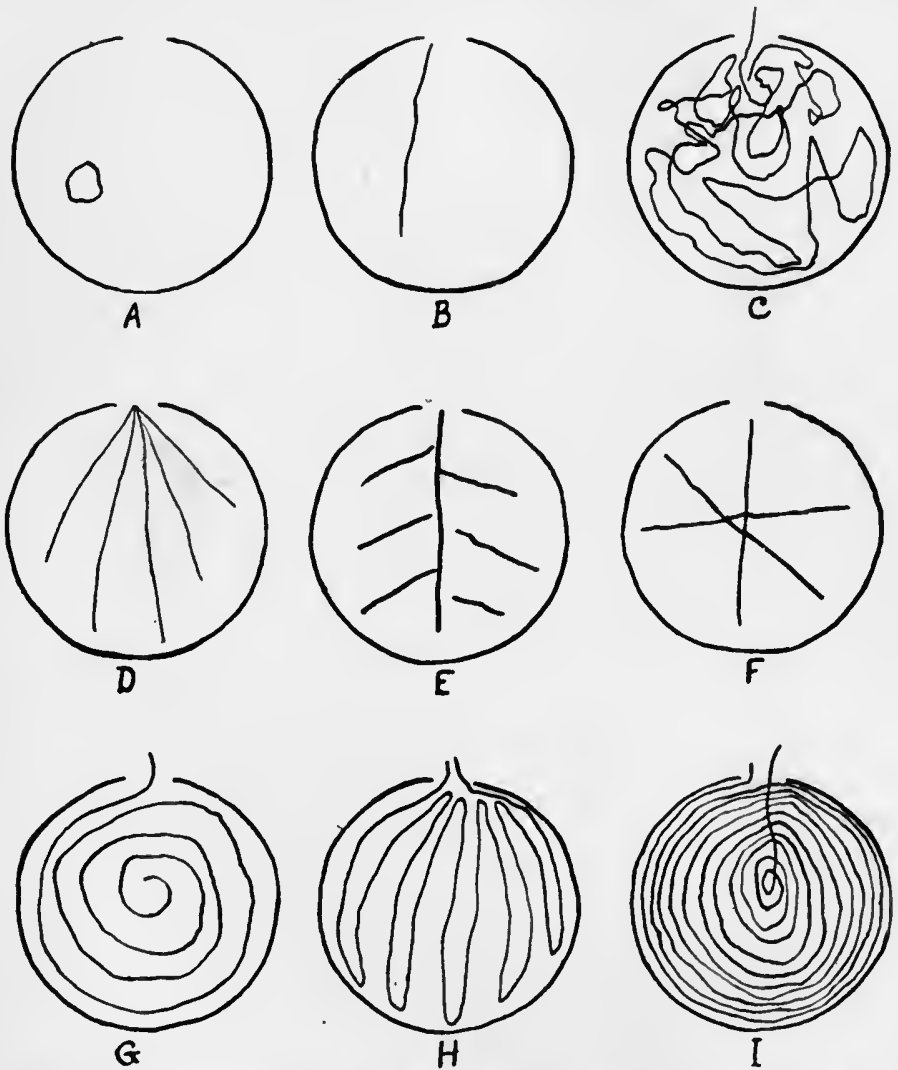

Fig. 10. - Various degrees of adequacy in response to Ball-and-Field Test. A, B, and $\mathrm{C}$ are adult imbeciles; $\mathrm{D}, \mathrm{E}$, and $\mathrm{F}$ are adult morons; G, $\mathbf{H}$, and $\mathbf{I}$ are normal adults.

sponses of the normal persons show sensitivity to all the subtle elements in the situation, and power to 
make a plan of behavior adapted to attain the desired end.

The responses here illustrated are significant indications of the quality of the social adaptations of the individuals concerned. At the time of testing, individual $A$ was under arrest for burglary (he broke into a freight car, because it was cold and he had no place to sleep); B was under arrest for petit larceny; C was under arrest for assault and battery; $D$ was under arrest, charged with impairing the morals of a minor; E had married two husbands, both of whom were living, without the formalities of divorce; $F$ was a drunkard. $\mathrm{G}$ and $\mathrm{H}$ were a teacher and a clerk respectively, neither of whom had ever been arrested. I was a man who for a long time had succeeded in executing a clever fraud.

Norsworthy found that the feeble-minded as a group draw farther and farther away from the norms as measurements are made which are increasingly tests of ability to deal with abstract ideas.

"They are two and a half times as far from the median for children in general in tests like the opposites test or the genusspecies test, as they are in tests like the A test or the perception of weight. To speak of idiots as being deficient in all the mental powers gives a false impression. The feeble-minded child may be weak on all sides of his mental make-up, in the sense that he is not of normal ability in any respect, but this is not telling the whole story. From the point of view of the psychologist and the educator it is fully as important to know that the ament's perceptive powers are almost two and a half times as strong and accurate as his intellectual powers, and almost balf as strong again as his powers of memory, as it is to know that he is weaker than an ordinary child in all these particulars." 
In regard to the ability to perceive it is worth noting that even low-grade defectives, who are not helpless and who can walk, move about without colliding with the furniture. So also do very young children. This is proof that the perception of objects in space, with respect to distance and direction, is developed at a low mental level. The same observations in the matter of perceptual ability which were made by Norsworthy, were later made independently by Binet, in his experiments.

The Instincts and the Emotions. Since it is our purpose to consider the instincts and emotions of the mentally defective at some length in a subsequent chapter, it will not be necessary to dwell upon the subject here, except to remark that in these respects the feeble-minded appear to approach rather closely to the norms. It is not possible to conduct exact experimental investigations touching the instincts and the emotions, as psychology has not as yet developed any technique for such experimentation. Common observation, and the statistics of their crimes and misdemeanors, however, lead us to believe that among the feeble-minded, intellectual deficiency is not very closely correlated with weakness of instinct and emotion.

Is an Individual Defective Uniformly Feeble in All His Abilities? Suppose we turn now from the consideration of defectives as a group, and consider the case of an individual defective child, with a view 
to teaching him. One of the important questions about him is this: Is he equally feeble in all of his abilities? We know from the fact that he has a mental age of let us say seven years, that he will fail in most situations requiring the exercise of an ordinary amount of abilities which develop above this level. So we are able to place him at once within certain limits, when we know his mental age. But is it true that he will be successful in all tasks at a given mental age? Will he fail in none below this age? Will he succeed in none above?

Unevenness of Abilities as Shown by Intelligence Tests. In testing children for the determination of mental age, we find that commonly the performance of a given child, no matter what may be his intellectual quality, touches several levels of the intelligence scale. A child whose level as finally determined is eight years, for example, may fail in some tasks at the seven-year level and at the same time be able to succeed in some tasks at the nine-year and ten-year levels.

On pages $122-123$ we have a photograph of the performance of a mentally defective child as measured on the Stanford Scale. The Roman numerals indicate the age levels to which the various tasks listed are appropriate. The plus signs indicate successful responses; the minus signs indicate unsuccessful responses. It can be seen at a glance that the responses are scattered over more than one level of 
efficiency, though within fairly narrow limits. The child is not equally feeble in all his capacities.

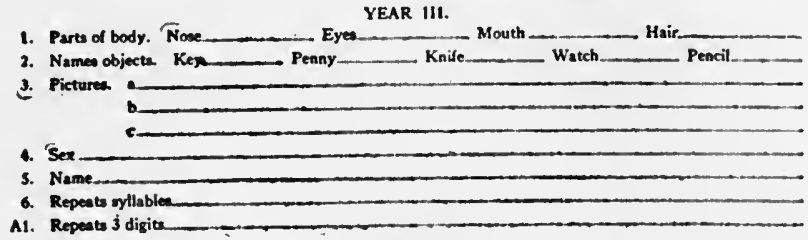

YEAR IV.

I. Compares lines.

2. Forms

3. Counts 4 pennies

4. Copies square

s. Comprebension.

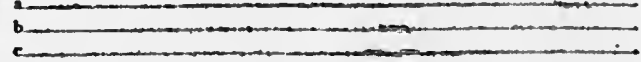

6. Repeats 4 digits

A1. Repeats 12-13 syllables

f1. Comparison of weighta

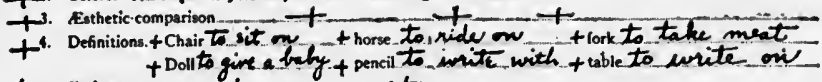

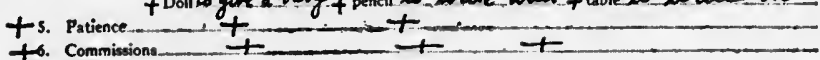

A1. Age

YEAR VI.

11. Right and left.

+3. Counts 13 pennies Jake unbrella or rain coat comprehension.ta tbcel firmen tc Mait till a car comes.

+5. Coins_ nickel _... + penny _ _ _ quarter _ + dime + _

6. Repeats 16-18 syllables

At. Morning or afterncon.

+1. Fingers 5 YEAR VIt.

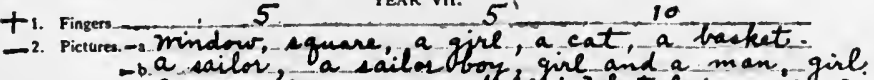
ta man. menc are wetchiti. What he's saying? +3 . Repeats 5 digits 4385

Fro. 11. - Typical record of a defective child's performance on the ties. (The birthday age of the

The same fact may be shown by the kind of diagram which is sometimes called a psychograph. In 
Figure 12, we have a picture of the performance of a feeble-minded girl, Katie $\mathrm{M}$ — The heavy black

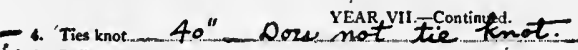

'f5. Differences:

-a. Butterly and fy Butterfly got uringe

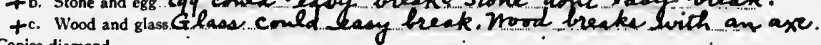

+6. Copies diamond.

A1. Repeats digits backwards.

-1. Ball in field (inferior plan, or better).... no YR

- 2. Counts backwards $20,19,25,55,75,85,100$.

-3. Comprehension ta Buy enstien one, and give it back. -b gothome.

-c.Got to scuse me

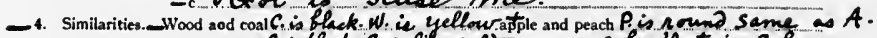

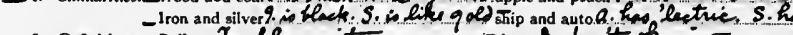

-5. Definitions. - Balloon Jo blour it viger d dort knovi -Football you kick it.

-6. Vocabulary-8 motals (20 required)

A). Dictation 30

Lhade.

' YEAR IX.

1. Date

2. Weights. 'a

t. Make change

6. Repeats 4 digits backwards.

5. Three words.

6. Rhymes, a

b.

A1. Months.

c.

A1. Stamps

1. Yocabulary.

YEAR $X$.

2. Absurdities.

3. Designs

4. Reading. Time

5. Comprehension.

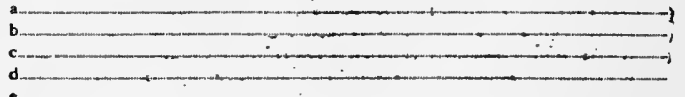

b.

b.

6. Words (free association)

At. Repeats digits.

A1. Repeats syllables.

A1. Form board.

Stanford Scale for Measuring Intelligence, showing unevenness of abilichild is 12 years 2 months).

line represents her mental age. The dotted lines connecting points above and below this heavy line repre- 


\section{PSYCHOLOGY OF SUBNORMAL CHILDREN}

sent her performance in single tests of mental and motor ability, as named at the foot of the graph.

CASE D.

Name: K_, M_. Examined by Dr. H_. Date of Blrth: Aug. 3, 1894

Clinical Date: Aug. 5, 1916 Education: Leth school from 4th

Type: Ments Delective

Class In Ireland

Nationality: Irish (in U.S.A. 4yrs.)

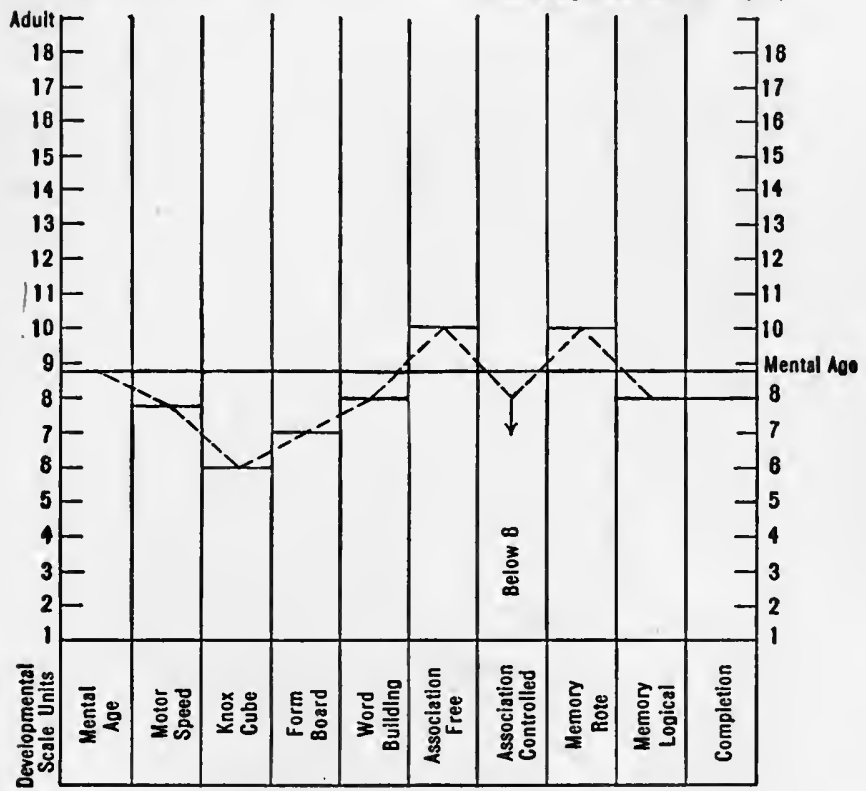

Fia. 12. - Psychograph of a feeble-minded adult, showing that she is not equally feeble in all abilities.

Katie $\mathrm{M} \longrightarrow$, whose chronological age is twentytwo years, is not normal in any ability tested; but she is measurably more capable in some respects than in others.

The Experiments of Ordahl and Ordahl. This 
matter of qualitative differences between children having the same general intelligence levels was also studied at the State School for the Feeble-Minded, at Faribault, Minnesota. Three groups of defectives were studied, - one group of individuals testing at six years; one group at eight years; and one group at ten years. All of these individuals were given special mental tests. When their performance was scored it was found that in any given test individuals showed a considerable amount of variation from what might have been expected on the basis of the general intelligence levels (mental ages). "For example, if the averages of the thirty individuals are arranged in order of rank with respect to the others in the experiment, one of the six-year-olds ranks up between the tenth and twentieth, two of the eight-year-olds twenty-second and twenty-third, and two of the tenyear-olds down among the lowest ten subjects."

This unevenness of ability in any given child is, of course, the basis for the use of a great variety of tests in the determination of general intelligence. The complexity of a human mind is such that it can never be assayed by the application of a single test.

Variability in School Attainment of Children with Identical Mental Ages. On this particular point investigators have as yet furnished us with very little information. The Department of Ungraded Classes in New York City has published a report on eighteen mentally defective children, all having a Binet score 
(mental age) of eight years. These children, all of equal mental age, were measured in ability to read and to do arithmetic. The results of these educational measurements are given in the following table, compiled under direction of Miss Elizabeth Farrell.

Table Showing Variability of Children of Equal Mental Age, in Reading and Arithmetic.

(From Farrell.)

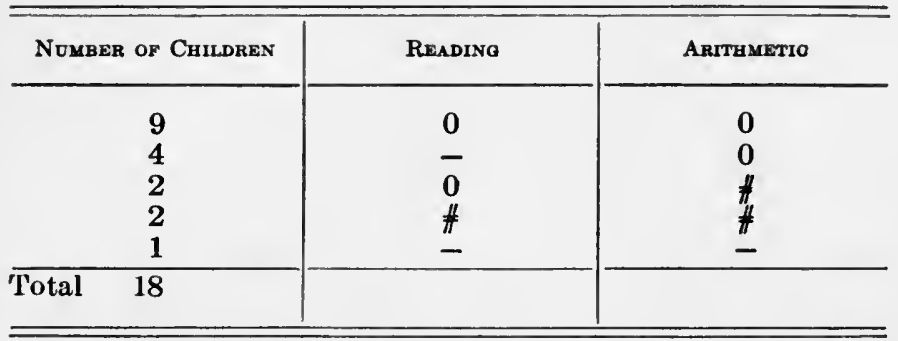

Note - 0 means no deviation from the age-grade limit for 8 years. \# means above the age-grade limit for 8 years. means below the age-grade limit for 8 years.

We see here that although mental age is the most important single factor conditioning achievement in reading and arithmetic, there are, nevertheless, children whose performance is above or below their general ability in one of these school subjects, who do either surprisingly well or surprisingly poorly in reading or arithmetic.

In the prevocational classes of Detroit, in which the pupils are decidedly subnormal in general intelligence, measurements of achievement in arithmetic; reading, and language have been made, and have 
been related to mental age. The result is apparent in the table which follows:

Showing the Pupils of Mental Ages Vili, IX, and $X$ as They Stand in Arithmetic, Reading, and Language.

Prevocational Classes, Detroit.

(From Renshaw)

The table presents the percentages of pupils who in the tests actually attained age and grade scores equivalent to expectations from their mental ages.

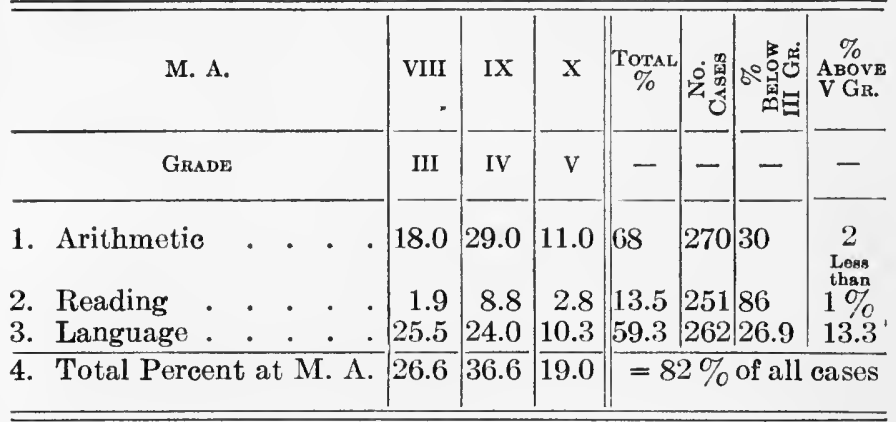

Many similar studies should be made, covering all mental ages, and all school subjects, and giving the amounts of deviation from expected score, with the frequency of each amount. It is possible that special abilities among defective children may be deserving of more attention than has hitherto been accorded in education.

Idiots-Savants. The unevenness of abilities which characterizes all persons in some degree, is strikingly exemplified in the idiots-savants (wise idiots). Very rarely a feeble-minded child or adult 
is found who shows some particular ability to a remarkable extent. Tredgold tells of an idiot-savant who could " remember the day when every person had been buried in the parish for thirty-five years, and could repeat with unvarying accuracy the name and age of the deceased, and the mourners at the funeral. But he was a complete ament. Outside of the line of burials he had not one idea, could not give an intelligible reply to a single question, nor be trusted even to feed himself."

The special talents of idiots-savants have usually consisted in ability to draw, to perform feats of arithmetical calculation, to memorize by rote, or to play musical instruments. Four idiots-savants have come within the experience of the present writer. The first was a man, an inmate of an institution for the feeble-minded. As this was before the technique of intelligence examination had been developed, his mental level was not known, but he was very definitely an institutional case, with stigmata of degeneration, and a childish manner. His special ability lay in the fact that he could very quickly tell the day of the week for any given day of the month and year, and took a great delight in this performance. The second was a boy, also an inmate of an institution for the feeble-minded, whose mental level was six years, his chronological age being seventeen years. This boy's special gift was musical. He could play very difficult compositions on the piano, and could repro- 
duce "by ear" complicated music which he heard played. In other respects he was no more competent than a six-year-old child. The third was a boy of eighteen years, whose mental level was eight years. When seen by the present writer he was an inmate of the Psychopathic Ward of Bellevue Hospital in New York City, having been arrested for vagrancy, and committed there for observation as to his mental condition. His special gift was the ability to draw pictures of mechanical objects, especially of locomotives. He occupied himself for hours during his detention in this fashion, offering to "do one" for first this then that attendant on the ward, and finally deciding to keep the product himself, in every instance. The fourth was a woman, about twenty-five years of age, an inmate of an institution for the feeble-minded. She was regarded as imbecile in all respects save one: she could plan and execute elaborate designs in crochet.

It should be emphasized that these cases of phenomenal special ability, occurring in the mentally defective, are exceedingly rare. Practically no scientific study has been made of such persons, and remarks touching upon them are limited to mere description of their idiosyncrasies.

Implications for Education. The psychological facts which have been set forth in this chapter are clearly of much value for the education of subnormal children. The implications may be briefly summa- 
rized thus: (1) The feeble-minded as a group, both as children and as adults, are inferior to the norms in all respects. (2) They are, however, not equally far from the norms in all respects. (3) They are nearest to the norms in physical size and strength, in sensory acuity, and in motor control. (4) They are farthest removed from the norms in intellectual capacity, especially in all those subtler capacities which are involved in abstract thinking, and which in normal persons develop after the age of childhood. (5) The feeble-minded as a group will therefore profit most by instruction which will lead to skill in eye-hand coördinations, and in tasks where physical and sensory capacities are useful. They will profit least from instruction which involves abstract thinking, and the comprehension of symbols. As adults they will be able, if properly taught, to perform many useful, routine industrial tasks, under supervision. These facts have great significance for those whose duty it is to establish the curriculum for special classes. (6) In any individual defective there will be found more or less unevenness of abilities. Very few feeble-minded children are equally deficient in all respects. On the other hand, very few show extreme unevenness of abilities, such as the idiotssavants show. It is possible that after much further study has been made on this point, it will appear that education can utilize special abilities among the subnormal more fully than has been feasible hitherto. 


\section{REFERENCES}

1. Bronner, A. F., The Psychology of Special Abilities and Disabilities. Bobbs-Merrill Co. Boston. 1917.

2. Farrell, E. E., Variability in School Attainment in Reading and Arithmetic of Children Who Have Identical Binet Score of Eight. Nineteenth Annual Report of the Superintendent of Schools. New York. 1916-1917.

3. Galton, F., Notes on Prehension in Idiots. Mind. 1887.

4. Johnson, G. E., Contribution to the Psychology and Pedagogy of Feeble-Minded Children. Pedagogical Seminary. 1895.

5. Lobsein, M., Einige Untersuchungen über das Gedächtniss bei Schwachbefähigten. Zeitschrift für Kinderforschung. 1903.

6. Mead, C. D., The Relation of General Intelligence to Certain Mental and Physical Traits. Teachers College Contributions to Education. No. 76. 1916.

7. Merrill, M. A., The Abilities of the Special Class Children in the Three R's. Pedagogical Seminary. March, 1918.

8. Norsworthy, N., The Psychology of Mentally Deficient Children. Archives of Psychology. Columbia University. 1906.

9. Ordahl, L. E., and Ordahl, G., Qualitative Differences bctween Levels of Intelligence in Feeble-Minded Children, Journal of Psycho-Asthenics. June, 1915.

10. Otis, M., A Study of Association in Defectives. Journal of Educational Psychology. 1915.

11. Petersen, A. M., and Doll, E. A., Sensory Discrimination in Normal and Feeble-Minded Children. Training School Bulletin. Nov. and Dec., 1914.

12. Renshaw, S., The Measurement of Abilities of Pupils in the Prevocational Classes. Special Classes of the Public Schools of Detroit. 1918.

13. Wreschner, A., Eine Experimentelle Studie über die Association in Einem Falle von Idiotie. Allgemeine Zeitschrift für Psychiatrie. Bd. LVII.

14. Wylie, R. T., Taste and Reaction Time of Feeble-Minded. Journal of Psycho-Asthenics. Vol. IV, 3.

15. Wylie, R. T., A Study of the Senses of the Feeble-Minded. Journal of Psycho-Asthenics. Vol. IV, 4.

16. Wylie. R. T., Motor Ability and Control of Feeble-Minded. Journal of Psycho-Asthenics. Vol. V, 2. 


\section{CHAPTER VIII}

PHYSICAL TRAITS OF THE FEEBLE-MINDED

The Correlation between Physical Traits and Mental Traits. The history of human thought shows many efforts to arrive at a knowledge of mental traits by a study of the physique and physiognomy. This was, perhaps, the most natural primitive approach to the very important problems involved in "reading character." Few matters are of greater moment for any person than the correct interpretation of the mental life of those about him. This is, however, mysterious and hidden; it is not presented to the senses directly; it can be inferred only from indirect manifestations. In seeking to know it, it was very natural that men should first examine attentively that which they can see, and which is intimately connected with the mind, namely the body. This method of approach was finally systematized in the pseudo-science of phrenology. According to phrenology, the intelligence of an individual, like other mental traits, is to be ascertained by measuring and scrutinizing his body.

The criminology of Lombroso is based on similar premises. Lombroso was an Italian, who undertook 
the study of criminals by the methods of anthropometry. He undertook to establish that "the criminal type "is to be recognized by deviations from the normal in proportions of physique and physiognomy, and by the presence of anatomical peculiarities, called stigmata of degeneration.

Subsequent research has shown that the relation between anatomical and mental is not very close, and that in any given case the greatest possible errors may be made in an attempt to infer the one from the other. Nevertheless, when large groups are measured and treated statistically, certain general tendencies are seen to hold, on the average, though not with very much reliability for single cases. It will be necessary to examine the facts somewhat at length, with respect to the physical characteristics of the mentally subnormal.

Height and Weight. It has already been stated in a previous chapter that in physical development the feeble-minded as a group approach much nearer to the norms than in mental development. When curves of physical growth are platted from the measurements of hundreds of feeble-minded children, and are then compared with the curves of growth for children chosen at random, it is always found that the former average shorter and lighter than the latter, age for age. It is seen furthermore, that the differences increase with the increase in degree of mental defect. Morons are slightly below the average 
for normals, imbeciles are below morons, and idiots are lowest of all.

These facts are presented graphically in the charts, Figure 13, which are taken from the published research of Dr. Goddard. The upper curves represent height in inches, and the lower curves represent weight in pounds. The normal curves are constructed from data collected by Dr. Boas, Dr. Burk, and Dr. Donaldson. The curves for the feebleminded are based on measurements of the inmates of institutions scattered over the United States, and include 5923 individuals. The ages range from birth to sixty years.

The total distributions from which the averages are made, are not given by Dr. Goddard, so that it is not possible to state the exact amount of over-lapping between normal and feeble-minded, and between different degrees of feeble-mindedness. With averages which approach each other as closely as these do, however, we are safe in assuming that the amount of over-lapping is very great; that many of the feeble-minded, even those of low grade, will be as tall and as heavy as the tallest and heaviest normals, age for age.

The facts shown in the curves reproduced from Dr. Goddard's study have been verified by other investigators. It has also been found that in sitting height, as in standing height, the feeble-minded of all grades are below normal, on the average, though with a great amount of over-lapping. 


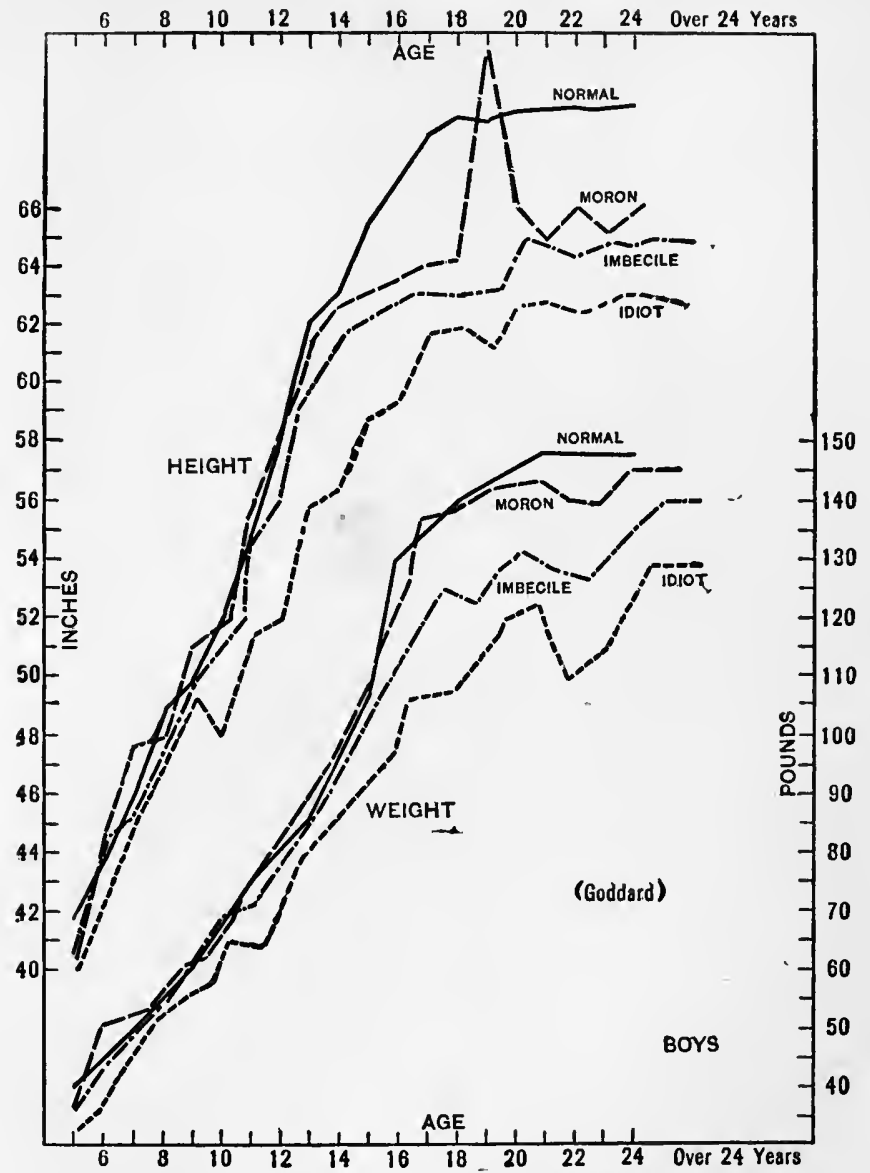

Fig. 13. - Curves showing the height and weight of feeble-minded inmates of American institutions, as compared with normals, age for age. (From Goddard. Reproduced by courtesy of The Journal of Nervous and Mental Disease.)

Cranial Measurements. Although the subject is interesting and important, cranial development as 
related to general intelligence has not been very extensively studied, by scientific methods. Such results as we have, indicate that in cranial measurements the amount of over-lapping between normal and feeble-minded is the most conspicuous feature of comparison. This holds true of whatever measurement we consider, whether it be circumference, capacity, diameters, or cephalic index. No diagnosis of mental deficiency can be made by measurement or inspection of the head. It is true that in certain cases of mental deficiency, there is marked deviation from the normal in one or more of the cranial measurements; but it is equally true that a great proportion of the feeble-minded fall well within the normal limits.

Even among children so low in general intelligence as to be considered fit subjects for detention in an institution, the Research Laboratory at Vineland has found that about 30 percent fall within the normal limits in all cranial measurements. About 70 percent of the institutional cases lie outside the normal limits in one or more of the measurements taken, which were, in this instance, capacity, diameters, and cephalic indices. These deviating cases doubtless include children suffering from such pathological conditions as hydrocephalus, though on this point the investigators have not furnished exact information.

Extensive and exact measurements of the cranium and of general intelligence, will most probably yield 
a result similar to that yielded in the case of height and weight. There will doubtless be found a difference in the medians and in the distribution of large groups of defectives, as compared with large groups of normals, although with a great amount of overlapping between the two.

Vital Capacity. Vital capacity is the measure of the amount of air that can be held by the lungs in a single inhalation. Measurement is made by means of an instrument called a spirometer. It has been found that the feeble-minded have a lower average, age for age, than normals in vital capacity. Indeed, the correlation between vital capacity and mental age as reported by Mr. Doll is very high ( $r=.64)$. This very high correlation raises the question as to whether the lack of intelligence itself is not to some extent involved here, as ability to comprehend and follow directions constitutes a part of the spirometer test. It may be that actual vital capacity of the feeble-minded may not be so closely in correspondence with mental age as is indicated by the figures obtained. Height, weight, and cranial measurements may be determined independently of the ability of those measured to understand and follow directions, so that no such complicating factor enters in the case of those traits.

Motor Ability. Under the subject of physical traits, motor ability is often considered. Motor control has already been considered in our discussion in 
Chapter VII. It would be superfluous to repcat in detail what has been said. In all tests of motor strength and control the feeble-minded are inferior to the normal, on the average, though with a considerable amount of over-lapping. In grip, in coördination, and in speed of voluntary movement the feeble-minded are inferior. The two hands are more nearly alike in the feeble-minded than in the normal, and there is a greater tendency to left-handedness in the former.

Gait is often awkward and shambling in the mentally subnormal. In the lower grades of defect this is quite noticeable. There is difficulty in learning to hop, skip, and jump, and to go up and down stairs. Quite often the feeble-minded have to be specifically trained to do these things, which normal children learn to do spontaneously.

Variability. A by-product of the various investigations in the anthropometry of the mentally deficient has been the discovery of the fact that they are more variable in physical traits than are normals, age for age. A thousand mentally defective ten-yearolds, for example, will scatter over a wider range of height or of weight, or of grip or of vital capacity, than will a thousand ten-year-olds who are mentally normal. This greater variability may be due to the fact that secondary cases, whose condition is due to a pathological cause, have been included in the measurements. The inclusion of a score of cretins among 
ten thousand defectives will spread the range downward in the direction of shortness, because one of the outstanding features of the disorder is stunted physical growth. If all secondary cases were excluded, the greater variability of the mentally deficient, age for age, might disappear in anthropometric tests.

Stigmata of Degeneration. By a stigma of degeneration is meant a physical anomaly, a congenitally deformed or misshapen part of the anatomy. Very elaborate tables of the stigmata of degeneration have been compiled since the time of Lombroso. The enthusiasm over this phase of the study of degeneracy has waned very decidedly in recent years, for it has been demonstrated that healthy normal children in public elementary schools, as well as ordinary, competent members of society in general, often show the presence of "stigmata." In fact if we were to class as "undesirables" all persons who fall within the categories prescribed by some writers on this subject, few would escape. The presence of a single stigma cannot be regarded as significant. But Lombroso's observations were not wholly invalid. When several pronounced stigmata occur in one individual, usually a condition of mental subnormality accompanies. In other words, it has been found that stigmata, though not by any means confined to neuropaths and mental defectives, are far more common among them than in the population at large. It is true also that in number and severity they are 
proportionate to the degree of defect. Morons usually have few or no stigmata; imbeciles often have several; while idiots usually bear exterior anomalies, which accompany their mental status.

Nearly any portion of the anatomy may be involved so as to become a stigma. Any feature which is too large or too small; too thick or too thin; too long or too short; misplaced; or otherwise deviating markedly from the usual may be so classified. It will suffice to call attention to certain of the more common and gross stigmata.

Abnormal developments of the skeleton are often seen among the lowest grades of the feeble-minded. The cranium, palate, and jaws are the parts most conspicuously affected. The head may be much too small, or much too large; it may be asymmetrical (one side larger than the other); it may be symmetrical, but of peculiar formation. Extreme smallness of the skull, with sloping forehead and receding chin, gives rise to one so-called clinical variety of mental defect, namely microcephaly (small-headedness).

In the case of the hard palate, it may be saddleshaped, in which malformation it extends upward to a considerable distance, where the nasal cavity is. In consequence it appears like the inside of a saddle, and so derives its name. Or the palate may be Vshaped, that is, narrowed to $\mathrm{a}$ as it comes forward. In this case we see overcrowding and protrusion of the front teeth. The most thorough investigations of 
the palate, made by means of instruments of precision, indicate that malformation is about as common among the mentally normal as among the mentally deficient. Cleft palate and hare-lip do not seem to be any more frequent among the deficient than among the normal, and by some authorities are not included as stigmata of degeneration.

The lower jaws may be either receding or protruding. Both of these deviations have been called stigmata. As for the teeth, a really good set of teeth is comparatively rare in mental defectives. They appear later than they should, according to the course of normal development, and are likely to be irregular in arrangement. Curiously enough, in a large percentage of cases the "wisdom teeth" do not appear at all. Occasionally one sees a set of double incisors.

Various deformities of fingers and toes occur by way of supernumerary digits, or absence of one or more digits. It may happen that two fingers are webbed together, two sets of bones being palpable within one covering of muscle and skin. Cases may be seen in which the hand consists of a thumb, and a shapeless mass resulting from the failure of the four fingers to differentiate. This stigma is called "lobster hand."

The special sense organs appear in a great variety of malformations, which it is impossible to enumerate. In the case of the ear, defects of the lobule 
are most frequent. The outer ear may be large, fieshy, and heavy, or it may be much diminished, or even entirely absent. The writer recalls an interesting case of ear deformity in an imbecile woman. There was no outer ear whatever, - nothing but a hole in each side of the head, with a wrinkle of skin around it. She had just given birth to a child, who displayed exactly the same feature.

Among anomalies of the eye, strabismus (more commonly called cross-eyes) is one of the commonest, and, of course, occurs quite frequently in persons of normal or superior intelligence. But it occurs often also among the feeble-minded. Strabismus may be either internal or external. In internal strabismus, one or both eyes are turned inward toward the nose; in external strabismus, one or both eyes turn outward away from the nose. In either case vision is impaired. Many anomalies of the eyes besides strabismus occur. The eyes may be each of a different color; one eye may be set high in the face, and the other low; but one eye may be present. In the clinical type called mongolians the eyes are set in small, obliquely slanting openings.

The nose is subject to wide variation and deviation from type. It may be a mere button, or it may be large and broad. Quite often it is crooked, owing to deviation of the septum. Of other prominent features of the physiognomy, the mouth may be crooked, or loose and flabby, and in idiots there is likely to be drooling of saliva. 
The generative system may remain infantile, or the organs of reproduction may be malformed. In idiots and imbeciles the advent of puberty is often delayed.

It is necessary to emphasize again the fact that all the stigmata mentioned here, and indeed all stigmata, may occur in human beings independently of mental status. A diagnosis of mental deficiency cannot be made on the basis of stigmata. It is not difficult to find imbeciles and morons who are very handsome, with excellent physiques. A case in point is that of a boy known to the present writer, who was the ward of a charitable organization. This child had been selected by four different families, each having the intention of adopting him; and in each case he had finally been returned, with the complaint that he "could not learn anything." The organization never had any trouble in placing the child anew, because he was very attractive in appearance, with large blue eyes, curly hair, and well-molded features. When he was returned for the fourth time, it was decided to ask for a mental examination. The examination showed that this child was between six and seven years in mental development, whereas his actual age was ten years. It is almost impossible to convince the ordinary observer of the facts in the case, because he is so pleasing in appearance. He has a defective sister, who is almost as handsome as he is.

This case illustrates in a practical way the 
vagueness of the relationship between mental and physical traits. Physically the mentally defective approach very near the norms. It is only when scores of cases are measured and compared that we find a small difference in the averages of two groups, one defective and the other normal mentally; and the amount of over-lapping is very great, even with children so low in mental status as to belong in institutions for the feeble-minded.

Mongolians. A few mentally defective children present a peculiar and marked combination of physical characteristics, which has won for them the designation mongolians. Their eyes are set in obliquely slanting slits, the skull is rounded and flat behind, and the tongue is large and fissured, with hypertrophied papillæ. In addition to these chief characteristics, the hair is generally dry, scant, and wiry; the cheeks are flushed; the fingers and toes are short; the little finger often curves in a peculiar fashion; and the joints of all the limbs are very lax. This last characteristic gives rise to hypermotility of the joints, so that it is possible to bend them to an extraordinary degree. The writer has in mind a mongolian imbecile, one of whose favorite tricks is to bend her lower limbs back behind her arms, in such a position that her feet touch the nape of her neck.

The mucous membranes of mongolians seem especially irritable, and they suffer with chronic catarrh, colds, bronchitis, and often contract tuberculosis. 
As a rule they do not live to adult years, the average age of death being about fourteen years.

In the early months of life mongolians are sometimes mistaken for cretins, but as development progresses the differential diagnosis becames easy. The characteristic combination of features, occurring repeatedly, has led to the expectation that research may some time reveal some specific pathology underlying the condition, just as has been found in the case of cretinism. It is not unreasonable to suppose that this, too, may be an endocrine disorder. However, no cause of mongolianism has ever been established, and no endocrine substance has been discovered to ameliorate the mental and physical state.

Microcephalics. Mental defectives who have exceptionally small heads have been designated microcephalics. They present no special features other than extreme smallness of the cranium, with recession of chin and forehead, and suggest no possible endocrine disorder, as the mongolians do.

By the term microcephalic is usually signified a person whose skull is not more than seventeen inches in its greatest circumference. The contour of face and head is that made familiar by the "Sunny Jim " advertisements, which were formerly displayed so freely. The microcephalics represent the extremely low end of the curve of distribution for cranial circumference.

Physical Education. Since the feeble-minded 
approach much nearer the norms in physical traits than in any other respect, it would be expected that they will respond to physical education relatively well. That such is indeed the case is repeatedly shown when special class children are seen in the drills of gymnasium or swimming tank. A spectator who sees them at this can scarcely believe that he is witnessing the performance of children who cannot learn to read or write acceptably, or to comprehend the fundamentals of arithmetic.

The principles of physical education are the same for the feeble-minded as for any other children. If defects are present which corrective gymnastics can improve, they should be applied. Physical exercise will do for the mentally subnormal just what it will do for children in general, that is, it will keep the body in condition, and conduce to muscular development.

Physical education will not raise the intelligence level, as the enthusiastic but uninformed have sometimes thought. From time to time one hears of a new system of "physiological training," or of "medico-pedagogical treatment," which purports to affect the growth of intelligence. No such system has ever been shown to have any effect upon the intelligence level.

Birth Rate and Mortality. At what rate are mentally defective children being born? This question assumes particular significance when asked in 
this way: At what rate are mentally defective children being born, as compared with children in general?

All reliable figures on the birth rate indicate that for many decades past the birth rate has been in inverse relation to intelligence; that the lower the intelligence, the higher the birth rate, and the higher the intelligence, the lower the birth rate. Parents who are of that degree of intelligence which is capable of passing through college and university have very few children, while the feeble-minded bear an unlimited progeny. Dr. Goddard believes on the basis of facts collected that the birth rate among defective parents is two to six times as great as the birth rate for the population as a whole. This differential birth rate is due to the fact that where there is lack of intelligence there is also lack of prudence. The unintelligent are at the mercy of instinct, which takes no thought for the future, and perceives no consequence. Late marriage from economic motives plays no part in reducing the birth rate among them, for they marry at will, regardless of circumstances, or procreate illegitimately. They are never restrained by the reflection that there is not enough to feed those already in existence. Their standard of living is exceedingly primitive. All of the prudential checks to procreation which operate through the intelligence are lacking in the feeble-minded, and in consequence an undue proportion of subnormal children are born. 
If left to the mercy of the natural laws of selection and survival, the death rate would also be very much higher among the subnormal than among the population at large. Many would starve, many would freeze, many would meet with fatal accidents, many would die of disease through not recognizing the laws of hygiene. But we do not allow the natural laws of selection and survival to operate in civilized society. We provide means of caring for the helpless. Thus the high birth rate among them is not offset by a high death rate. Society does not interfere effectively with the former, but it does interfere with the latter.

Nevertheless, though social agencies in the form of public and private charities, do all they can to carry the social burden humanely, and to prevent the high death rate which is a natural consequence of mental deficiency, mortality among the feebleminded is somewhat higher than among the population in general. The data upon which this statement is based come from institutions for the feebleminded. The two commonest causes of death are tuberculosis, and pneumonia. From this it might be inferred that the vitality of the feeble-minded is lower than that of children chosen at random, on the average.

\section{References}

1. Case, I., The Correlation between Mental Defect and Anomalies of the Hard Palate. American Journal of Insanity. April, 1919. 
2. Channing, W., and Wisler, C., Comparative Measurements of the Hard Palate in Normal and Feeble-Minded Individuals. A Preliminary Report. American Journal of Insanity. Vol. 61, pp. $687-697$.

3. Doll, E. A., Anthropometry as an Aid to Mental Diagnosis. The Training School. Vineland, N. J. 1916.

4. Goddard, H. H., The Height and Weight of Feeble-Minded Children in American Institutions. The Journal of Mental and Nervous Disease. April, 1912.

5. Goddard, H. H., The Menace of Mental Deficiency from the Standpoint of Heredity. Boston Medical and Surgical Journal. Aug. 24, 1916.

6. Mead, C. D., Height and Weight of Children in Relation to General Intelligence. Pedagogical Seminary. 1914.

7. Norsworthy, N., The Psychology of Mentally Deficient Children. Archives of Psychology. 1906.

8. Porteus, S. D., Cephalometry of Feeble-Minded. The Training School Bulletin. June, 1919.

9. Shaw, T. C., Measurement of the Palate in Idiots and Imbeciles. Journal of Mental Science. July, 1876.

10. Shuttleworth, G. E., The Health and Development of Idiots Compared with Mentally Sound Children of the Same Age. Proceedings of the Association of Medical Officers of the American Institute for Idiotic and Feeble-Minded Persons. 1876-1886. 


\section{CHAPTER IX}

\section{THE INSTINCTS AND EMOTIONS OF THE}

FEEBLE-MINDED

General Consideration of Instinct and Emotion. At the very inception of life every organism is innately gifted with tendencies to respond to the situations which life offers, apart from all training. Of these tendencies, those which are fairly complicated in character, and which have not been learned as a result of experience, are called instincts.

Some of the clearest examples of instinct that can be adduced in illustration are found among insects. The locust goes through the fairly elaborate behavior of flying, eating, "singing," and depositing its larvæ in such a way that offspring will come forth in due season; yet all this is done without any learning whatever. There is no elderly locust to teach the new generation what to do in the situations offered by life. No ideas of remote ends to be attained guide the locust. These activities are instinctive, innate in the organism, as a result of centuries of natural selection.

It is no part of the purpose of this volume to undertake an exhaustive discussion of human 
instincts. Such discussions are to be sought in standard texts on social and educational psychology. We shall note briefly here only a few of the human instincts, which are most significant for the understanding of the behavior of the mentally defective, as related to the social ideals of our day. Among these are (1) the tendency to acquire and possess objects of attractive size and appearance, (2) the tendency to resist the abstraction of objects once acquired, (3) the tendency to seek, seize, and ingest food, (4) the tendency to notice, approach, and mate with members of the opposite sex, (5) the tendency to be angry when thwarted in the pursuit of a desired end, (6) the tendency to seek the company of fellow beings rather than isolation, (7) the tendency to feel pleased at the approval of others, and to feel miserable at their scorn or disapproval, (8) the tendency to be satisfied when others are happy, and to be dissatisfied when others are wretched or in pain, (9) the tendency to flee from large, strange objects which approach, (10) the tendency to manipulate the environment, (11) the tendency to behave submissively in the presence of those who are obviously superior in power, and to behave aggressively in the presence of inferiors, (12) the tendency to try to "get ahead" of others, who are engaged in the same activities.

These are a few of the responses which human beings make by original nature, without training. Rarely 
is it necessary to teach any child to make such responses. The great problem of moral education, on the contrary, is to teach children to inhibit and control these strong innate tendencies, to an extent which will make social relations possible.

It is of the essence of an instinct that it is aimless, blind, in the sense that it is not guided by conscious purpose or thought of consequence. Purpose and consequence can be apprehended only by the intelligence. $^{1}$ They must be apprehended as ideas, and instinct functions without the direction of ideas, by original nature.

Since instincts are blind to purpose and consequence, how is it possible to secure that control and inhibition of them, that we call moral conduct? The answer is that moral conduct is secured through the agency of the intelligence, through the agency of man's capacity to learn and to make adaptations on the basis of experience. Codes of morals and ethics rest primarily on the intellectual recognition that, on the whole and in the long run, life is more satisfying if tendencies to act are controlled and inhibited in certain ways. This recognition is passed on from one generation to another under the name of moral education, and the younger generation receives the instruction partly through its ability to comprehend ideas of purpose and consequence, partly through its

1 Intelligence, also, may be listed as an instinct, in the sense that it is inborn. 
own personal experience of punishment when certain responses are made, and of reward when certain others are substituted. Thus moral conduct is directly dependent upon ability to comprehend ideas, and capacity to profit by experience.

It is now clear why the young child or the feebleminded person cannot be depended upon to act in accordance with the code of morals and ethics. Children and the feeble-minded need supervision in their social relations, because intelligence is inadequate for the complicated task of controlling and inhibiting the instincts, in situations which arouse them. To act on an immediate impulse is always easy; to postpone a present satisfaction for the sake of remote consequence, which exists only as an idea, is always difficult. Small wonder, then, that a being who is incapable of formulating ideas of consequence should act in whatever way will bring immediate satisfaction.

A word concerning emotion will be timely at this point. Every instinctive act, and the thwarting of every instinctive act, carries with it an affective experience of some degree. To follow out instinctive promptings without hindrance is satisfying; to be thwarted, or to be compelled to act against instinctive promptings is unsatisfying. These satisfactions and dissatisfactions are expressed in the form of the emotions. Popularly certain well recognized words such as anger, shame, disgust, joy, terror, have been used 
to designate emotional behavior. No analysis of these terms can be undertaken here, but it may be stated that man is usually aware of his emotional reactions, so that emotion has been called "the conscious side of instinct," since the two are inseparably associated.

The Instinctive and Emotional Life of the FeebleMinded. No prolonged and systematic study has been made of the instinctive and emotional life of the feeble-minded. The intelligence of the defective has claimed most of the interest of investigators. This fact is to be explained, no doubt, by the greater difficulty of devising an experimental technique for the study of instinct and emotion. We are indebted to Binet for a few direct observations upon the character of imbeciles and morons, but these have not been amplified by psychologists, as his observations upon the intelligence have been.

As long ago as 1736 Felix Platter, in his Praxeos Medicæ, writing upon "Mental Imbecility, Mental Consternation, and Mental Alienation," noted that "Friendly emotions and affects may be encountered with intellectual backwardness." Indeed, there seems no possible doubt that in respect to instincts and emotions the feeble-minded approach much nearer the norms than they do in intellectual traits. It is to be observed, also, that children are much more like adults in instinct than they are in intellect. Anyone who has worked much with and among 
mentally deficient children knows that they differ greatly in character, just as all children do. There are all degrees of docility, of aggressiveness, of instability, of stolidity, and so on, through all the traits of temperament. Perhaps the simplest way to approach the instinctive and emotional life of the feeble-minded for our present purpose will be through an analysis of their crimes and misdemeanors. The commission of a crime or misdemeanor constitutes objective evidence of the existence of an instinct, since violations of the moral code (which eventually becomes the legal code) by instinctive acts, are called crimes and misdemeanors.

Analysis of the Crimes and Misdemeanors of the Feeble-Minded. In 1913 a number of children who had been referred from the Children's Court in New York City for mental examination were studied, and the charges made against the mentally defective were in order of frequency as follows: theft and accomplice in burglary, truancy, sexual misbehavior, incorrigibility, disorderly conduct, fighting and assault, truancy and theft (double charge), associating with vile and vicious persons, murder and attempted murder, vagrancy, intoxication, arson, begging, peddling without a license, destroying property, intolerable nuisance, and violating child labor laws.

Theft is the commonest offence committed. The tendency to acquire and possess objects of suitable size and attractiveness is involved here, as is also 
the tendency to seek, seize, and ingest food. These mentally deficient children stole such objects as money, old brass, tin foil, copper wire, apples, ladies' dresses, a rabbit, a baby-cart, peanuts, bicycles, newspapers, a cake of ice, and a horse and buggy. The instinct to acquire and possess is very well developed in these children. The same is true of the instincts connected with food. In the adult feeble-minded, food-getting is one of the chief incentives to petit larceny, which is one of the commonest charges made against them in the courts.

The following conversation ensued with an adolescent boy of sixteen years, with an IQ of 51, who had been arraigned in the courts for burglary. His mother was a janitress in an apartment house, and he worked about the place, helping her. In the course of the day's work, he had entered the apartment of a tenant, which was conveniently accessible, and had stolen a small sum of money.

Q. Why are you here?

A. I done wrong.

Q. What did you do that was wrong?

A. Stole three dollars.

Q. From whom did you take it?

A. A lady in the apartment.

Q. Why did you take the money?

A. I seen it lyin' there.

Q. What did you do with the money?

A. Bought fruit and crackers. That's all. 
Q. Why is it wrong to steal?

A. Because a cop will get you. Because you get in bad.

Q. Why do you get in bad?

A. (No response. Shakes head.) Don't know.

Q. What place is this?

A. A room, with windows.

Q. Why should you be sent to this place?

A. I don't know.

The next most common offence is truancy. To the question, "What do you do when you go on the hook?" Miss Irwin elicited interesting answers from subnormal children. " Oh, I go all round," was often the response. Others went "to the Park to see the animals." Still others joined gangs, and went to fly pigeons from the roofs of the tenements. In other communities these pursuits would be replaced by fishing, playing marbles, shooting craps, and the like. The instincts which underlie truancy are doubtless many. General manipulation of the environment, the tendency to seek one's kind, dread of disapproval and scorn, are prominent. The truant is he who is isolated in the midst of children hopelessly beyond him in ability and interests, who is always "at the bottom of the class" and hence the object of the teacher's disapproval and the pupils' scorn. He cannot manipulate the environment of the classroom, so he seeks an environment which he can manipulate. 
In the frequency of charges which have to do with the sexual instinct, we see that this element is well developed. If the sexual instinct were weak in feeble-minded persons, the problem of mental deficiency would be largely self-solving, and no eugenic program would be necessary. The indication is that the feeble-minded approach the norms in this particular. The inhibitions due to ideas being weak in them, this well-developed instinct determines conduct, and in adolescent and adult defectives we have, as a result, illegitimacy, illegal co-habitation, and all the other violations of the rules which organized society has set up for the regulation of the sexual instinct.

Incorrigibility and disorderly conduct cover such specific acts as cursing, throwing stones, staying out nights, quarreling, and the like. There is a revelation of instincts in great variety here, and the charges result from habitual yielding to minor impulses.

Fighting, assault, and murder result in the majority of cases from anger at being thwarted. A few concrete cases will make this clear. $\mathrm{R}-\mathrm{N}-$, a boy thirteen years of age, with a mental age of eight years, drew a knife on the teacher. The teacher had reproved him for something he had undertaken, and had asked him to stop. He had been placed with this teacher, who was a good disciplinarian, because he had thrown a heavy flower-pot at his former teacher, when thwarted in some act. He remained 
good-natured and grinning, so long as he was permitted to have his way.

Sometimes fighting and assault are motivated by the tendency to resist the abstraction of goods acquired. The following is the verbatim story of a woman thirty-four years old, with a mental age of six years, six months, an inmate of an institution for the feeble-minded. She appeared before the examiner with a blackened and swollen eye, and the following conversation took place.

Q. How did you get that black eye?

A. You know we have chicken for dinner on Sunday, and I took that girl's chicken away from her plate. So she pulled my hair first, and she knocked me on to the floor, and she landed on my stomach, too. But I give it to her back though. I pulled her hair. That's all. See, that girl didn't want me to do it. And then I went up to wash my hands, because they was all greasy from holding on to the chicken. She didn't like me, that girl.

Again, fighting and assault, and at times murder, may be motivated by resentment at being scorned, as in the account of a feeble-minded girl fifteen years of age, also an inmate of an institution, who appeared with a black eye.

Q. How did you get that black eye?

A. (After a sulky silence.) Well, there's a girl, and she called me a - sheeney, and I called it to her back a — guinea, and she hit me in the eye, and I hit her in the nose. 
As for the other offenses listed, vagrancy often results from destitution, with consequent aimless wandering about in search of food and shelter; arson may result from curiosity and general manipulation of the environment, including matches, and inflammable materials; begging, peddling without a license, and violating the child labor laws are infrequent charges, and come from the attempt to get food and shelter indirectly, without, however, taking cognizance of the rules; being an intolerable nuisance may result simply from general lack of control, such as is found in any creature with strong tendencies to activity, but without much intelligence.

Dr. Glueck classified the crimes of ninety-eight feeble-minded offenders committed to Sing Sing Prison on the basis of instinct, as follows.

Crimes which had their impulse in the instinct of acquisitiveness. . . . . . . . . . . . . . . . . 58 Crimes which had their impulse in the instinct of pugnacity 26 Crimes which had their impulse in the instinct of sex . . 13 Arson (no instinct assigned) . . . . . . . . . 1

The instinct of submission to those who are obviously more powerful is an important factor in the misdoings of the defective, because through it they easily become the tools of those "higher up." The guardians of feeble-minded children reiterate the complaint, "He does all that other boys tell him to do, and believes everything they say." This instinct to submit is sometimes discussed as suggestibility. 
The feeble-minded are credulous and gullible, being unable to combat the judgments of those about them, because they lack the power of formulating judgments for themselves.

To assent without motive to any obscure statement made in a tone of authority, is characteristic of the majority of human beings, but it becomes increasingly characteristic as we go downward in the scale of intelligence. In the case of idiots and imbeciles it is often sufficient to look at them, and to say in a tone of authority, "Isn't that so? " without ever having made any preliminary remark at all. Immediately they nod, or reply, "Yes," as though a truth had been uttered.

In his discussion of suggestibility Binet notes that little children under three or four years of age can be made to react in the same way almost invariably, and many children older than this will react so. Above the age of seven or eight years, however, a normal child remains unmoved, does not reply, "looks at one in a scandalized manner," or demands an explanation.

Binet tells of various experiments in submission performed on imbeciles, where the suggestions were such as to outrage common sense, and which could not possibly have succeeded except with subjects very low in the scale of intelligence. Binet would rise, take a chair, and show it to the imbecile, whom he was studying, with the following results: 
Q. What is this?

A. A chair.

Q. Dreadful mistake! It is not a chair; it is a corkscrew. (Pause.) Now let us see. What is this? (Again showing the chair.)

A. A corkscrew.

Q. Now, upon what are you sitting?

A. A corkscrew.

The following conversation with an imbecile prisoner shows at the same time the instinct of submission, leading him into absurd contradictions, and his inábility to grasp the social organization under the rules of which he had been eight times committed to workhouse and penitentiary by the time he had reached his thirty-fifth year. This prisoner had been arraigned on the occasion of this conversation for breaking into a freight car, in winter, in search of shelter. His mental age was found to be six years, four months. The conversation ran thus:

Q. What place is this? (Room in observation ward.)

A. A room.

Q. What kind of a room?

A. A big room.

Q. Why were you sent here?

A. Judge said I'd be well took care of here.

Q. How did you get before the judge?

A. I was in Bronx Park. Little drunk.

Q. (In startled, disapproving tones.) You were drunk? 


\section{A. (Hastily.) No, ma'am, not drunk.}

Q. And where were you before you were in the Park?

A. In penitentiary.

Q. What's a penitentiary?

A. Place where you stay and work.

Q. What do you stay for?

A. Place like Blackwell's Island.

Q. What kind of place is Blackwell's Island?

A. Place where you work. Like a prison.

Q. What's a prison?

A. Place where you do housework.

Q. And you weren't drunk this time, were you?

A. No, ma'am, not drunk.

Q. (In tone of authority.) But you were drunk, weren't you?

A. (In hasty agreement.) Yes, ma'am, drunk.

Under the circumstances in which he finds himself, it would be easy to make this imbecile agree to anything. Whether he responds in the affirmative or in the negative depends upon the form of the question, the tone in which it is put, and the attitude and facial expression of the examiner.

It is unnecessary to comment at length upon the ease with which such a mind becomes the tool and dupe of others more powerful. Of course a six-year mentality would be of little use in the performance of a complicated crime, but eight-, nine-, and tenyear mentality can be very useful, and what is true 
of this imbecile is also true of those of higher grade, though true in lesser degree.

The feeble-minded are, however, not subinissive to each other, nor to those lower in power than they themselves. Like others, they show all degrees of submissive and of aggressive behavior, in response to situations which by nature call these reactions forth.

Certainly it seems that instincts are nearly as strong among the intellectually subnormal as they are among the normal and superior. It is this disproportion between the strength of instinct and the amount of intelligence which is responsible for the unsocial and anti-social behavior of the mentally deficient, which in turn makes of them such objects of concern. If there were a perfect correlation between instinct and intelligence, so that a feeble intellect would always insure equally feeble instincts, many of the difficulties of life would disappear automatically.

Of the instincts which do not ordinarily lead to crime, such as the tendency to feel pleased at the approval of others, and the tendency to be satisfied by seeing others comfortable and happy, there is every reason to suppose that these are as well developed in the subnormal as are the instincts which lead more readily into difficulty. Mentally deficient children are as susceptible as others to nods and pats of approval, to smiles, praise, and rewards, and their 
affection attaches as readily to those who win their confidence.

The study of the instinctive and emotional life of the feeble-minded may prove most valuable for normal psychology. One of the great obstacles to the scientific study of instinct has been the difficulty of distinguishing between what is really innate and what is learned, in the behavior of human beings. If it were possible to study human beings who approach the norm in their equipment of instincts, but who can learn relatively little, many questions about instinct might be illuminated.

Legal Responsibility. It has long been recognized in courts of law that children are not to be held responsible for their acts below a certain age. This age varies considerably in different times and different countries. In old English law the child could not be legally punished for his acts before the age of seven. According to the Jewish code, the sins "go on the parents" until the child is twelve years old, when he becomes responsible. The laws relating to juvenile courts usually place the age of responsibility at sixteen years, by allowing only those under that age to be arraigned in the children's court. The age of legal responsibility does not at present rest upon the results of scientific research, but upon the "general notion" of lawmakers as to the age at which the intelligence is sufficiently developed to take the instincts in charge. 
It is possible that as civilization advances and the environment becomes more and more complex, the age of legal responsibility should be advanced also. Perhaps it was right that centuries ago the age of responsibility should have been seven years, and right that now it should be sixteen years. At all events, the problem remains temptingly open to sociological and psychological research, as does also the question of the age of consent, which is now determined without regard to psychological principles.

This matter of the age of legal responsibility is important for students of the feeble-minded. Presumably all persons below a given mental age, regardless of chronological age, should be held irresponsible before the law. Responsibility should not be determined by the number of years an individual has been in existence, but by the mental level which he has attained. It is therefore very important to determine at what mental age the intelligence is sufficient to constitute " responsibility."

Present practice in the courts is much confused on this point. In New York City, for example, all individuals who have been in existence less than sixteen years are held to be irresponsible or partially responsible, regardless of mental acuity. This would lead to the supposition that a mental age of sixteen years is regarded as the criterion of full legal responsibility. This is not, however, the case, for adult prisoners of a mental age of about nine years and over 
are not provided for in law in any way other than by the procedure for conviction and punishment, common to all who have been in existence for more than sixteen years. These discrepancies in practice will, of course, disappear as knowledge grows and becomes disseminated.

Moral Imbeciles. The term moral imbecile has been used with many different connotations. When used to designate a person whose intelligence is defective, the term is superfluous, for mental imbeciles are moral imbeciles also, since "having morals" involves a use of ideas of which they are incapable.

The term is meaningful only when applied to designate persons of good intelligence, who are defective or perverted in instinct. There exist persons who are intelligent, yet incorrigible; persons who persist in criminal behavior, who do not feel the emotions ordinarily felt, and who seem incapable of responding to ethical ideals. These may properly be called moral imbeciles.

The Moral Training of Mental Defectives. Can the school do anything to instill morals in the mentally defective children? Can the school aid at all in preventing the crimes and misdemeanors which they commit, as children and as adults?

We must refer forward for a moment to the discussion of the way in which improvement takes place in the feeble-minded. It takes place only through the formation of specific habits. What is true of skill, is true of morals as well. 
If it were possible for the school to foresee and reproduce every situation involving instinct to which the defective would have to respond in the course of life, and could by repetition connect permanently the desired response with each situation, it might insure morals just as it can insure skill. This being utterly impossible, the school can only select certain general situations, and strive to connect the desired response with each, by many repetitions. To the situation 'a dumb animal' it may strive to attack the response 'be kind'; to the situation 'an object that is not mine' it may strive to attach the response ' don't take it'; to the situation ' being angry ' it may strive to attach the response ' don't strike.'

The difficulty always is that the very limited intelligence is usually not capable of even this amount of generalization. The instruction tends to degenerate in the mind of the instructed into the much more concrete situation 'being angry at Johnny' and the response 'don't hit him,' without affecting relations with Tom, or Joe, or with people at whom he will be angry ten years after leaving school.

It is true, of course, that these same limitations apply, though with less and less force, as we go up through all the degrees of intelligence. With the majority of us the moral code is to some extent a matter of specific instruction, and it is only the exceptional intellect that can construct for itself a code of morals on an independent basis, if once the orthodox code 
handed down by specific instruction has been undermined. Normal intelligence is capable of learning the response 'don't take it' to the situation 'something that is not mine.' Yet it tends to apprehend the words very concretely, and seldom makes the generalization to include the time of busy persons, taxes that the state forgot to collect, or sacrifices of others who toil in its behalf.

In amenability to moral education, as in all other respects, the feeble-minded differ from the normal not in kind, but only in degree.

\section{REFERENCES}

1. Binet, A., and Simon, Th., The Intelligence of the FeebleMinded. Trans. by E. Kite. The Training School. Vineland, N. J. 1916.

2. Ellis, F. W., and Bingham, A. T., Mental Examinations. New York Probation and Protective Association. 1915.

3. Fernald, W. E., The Imbecile with Criminal Instincts. American Journal of Insanity. April, 1909.

4. Goddard, H. H., The Criminal Imbecile. The Macmillan Company, New York. 1915.

5. Grossmann, W. H., The Atypical Child - Its Instincts and Moral Status. Bulletin of the American Academy of Medicine. April, 1907.

6. Hastings, G. A., What Shall be Done with Defective Delinquents? New York Committee on Feeble-Mindedness. New York. 1918.

7. McDougall, W., Social Psychology. Methuen and Company, London. 1908.

8. McLear, M., The Fact of Personality in the Development of an Atypical Child. Pedagogical Seminary. March, 1913.

9. Moore, F., Mending Immoral Morons. National Prison Congress. Oct., 1911.

10. Thorndike, E. L., The Original Nature of Man. Teachers College, Columbia University. 1914.

11. Weidensall, J., The Mentality of the Criminal Woman. Warwick and York, Baltimore. 1916. 


\section{CHAPTER X}

HOW DO THE MENTALLY DEFECTIVE LEARN?

The Learning Process. In Chapter $\mathrm{V}$ we showed that the feeble-minded differ from the normal and superior not in kind, but only in degree. Thus the nature of learning will be of the same kind in them as in ordinary children. It is not a part of the purpose of this book to present in full the psychology of the learning process. For these facts a standard text on educational psychology should be consulted. Briefly it may be stated that all behavior, both learned and unlearned, may be reduced in the last analysis to specific responses to given situations. We spend our days being stimulated by our environment and responding to it. The responses of which men and other animals are by original nature capable are instinctive, or unlearned. It is the task of education to modify and amplify these responses in such a way that the individual may become as well adapted as may be to the purposes of the social body of which he is a member. The extent to which education is effective varies greatly with individual differences in original nature, which were discussed in Chapter I. The psychology which underlies such 
modification is, however, the same in kind for all animals, both brutes and men. A definite response is made over and over again to a given situation, and a bond is formed in the nervous system of the learner, so that when that situation is presented to him he makes that response. This is the principle of practice, upon which all learning depends. Its basis is physiological. The elements of the nervous system having acted in a certain way, tend more easily to act in that way again, (provided that the action be not followed by pain or discomfort). When the response through long practice comes very easily and ouickly, we say that a habit has been formed.

The kinds and complexity of habits which an individual can form depend, of course, not only on practice, but also on the sensitivity and complexity of his nervous system. A baby of one year cannot form habits of reading and writing, because he is not as yet sensitive to the situation 'a white page containing numerous tiny black marks, each of which has a definite meaning peculiar to it.' Human beings learn that which they can learn according to the same general laws, but not all are capable of learning the same things, even with a maximum of practice.

How Do the Feeble-Minded Compare with Normals of the Same Age? Some years ago, before any experimental study of the feeble-minded had been made, it was often affirmed that they are characterized by incapacity for sustained voluntary effort, by 
lack of attention, in short by inability to learn. These conclusions came no doubt from general observation of the fact that compared with normal persons of the same age they are unable to profit by instruction.

This general observation was later borne out by experimental studies of feeble-minded children, as compared with normal children of their age, or with normal children in the same school grade. Figure 14 shows graphically the rate of learning of a subnormal school child, as compared with a normal member of his grade in school. It is noticeable that the curve for the subnormal child rises slowly, and never attains the goal finally attained by normal children, who are as old as he is.

How Do the Feeble-Minded Compare with Normals of the Same Mental Age? The comparison of the feeble-minded with normals of the same chronological age is not the only, nor yet the most fruitful method of gleaning the desired information about the learning processes of the former. Another method of analysis is to compare the learning of the feeble-minded with the learning of normal children of the same mental age. We know very well, both from common observation and from experiment, that a fifteen-year-old defective, with a mental age of eight years, cannot learn as a normal fifteen-year-old can. The question is, can he learn as well as, or better than, an average eight-year-old can? 


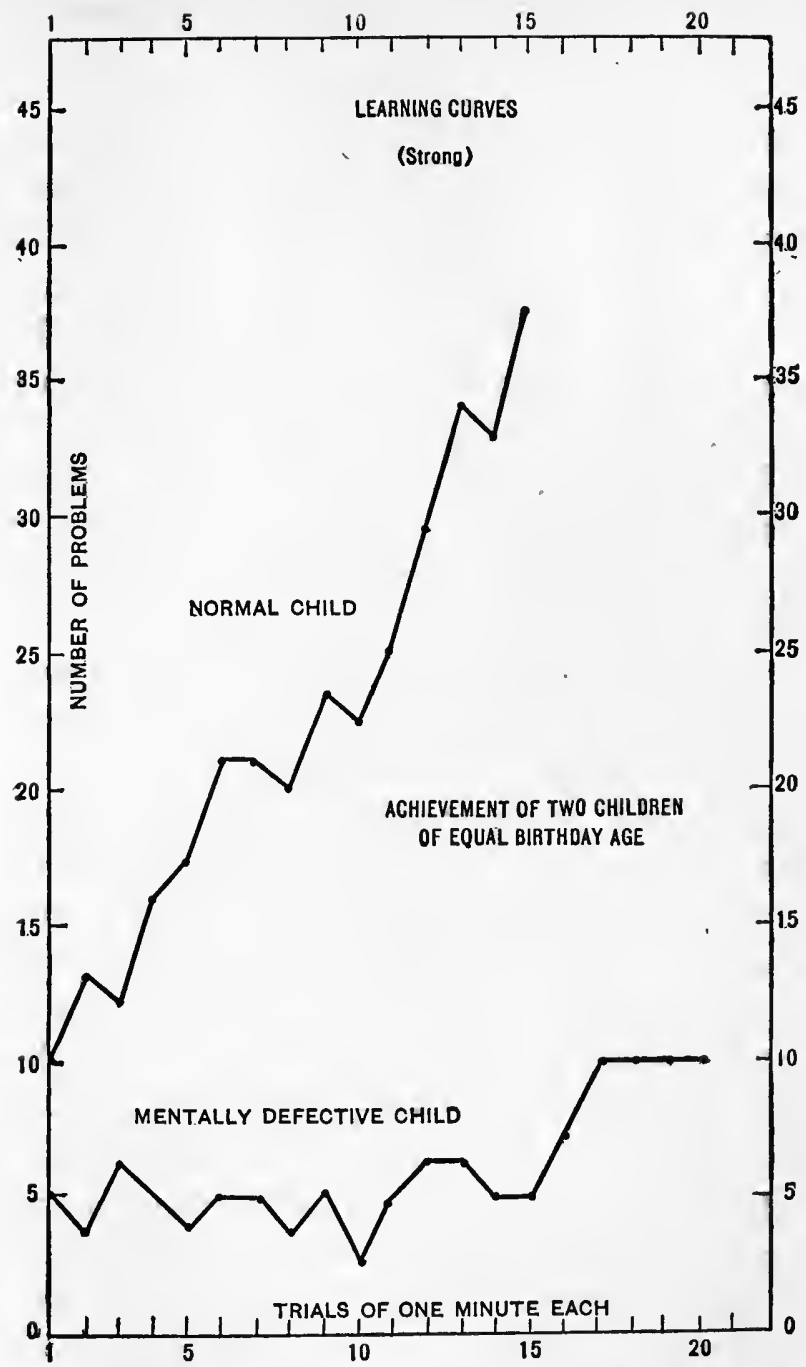

Fra. 14. - Curves showing the course of learning in a defective child, and in a normal child, of equal birthday age. (From Strong. Reproduced by courtesy of The Psychological Bulletin.) 
Dr. Woodrow studied this question, at the State School for the Feeble-Minded, in Faribault, Minnesota. A group of feeble-minded inmates, averaging a mental age of 8 years, 10 months was compared with a group of normal public school children, averaging 9 years, 1 month in age. (Both of these groups may be said to have been 9 years old mentally.) These children in both groups were of equal initial ability in the tasks which were set them, namely, sorting sticks into boxes, sorting colored pegs, cancelling letters, and cancelling geometrical forms.

These two groups, almost exactly equal in mental age, and in initial ability in the situations named, were given thirteen days of practice in sorting gun wads, on which were pasted labels bearing the printed outlines of simple geometrical forms. There were five different kinds of these labels, and wads bearing the same kind of label had to be sorted into the same box. It is easy to see that this task has many elements in common with simple factory operations.

After thirteen days of practice (consecutive except for Saturday and Sunday) the records of both the feeble-minded and the normal were scored, in order to compare the two groups in learning. The facts can be conveyed most clearly by presenting the complete table of results. The table shows the initial trial, the final trial, and the improvement (amount of learning) is given for each child, both 
feeble-minded and normal, in terms of the number of wads correctly sorted. The percentage improvement is also given.

The Absoldte and Pencentage Impronement of Each Child of Both Normal and Feeble-Minded Groups (Woodrow)

\begin{tabular}{|c|c|c|c|c|c|c|c|c|}
\hline \multicolumn{5}{|c|}{ Feeble-Minded } & \multicolumn{4}{|c|}{ Normal } \\
\hline Child & $\begin{array}{c}\text { Initial } \\
\text { Trial }\end{array}$ & $\begin{array}{l}\text { Final } \\
\text { Trial }\end{array}$ & $\begin{array}{l}\text { Im- } \\
\text { prove- } \\
\text { ment }\end{array}$ & $\begin{array}{c}\% \\
\text { Imp. }\end{array}$ & $\begin{array}{c}\text { Initial } \\
\text { Trial }\end{array}$ & $\begin{array}{l}\text { Final } \\
\text { Trial }\end{array}$ & $\begin{array}{c}\text { Im- } \\
\text { prove- } \\
\text { ment }\end{array}$ & $\begin{array}{c}\% \\
\text { Imp. }\end{array}$ \\
\hline 1 & 129 & 175 & 46 & 36 & 147 & 197 & 50 & 34 \\
\hline 2 & 94 & 146 & 52 & 55 & 144 & 176 & 32 & 22 \\
\hline 3 & 154 & 201 & 47 & 33 & 130 & 191 & 61 & 47 \\
\hline 4 & 112 & 203 & 91 & 81 & 119 & 166 & 47 & 39 \\
\hline 5 & 120 & 193 & 73 & 61 & 114 & 197 & 83 & 73 \\
\hline 6 & 108 & 167 & 59 & 55 & 118 & 159 & 41 & 35 \\
\hline 7 & 127 & 144 & 17 & 13 & 107 & 173 & 66 & 62 \\
\hline 8 & 94 & 209 & 115 & 123 & 125 & 163 & 38 & 30 \\
\hline 9 & 136 & 166 & 30 & 22 & 100 & 132 & 32 & 32 \\
\hline 10 & 120 & 142 & 22 & 18 & 122 & 213 & 91 & 75 \\
\hline 11 & 138 & 184 & 46 & 33 & 113 & 186 & 73 & 65 \\
\hline 12 & 125 & 182 & 57 & 46 & 104 & 163 & 59 & 57 \\
\hline 13 & 83 & 111 & 28 & 34 & 99 & 144 & 45 & 45 \\
\hline 14 & 127 & 212 & 85 & 67 & 121 & 156 & 35 & 29 \\
\hline 15 & 122 & 103 & -19 & -16 & 155 & 204 & 49 & 32 \\
\hline 16 & 104 & 149 & 45 & 43 & 129 & 199 & 70 & 54 \\
\hline 17 & 124 & 179 & 55 & 44 & & & & \\
\hline 18 & 140 & 214 & 74 & 53 & & & & \\
\hline 19 & 142 & 208 & 66 & 47 & & & & \\
\hline 20 & 114 & 203 & 89 & 78 & & & & \\
\hline Av. . & 121 & 175 & 54 & 49 & 122 & 176 & 54 & 46 \\
\hline
\end{tabular}

It is worth while to dwell at some length upon this investigation, because the results of such an experiment are worth more than all the surmises and ex- 
pressions of personal opinion that could be collected. The time has passed when educators were satisfied to base their procedure on dogmatic opinions. They are now seeking the basis of sound experimentation. The question whether feeble-minded children show the same improvement with practice as do normal children of the same mental age, is answered affirmatively in this experiment. They learn as much, and they learn at the same rate, as do the normal nineyear-old children. In actual (chronological) age the two groups were, of course, very different. The feeble-minded learners ranged from nineteen years to ten years, with an average age of thirteen years, eight months. The normal children ranged between ten years and eight years in actual age, with an average of nine years, one month.

The curves in Figure 15 present a graphic picture of the comparative performance of the two groups. They travel together, crossing and re-crossing each other from trial to trial.

If we had a curve showing the performance of normal children, of an average age of fourteen years, it would undoubtedly travel above these two curves, even in a process as simple as this of sorting forms. The older normal children would learn faster and would learn more than would the younger normal children, or the feeble-minded of their own age.

One further experiment in the learning of the feeble-minded as compared with normals of the same 
mental age has been carried out. In order to measure the amount of material learned in a year by feeble-minded children, as compared with normal children of the same mental age, Dr. Murdoch studied a number of inmates at the Pennsylvania School

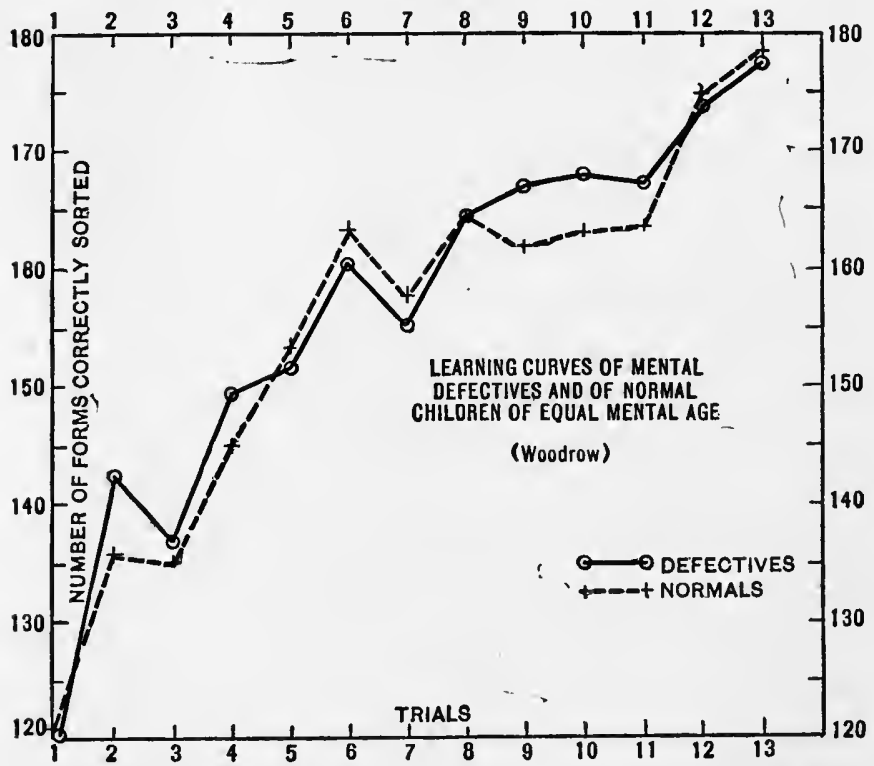

FIg. 15. - Curves showing the course of learning in defectives and in normal children, of equal mental age. (From Woodrow. Reproduced by courtesy of The Journal of Educational Psychology.)

for the Feeble-Minded, whose mental ages had been ascertained. First the ability of these children was determined by educational measurement, in reading, spelling, arithmetic, handwriting, composition, drawing, and language. Exactly one year later they were 
remeasured in the same abilities. Since it is known how much average children of each school grade improve in these abilities in a year, and since it is known what the average age in each grade is, comparison between the feeble-minded and the normal on the basis of mental age seems permissible.

The outcome of the investigation was that of children starting the year's work with the same mental age, the normal learn much more within the allotted period than do the feeble-minded. From this result the investigator drew the conclusion that the feebleminded learn much less than do normal children of equal mental age, in those school subjects which she studied; and that Woodrow's results, showing equality of improvement in sorting forms, was not substantiated for the presumably more complex abilities, - reading, spelling, arithmetic, handwriting, composition, drawing, and language.

Analysis will soon show us, however, that there is no discrepancy between the results of the two experiments. The fact simply is that in the case of a learning process, which extends over a period as long as a year, the children do not remain of equal mental age. If we start a year's task with a group of feebleminded, who are nine years old mentally, and a group of normal children who are nine years old, at the end of the year the feeble-minded will still be approximately nine years old mentally, whereas the normal children will have reached the mental age of ten years. 
This is true because the normal children are growing mentally at the average rate, while the feeble-minded are not. In the lapse of thirteen days the two groups do not have time to draw apart appreciably in growth. Hence in the first experiment, that of Dr. Woodrow, we really have a comparison of groups of equal mental age throughout. In three hundred and sixty-five days, however, the two groups draw very definitely apart. Hence in Dr. Murdoch's experiment we soon cease to have groups of equal mental age for comparison. The superior records of the normal children are due, most probably, to growth, and not to superior ability to practice at the mental age specified. The results of these two studies are thus in no way contradictory. On the contrary, they supplement each other.

Transfer of Training in Normal and FeebleMinded Children. It is a fundamental principle of educational psychology that by practicing for a period of time in the performance of a given task, an individual will be aided in the performance of other tasks, which have elements in common with it. This principle is usually called the principle of transfer of training. Now it might be that normal and feeble-minded children of equal mental age show the same improvement in an activity practiced, but unequal transfer of that learning to related activities.

That there is no spread of improvement in the case of the feeble-minded has been affirmed. As in the 
case of the question of improvement in a task specifcally practiced, this statement has rested on common observations, comparing the feeble-minded with normal persons of equal chronological age. Many anecdotes are current in illustration of this point. For instance, an imbecile by prolonged practice under instruction learned to make beds very well, working by herself. After a time it was desired to expedite the bed-making, and another girl was assigned to work with the first, in the performance of her task, the plan being to have them work simultaneously on a bed. It was then found that the imbecile who had learned to make the beds by herself had to be retaught to make beds with a helper. As soon as the situation became different in certain elements, what she had learned ceased to function.

Another illustration may be cited in the case of three imbecile men who were asked to scrub a large floor. Each man had learned to scrub a floor by himself, bringing the water and soap, scouring the boards, rinsing off the soap, and wiping up as he went. Each of them began in this manner on a section of the floor. The psychologist of the institution decided to introduce coöperation as an experiment. She showed how one of them could bring the water, another could scour, and the third could wipe up the suds after him. This innovation resulted in much confusion. As compared with what would have been the case with normal men of their chronological age, 
there appeared to be no transfer of training in the one activity to the other so closely like it. But it is necessary to remember in all these instances that the mental ages of these imbeciles ranged between three and five years. The transfer of skill may well have been fully as great in their case as it would have been with normal children of three to five years.

In order to throw light upon this question in the learning of the feeble-minded, Dr. Woodrow experimented further with his groups of children. At the end of the thirteen days of practice in sorting geometrical forms, all the children were again tested for sorting sticks and pegs, for cancelling forms and letters. It is not necessary to rehearse the procedure in full detail here. It is sufficient to say that all the requirements of scientific method were fulfilled in the experiment (including " control groups" of both normal and feeble-minded children, who took the end tests in each instance, but who did not practice sorting forms during the thirteen intervening days). The result showed that no difference in amount of transference of improvement could be demonstrated, between the normal and the feeble-minded of equal mental age.

The Importance of Mental Age in Learning. It is obvious that none of these facts of educational psychology, so illuminating to the teacher of defectives, could have been discovered before means had been devised for determining mental age. Mental age, 
182 PSYCHOLOGY OF SUBNORMAL CHILDREN not chronological age, is the basis of the learning curve. Ability to profit by instruction depends not

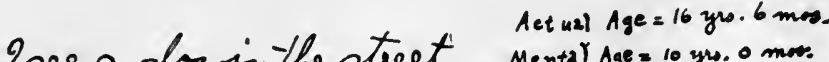
Mental Age = 10 gro. 0 more. 8 see a dug in the street. Meturl Age $=10$ yo. 8 mos.

9 sea a dog Actual Age. 14 you. 7 mos. in the eft.

Mental Age = 7 yrs. 10 mar.
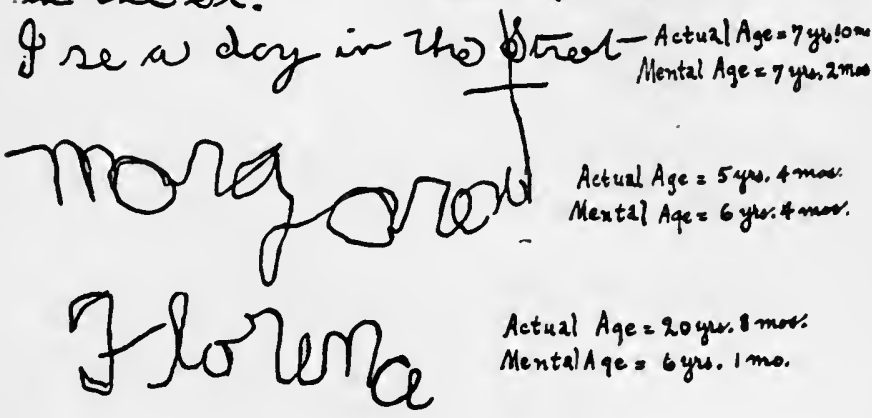

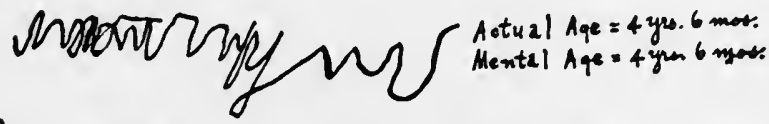

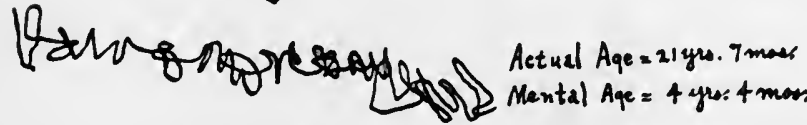

Fra. 16. - Writing of feebleminded individuals, as compared with that of normal children of equal mental age; illustrating the importance of mental age in achievement.

on how long the individual has been in existence, but on the complexity and sensitivity of his nervous system. This complexity and sensitivity is repro- 
sented by the concept of mental age, which shows the stage of intellectual growth attained.

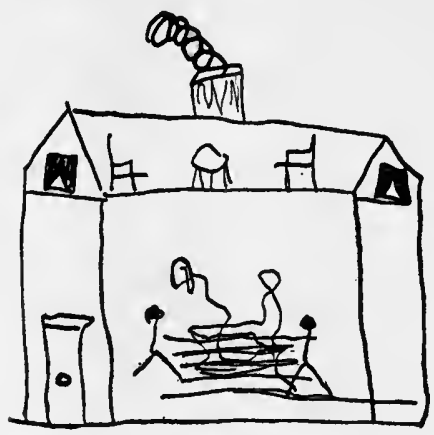

Actual Age $=28$ gros 7 mor.

Mestal Age $=8$ yos: 2 mose

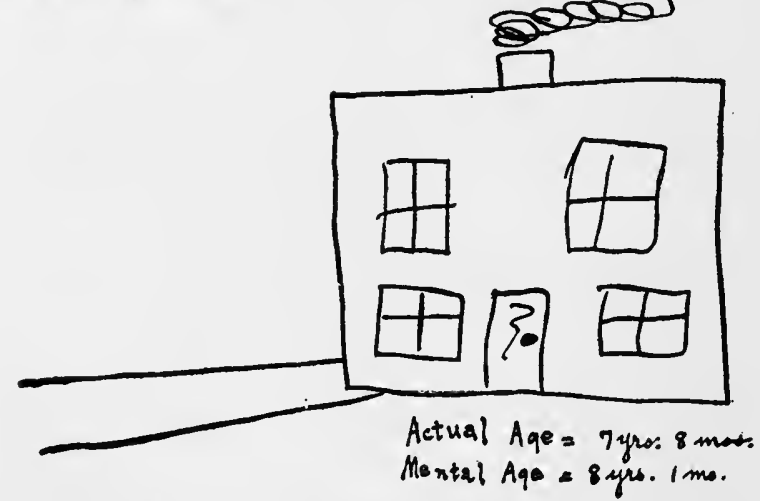

FIG. 17. - Drawings of a house, comparing a feeble-minded adult with a normal child of equal mental age; illustrating the importance of mental age in achievement.

In children the nervous system becomes sensitive to a greater number of situations, as it grows from year to year. This is true of all children, but the 
rate of growth and the ultimate limits of growth vary greatly from individual to individual. The kind and number of habits an individual can form at any given time are conditioned by the stage of mental growth

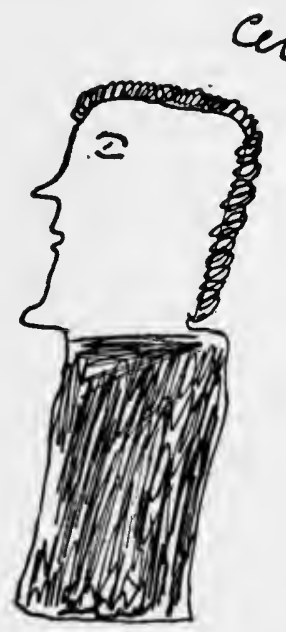

Actual Age $=7$ yro. 4 mos. Mental Age $=8$ ysu. omoo.
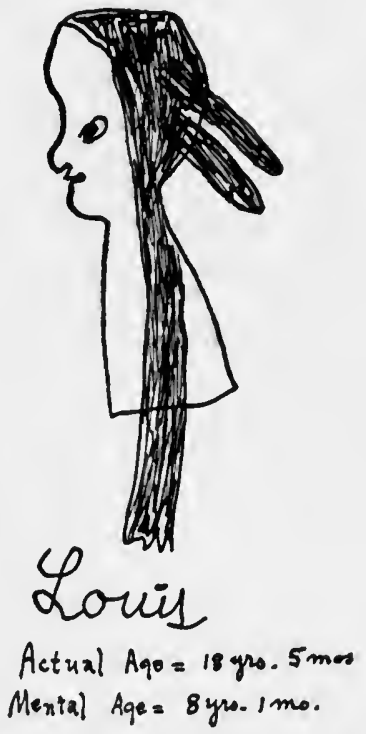

Fig. 18. - Drawings of a man, comparing a feeble-minded adult with a normal child of equal mental age; illustrating the importance of mental age in achievement.

which he has then reached. Thus one of the first questions which a teacher needs to have answered about the child placed under her care is this: What is his mental age?

It is for the psychology of the immediate future 
to discover much more than is now known about the kinds of habits which are learnable at various mental levels. As far as the standard school curriculum is concerned this has been worked out by the rough method of trial and error, so that on the whole there is given in each school grade that which can be grasped and learned by children of the age which is average for that grade. For tasks not included in the conventional school curriculum, we are almost altogether without this information. At what mental age is it possible to form adequately the habits of a chauffeur? of a gardener? of a cook? of a paper-box maker? of a chemist? In answer to these questions we have only preliminary data collected from the mental tests in the army, and a few preliminary studies of ungraded class children whose industrial careers have been followed after they left school.

Mental Age Is Not the Sole Condition of Learning, though it is the single most important condition. We have already seen that children of the same mental age vary somewhat in their ability to perform given tasks. The human mind is far too complex to be completely inventoried by a single figure representing the general level of intelligence. We find cases of very marked special ability or disability in the feeble-minded, just as we find them in children of every other quality of general intelligence. This has already been fully discussed in a previous chapter. Moreover, differences in temperament, interest, 
and control, which are not intellectual traits, are found among persons of equal mental age, and they too exert an influence on learning, by determining attitude. Sensory defects and physical defects sometimes play a part, also, in producing differences in improvement among those of the same degree of general intellectual capacity.

Summary of the Psychology of Learning in the Case of Subnormal Children. We may summarize our present knowledge of the learning process in the feeble-minded thus: (1) The feeble-minded cannot learn as well as the normal of equal chronological age. They cannot learn simple tasks at the same rate, and they cannot learn the more difficult tasks at all. (2) The feeble-minded learn at the same rate, and in the same way, as normal children of equal mental age, in tasks in which both have been experimentally tested. ${ }^{1}$ (3) There is no necessary relation between ability to learn specific tasks appropriate to a given mental age, and ability to grow from one mental age to another. (4) No difference in amount of transference of training from practice in one task to the performance of other tasks having common elements, has been demonstrated to exist between

1 I am informed by Dr. S. S. Colvin that the unpublished data from his experiments on the learning of the feeble-minded as compared with normal children of equal mental age, show that the former learned as much as did the latter, in the tasks which were set; but that the learning curves of the feeble-minded were decidedly more irregular in outline than were those of the normal children. 
the feeble-minded and normal children of equal mental age. The spread of improvement is apparently the same for both.

Implications for Education. The teacher who has thoroughly mastered the results of these studies will be in position to understand many of the most essential principles underlying the educational treatment of subnormal children. In the first place it is apparent that no intelligent plan for the instruction of a child can be instituted until his mental level is known. Under ideal conditions this will be determined by the school psychologist, whose work it is to make mental examinations and determine traits and aptitudes. At present only a few state departments of education are equipped to furnish the services of well trained psychologists. In the larger cities such services are rapidly becoming available, particularly where special classes have been organized.

In the second place, the child will generally be capable of performing school work which can be mastered by average children of his mental level. If his mental age is eight years, he will be able to learn subject matter becoming to ordinary eight-year-olds. Eight-year-olds are normally in the second or third grade (according to community).

However, where special classes have been organized it is usual to prescribe a special curriculum for the subnormal children, since their ultimate achievement 
will be very limited at best. It is a waste of time and effort to teach deficient children the subject matter which underlies the understanding of fractions, or of syntax, when it is known that no matter how long they may live they will never attain a mental level which is capable of learning fractions and syntax. From these practical economic and social considerations a modified curriculum has been worked out, and will continue to be worked out as our knowledge of applied psychology increases. The content and organization of this curriculum cannot, however, be determined by psychology, but by educational aims and educational methods, emanating from current social philosophy.

\section{REFERENCES}

1. Baldwin, B. T., The Learning of Delinquent Adolescent Girls as Shown by a Substitution Test. Journal of Educational Psychology. June, 1913.

2. Colvin, S. S., The Learning Process. The Macmillan Company, New York. 13th ed. 1918.

3. Colvin, S. S., Aspects of the Learning Curve. Proceedings of the American Psychological Association. Psychological Bulletin. 1915.

4. Johnson, B., Practice Effects in a Target Test. A Comparison of Groups Varying in Intelligence. Psychological Review. July, 1919.

5. Kuhlmann, F., Experimental Studies in Mental Deficiency. American Journal of Psychology. 1904.

6. Murdoch, K., Rate of Improvement of the Feeble-Minded as Shown by Standardized Educational Tests. Journal of Applied Psychology. Sept., 1918.

7. Strong, E. K., The Learning Curve as a Diagnostic Measure of Intelligence. Psychological Bulletin. Vol. XIV, p. 153. 1917. 
8. Thorndike, E. L., The Psychology of Learning. Educational Psychology, Vol. II. Teachers College, Columbia University. 1913.

9. Woodrow, H., Practice and Transference in Normal and Feeble-Minded Children. Journal of Educational Psychology. Feb., 1916 and March, 1917. 


\section{CHAPTER XI}

CAN THE MENTALLY DEFICIENT BE MADE NORMAL BY ANY SYSTEM OF EDUCATION?

Is it Possible to Overcome Mental Deficiency? It has already been stated that the proper treatment of mental deficiency is educational. Science knows of no medical or surgical treatment which has any remedial effect, except in cretinism, and in those few cases which result from injury to the nervous system in children who were potentially normal. These facts are well stated by Tredgold, who is the most scientific and authoritative writer on the subject among medical men:

"In view of the fact that primary amentia - to which form tiue great majority of cases of mental deficiency belong - is due to a diminished innate potentiality for development - in other words, to a formative defect of the tissue which constitutes the physical basis of mind - it is hardly to be expected that medicaments would have any remedial effect, and, as a matter of fact, there is no drug which has the slightest direct or specific influence upon this condition. Cases of secondary amentia, however, stand on a different plane, in that in them the mental defect is not due to an innate blight, but to the fact that development has been liandicapped or arrested by some external factor, and where this can be overcome by the administration of drugs, a considerable improvement, or even cure, may be brought about. ... At the same time the cases which may possibly be treated in this way are very few in number, and in the great majority of instances of 
secondary as well as of primary amentia it must be said that drugs have no direct effect.

"The same must be said of surgical treatment. When the theory was propounded that microcephalus was due to premature synostosis it was natural that the surgeon should. suggest relief by craniectomy. During the year 1890 , and for a time after, a considerable number of operations were performed by eminent men. ... The mortality was exceedingly high (about 25 per cent), and those who survived showed no mental improvement. It is not surprising that the operation should have been gradually abandoned by reputable surgeons, and to-day it is practically unheard of. It was indeed founded upon a mistaken notion of the pathology of this condition, and it may be said that to-day operations of this kind upon cases of primary amentia are absolutely unjustifiable."

We say that the appropriate treatment of mental deficiency is educational. Do we mean by this that by training we can bring a mental defective up to normal? Or do we mean only that we can improve his condition? And if we can bring about improvement, in just what does such improvement consist?

These are questions which are asked with burning interest by those who are responsible for subnormal children.

Can Innate Capacity for Learning Be Increased? Parents, and indeed all who are interested in the welfare of human beings, hope most eagerly for an affirmative answer to this question. Unfortunately the answer of science is a negative one. Centuries ago it was observed that man by taking thought cannot "add one cubit to his stature." Just so, by taking thought no educator can add to the intelligence quotient of a defective child. Accident or 
disease may degrade to the level of idiocy an intelligence that was potentially normal or superior, but no means has ever been discovered of increasing the intellectual capacity of the inferior and the mediocre.

Children in state training schools, whose education has been scientifically directed, and whose mental growth has been carefully studied in the meantime by psychologists, have not tended to become normal as a result of their training. On the contrary, they show the same very slight and gradual decrease of the intelligence quotient which is shown by subnormal children in general, as the years of their development pass.

Intelligence, the capacity for learning, the capacity for comprehending and making adaptations to the environment, is the result of growth, and cannot be acquired by any course of training. As has been reiterated in these pages, its basis is physiological, and dependent upon the inherited potentiality of the nervous system to become complex and sensitive. Nervous systems vary in respect to this potentiality, just as eyes vary in color, and teeth in hardness, from individual to individual. Education cannot supply complexity and sensitivity. Education can only direct and control such complexity and sensitivity as are constitutionally present in the individual.

Fallacies Based on Inadequate Experimentation. Mistaken conclusions have sometimes been drawn in the past by well-meaning persons, without sufficient 
knowledge of scientific method. For example, the present writer knows of various cases in which a child has been measured at the beginning of a course of training, and then remeasured at the end of a year or two, and in which the experimenters have enthusiastically ascribed the rise in mental level found on the last examination to the training undergone in the meantime. The humane desire to demonstrate that "there is hope for such children" has in such instances supplanted ideas of scientific procedure. The fact is not considered that mental development would undoubtedly have taken place in the interim, even if the child had had no special training. The question never is, Has development taken place? The question is, Has greater development taken place than would have taken place without the special education?

The investigation of this question may properly be undertaken in either of two ways. The investigator may measure a number of feeble-minded subjects who are past the age when any spontaneous growth will take place. After measuring them, he may subject them for a long period to whatever educational system he may deem desirable. Thereafter he would remeasure them by the same tests as before or, better still, by a new set having exactly equal value. If the second test showed a real gain in capacity, educational treatment might properly be said to have raised the actual intelligence level, for 
in adult subjects the improvement could not be ascribed to spontaneous growth.

However, it might be deemed that such experiments are inconclusive, because the possibility would remain that during years of development growth might be accelerated, though it could not be stimulated to begin again in the adult feeble-minded. The second method of inquiry, therefore, would be to take two groups of feeble-minded children of equal initial capacity as measured by standard tests, and after measuring them, to subject one group to the desired system of instruction, letting the other group go free. If at the end of a period of time, upon being remeasured, the instructed group showed a reliable gain over the uninstructed group in mental level, the training could properly be said to have raised the intelligence quotient in and of itself.

It is true that psychological experiments as precise and extensive as those here suggested have never been reported. We have only the information that the feeble-minded inmates of state training schools do not tend to become normal as a result of the instruction given them. We have also Dr. Terman's report of repeated measurements of mentally deficient children in the public schools, which show that they do not tend to improve intellectually as a result of their school training. Thus all the data at present available point in a consistent direction, indicating that educational treatment cannot increase the innate capacity of a child. 
What Can Educational Treatment Do for Subnormal Children? If the actual intellectual level cannot be raised, what are the advantages to be gained by the training of defective children? What is the use of bestowing any educational attention upon them? The answer is to be found in the psychology of habit formation. The same considerations apply to them that apply to all other children, only with special emphasis in their case, since they will need to be taught many habits which are spontaneously acquired by ordinary children. It is possible to impart to the feeble-minded specific information, and to inculcate in them specific habits, up to the limits of their capacity, whereas without skilled training they grow up savage, filthy, antisocial, helpless, - a great social burden. It is in these facts that the most important principles of the training of the mentally deficient are grounded. Such improvement as they are capable of must come through education, and their education must be grounded on their capacity for forming specific associations and specific habits of conduct, up to the limits of their intelligence.

To make this clearer let us cite concrete matters. Suppose a teacher to be confronted with a ten-yearold child with an intelligence quotient of 50 . She cannot by any educational effort raise him to 70 or 100 intelligence quotient. She can, however, by an educational process teach him to eat with his spoon 
instead of with his fingers; to drink from his glass without spilling the fluid all down the front of his clothing; to comb his hair instead of leaving it a matted and tangled mass; to obey when spoken to, instead of yelling and kicking; and to perform simple manual tasks which will occupy him, and in doing which he may gradually become useful, instead of leaving him to a savage and helpless existence. All of these improvements can be brought about by education, and by no other means. Even though this child be destined to an ultimate level of only eight years, he may be when adult either a clean, orderly individual, happily occupied with some appropriate work under intelligent guidance, or a helpless, filthy and disorderly person, without any appropriate means of employing his time. Which he shall be depends on training, and thus directly upon teachers.

In undertaking the education of any child it is wise to learn, if possible, what his stage of mental development is, but with exceptional children this is especially important. Mental level being known, the next step is to begin the formation of habits and the imparting of information suitable to the state of intellect. For example, it would be folly to spend time trying to teach a mentality of four years to read and write. The formation of reading and writing habits is not possible at this level of intelligence. But cleanliness in personal habits, proper ways of feeding oneself, and intelligible speech are all pos- 
sible at this level, and can be taught. Thus lowgrade imbeciles, who without education would be filthy, unintelligible, and disgusting may be rendered presentable by training, and that without modifying the intelligence quotient in the slightest.

The Nature of Improvement in the Feebleminded. It is in the way just described that improvement takes place in the feeble-minded. A parent or guardian is often highly gratified at the improvement that is shown by a defective child during a year of residence in one of the very good boarding schools for the feeble-minded, or under the tutelage of a skilled teacher. They find that the child who formerly could not dress himself, speak intelligibly, or write his name is now able to do all of these things, and much more. Their inference almost invariably is that he is "getting brighter." Of course some actual growth will have taken place in the young child, but the improvement which is noted is due to the formation of specific habits, and to the inculcation of specific information, far more than to mental growth. The child is not really "getting brighter" in any true sense. He is simply being trained up to the limits of his capacity. No hope is to be entertained that this newly acquired ability to dress himself where formerly he could not, implies the growth of ability to keep out of trouble on the streets, or to compete successfully with his fellows in school work.

Such erroneous inferences are very naturally 
drawn by persons who have no knowledge of the psychological facts. For instance, a very intelligent young woman recently came to consult the present writer about a relative who is mentally defective. This deficient woman is now over thirty years of age, and psychological examination shows her to have a mental age of seven years. The young woman who came to consult about the case felt that mental development must be taking place in the defective relative, because the latter had now been taught to lace her own shoes since removal to her aunt's home, whereas formerly her mother (now dead) had always been obliged to lace them for her. It was desired to learn whether in view of this improvement it would not ultimately become possible to trust this relative to go about like others, and to be responsible for her affairs. It seemed to her family that since she had now learned to lace her shoes she must be "getting brighter."

This difference between intelligence and specific habit is very nicely illustrated in defectives who have been trained by persistent effort to write a certain number of words, but whose mental level does not permit of the formation of general reading and writing habits. Often one finds a defective who can write his name, but little or nothing else. Such a one was Edward, whose performances are illustrated in Figure 19. Asked to write his name he wrote "Edward." Asked then to write "Ed" he grinned 
sheepishly, chewed his pencil, muttered, "I can't," but being commanded in a tone of authority to write "Ed," he finally scrawled "cat," which was one of the half-dozen other words which he could fashion. He could not adapt his behavior even slightly, but was able to respond to the new demand only with another specific habit, because he was not

Stimulus: Write your name.

L Response:

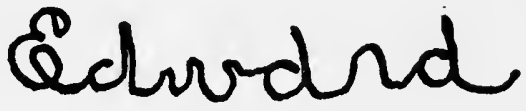

Stimulus: Now write, Ed.

Response (after much hesitation) :

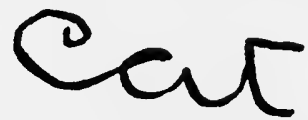

FIG. 19. - Responses of a feeble-minded man who is able to write "Edward," but cannot write "Ed," which he has never been specifically taught to write; illustrating the fact that specific training is powerless to raise the level of general intelligence.

intellectually at a level where such adaptations are possible.

Scores of anecdotes are current among students of the feeble-minded which illustrate this power of specific habits in their lives. A feeble-minded man was sent out under the supervision of a farmer to drive a team during the haying season. After a week the farmer reported on his new "help" as follows: "He helps fine. Drives the team back and forth all day long. There's only one thing against him. He 
will go to bed every night at seven o'clock, no matter what happens." In the institution where this man had lived for years, the retiring hour was seven o'clock.

The Importance of Early Diagnosis. Since training, consisting in the formation of proper specific habits, is the chief instrument for the improvement of the feeble-minded, it is of first rate importance to make a diagnosis at the earliest possible moment. The hopeful laissez faire notion that the child "will outgrow" his weaknesses is all too frequently held, and parents are encouraged to suppose that their offspring will become normal later in life, most probably at the age of puberty. The primitive myth of a new birth at puberty survives among us in this form. All that is wrong with children is supposed to come right at puberty. Some change of personality is hoped for, whereby the dull will become bright, and the bad will become good during adolescence, though the hope is rarely sustained in the actual experiences of life. Over and over we hear the parents of defective children and others interested in their welfare, hoping and believing that all is destined to be corrected later on. The really kind thing in such cases is to disillusion them, for after all it is only the truth that can make them free, in this matter as in others.

Take, as an example of wrong management, the case of a feeble-minded woman, first seen by the 
present writer at the age of thirty-two years. Her history from the beginning is that of a defective. She was delayed in walking and talking, was never able to behave as other children behave, and could not learn at school. In the early childhood of this individual her parents had been told by the family physician that she would outgrow her peculiarities, that she was a healthy child, only a little slow in developing, but that she would gradually " catch up," and would be all right after adolescence. The parents gladly rested there so far as professional advice was concerned. They were wealthy, and insisted on sending their daughter to boarding school in the approved fashion. When she failed to progress there, they hired special teachers of French, music, and other accomplishments to give her private lessons. The result of this unwise procedure was that the girl never learned anything that was suitable to her intellectual status. Most of the information and skills that were presented to her for learning were so far beyond her capacity that she might almost as well have remained without instruction. No one thought of such a thing as teaching her to mend stockings, to do plain sewing, to wash dishes nicely, or to weave. She has a mental level of eight years, and could have learned all these things. But French syntax has utterly escaped her, and she has not mastered even the simplest melodies on the piano. It was not until after the death of both her 
parents that a sensible relative took her in charge, and secured instruction for her that was suited to her intellectual capacity, as scientifically ascertained. Being suitably occupied, she soon ceased to be destructive and ill-tempered, as she had been.

An example on a large scale of the evils of failure to identify the mentally defective during early childhood was offered some years ago by an investigation carried out at the Municipal Lodging House in New York City. This lodging house is conducted by the Department of Public Charities, and persons who find themselves shelterless and without means are at liberty to apply there for supper and bed. In the winter of 1914 two thousand successive applicants for shelter were examined physically and mentally. One in eight of the men applying was found to be so low intellectually as to be technically designated feeble-minded. Of these practically none had ever had any training in industrial processes, or in any kind of manual work. They were all " unskilled labor," having spent, on an average, several years in the public schools trying to learn the usual school subjects which they could not grasp. Their education had thus been almost wholly neglected by the state, which at the same time had spent much money offering them a training they could not use.

Ability to Learn versus Ability to Grow. From all of the foregoing discussion of this chapter it will be seen that we must make a clear distinction between 
ability to learn specific habits appropriate to a given intellectual level, and ability to change from that intellectual level to one higher. The former does not imply the latter, and of this fact those directing educational policy are becoming increasingly cognizant, as is shown by the widespread movement for the establishment of special classes in many communities.

The First Recorded Exiperiment in the Education of a Mental Defective. Bonaterre, Professor of Natural History in the Central School of the Department of Aveyron, France, reported in the year 1799 the case of a boy found in the woods, without language and behaving like a savage. Bonaterre took a philosophical interest in the lad, thinking that, "A phenomenon like this would furnish to philosophy and natural history important notions on the original constitution of man, and on the development of his primitive faculties; provided that the state of imbecility we have noticed in this child does not offer an obstacle to his instruction."

It eventually came about that Itard, a French physician whose professional interest was in deaf mutes, undertook the training of the boy, believing him to be simply "savage," and dissenting from the idea that he was an "idiot." His purpose was "to solve the metaphysical problem of determining what might be the degree of intelligence and the nature of the ideas in a lad, who, deprived from birth of all 
education, should have lived entirely separated from the individuals of his kind."

For more than a year Itard proceeded upon the assumption that he could educate the "savage," but later he became convinced that his diagnosis was in error, for he was unable to make a normal human being out of his pupil. At last abandoning hope of developing a normal intelligence in his charge by education, he exclaimed, "Unfortunate! Since my pains are lost, and my efforts fruitless, take yourself back to your forests and primitive tastes." It seemed to him at that moment, apparently, that all his labor had gone for naught. However, when the "savage" was brought again before The French Academy, the members of which had seen the lad in his former state, before his education had been undertaken, there was astonishment at the amount of improvement evident. Itard had brought about certain noticeable changes in the habits of the boy, especially in regard to simple matters like sleeping and eating, though he had not affected his general intelligence.

Thus the first recorded experiment in the education of a mental defective was of the greatest significance for the teachers of subsequent times, though its importance was not fully realized by those who carried it out. It ended as all such undertakings end, - by inculcating specific desirable habits in the child, up to the limits of his native capacity, 
without changing that native capacity. This is all that education can do for any child, normal, subnormal or supernormal.

Itard never carried his work further, but his pupil, Seguin, of whom we have already spoken, based his physiological method on the beginnings that Itard had made.

\section{REFERENCES}

1. Barr, M. W., The How, the Why, and the Wherefore of the Training of Feeble-Minded Children. Journal of Psycho-Asthenics. Sept., 1899.

2. Bonaterre, Notice Historique sur le Sauvage de l'Aveyron. Paris. 1799.

3. Itard, J., De l'Education d'un Homme Sauvage. Paris. 1801.

4. Williams, G., The Problem of Restoration; A Clinical Study. University of Pennsylvania. 1918. 


\section{CHAPTER XII}

\section{THE CAUSES AND THE PREVENTION OF MENTAL DEFICIENCY}

Prevention of Mental Deficiency Must be Based Upon Knowledge of Its Causes. We study mentally defective children in order that we may improve as much as possible those whom we find among us, but we also study them in order to learn how we may reduce their number in future generations. There has been much argument as to whether there is a place for mentally defective persons in a democratic society. It has been contended that in a democracy it is highly undesirable that there should be a considerable body of persons who are incapable by original nature of ever attaining economic or intellectual independence, even though they be well trained in the performance of automatic, routine tasks. Others argue that society needs the services of the defectives. There are and probably always will be multitudes of simple, routine tasks, which require for their performance only such abilities as the feeble-minded have. To those who take this view, it seems a veritable social blessing that there are large numbers of persons in the world who can do this essential monotonous work and find satisfaction in it. 
As one writer says, "They are the world's hewers of wood and drawers of water," who are fitted by original nature for this routine labor, from which they free the strong and able for the progress of the majority of mankind.

Whichever of these views may finally prevail, certain it is that a revision of the prevalent concept of democracy will be involved. When our forefathers believed that men were created free and equal, no psychological laboratories had been established. During the past century we have learned that all men are, as a matter of biological fact, created unequal. All that a democratic society can do is to equalize opportunity; it cannot equalize men. All that a democratic school can do is to equalize opportunity; it cannot equalize the children.

The most serious objection to the view of those who claim for the subnormal a legitimate place in the social order is that which was discussed in the chapter on instinct and emotion. It is true that all defectives above a mental level of six or seven years might well claim inclusion in the social order on the basis of sufficient usefulness. The great diffculty is that they are "irresponsible," incapable of participating in the moral and ethical ideals of the community. They fall prey over and over again to impulse, and this is inevitable, since they lack that intelligence which in the average person rules and guides conduct. 
Psychology cannot, however, solve all of these economic, social, and political problems, which are raised by the mental defectives it has revealed. A certain writer has said reproachfully, "They (the psychologists) are responsible for the feeble-minded becoming a problem." Perhaps psychologists would hesitate to assume this responsibility. Certainly the solution of the problem rests with society as a whole, especially with educators, economists, social workers, jurists, the clergy, and organized labor. Psychologists can but identify the deficient, and give information as to the causes of deficiency.

Heredity and Variation. The great majority of the subnormal originate no doubt in the same way in which all grades of intellect originate, the normal and the supernormal also, - namely, according to the biological law that like produces like, but not identical. The principle that like produces like we call heredity. The principle that offspring is never identical with parents we call variation. Subnormal parents tend to produce subnormal offspring just as superior parents tend to produce superior offspring, and mediocre parents tend to produce mediocre offspring. The question is not, Why should it be thus? The astonishing thing would be if it should be otherwise. We have been long accustomed to recognize this principle in the case of plants and animals, and in physical characteristics in the case of human beings. Research shows that the same principle holds for mental traits as well. 
Although offspring resemble their own parents and each other much more closely than they resemble parents and offspring chosen at random, brothers and sisters are never identical with their parents nor with each other. Even twins who very closely resemble each other will be seen to be somewhat dissimilar if scrutinized and measured, both physically and mentally. Why organisms should vary from type instead of being all identical, like bolts cast in a mold, we do not know. Much speculation has gone on in the matter, and much research has been carried out, yet the fundamental causes underlying variation remain largely unknown. We know neither how to control nor how to produce variations.

Samples of Studies in the Heredity of Mental Defect. The rôle played by heredity in the production of feeble-mindedness has been shown repeatedly by the students of the subject. These studies have now, indeed, become sufficiently numerous and sufficiently well known to have made a considerable impression upon people in general, who have undertaken no systematic study of the subject. Dugdale, with his report on the Jukes Family, was a pioneer in this field. Briefly, Dugdale's study embraced the members of a degenerate family, whom he called "The Jukes," for seven generations. His description is as follows:

"Between the years 1720 and 1740 was born a man who shall herein be called Max. He was a descendant of the early Dutch 
settlers, and lived much as the backwoodsmen upon our frontiers do now. He is described as a 'hunter and fisher, a hard drinker, jolly and companionable, averse to steady toil,' working hard by spurts, and idling by turns, becoming blind in his old age, and entailing his blindness upon his children and grandchildren. $\mathrm{He}$ had numerous progeny, some of them almost certainly illegitimate. Two of his sons married two out of six sisters (called Jukes in these pages) who were born between the years 1740 and 1770 , but whose parentage has not been absolutely ascertained. The probability is they were not full sisters, that some, if not all of them were illegitimate. The family name, in two cases, is obscure, which accords with the supposition that at least two of the women were half sisters to the other four, the legitimate daughters bearing the family name, the illegitimate keeping the mother's name, or adopting that of the reputed father. Five of these women in the first generation were married; the sixth one it has been impossible to trace, for she moved out of the country. Of the five that are known, three have had illegitimate children before marriage. One who is called in these pages Ada Juke, but who is better known as Margaret, the mother of criminals, had one illegitimate son, who is the progenitor of the distinctively criminal line. Another sister had two illegitimate sons, who appear to have had no children. A third sister had four, three boys and one girl, the three oldest children being mulattoes, and the youngest white. The fourth sister is reputed chaste, while no information could be gathered respecting the fifth in this respect, but she was the mother of one of the distinctively pauperized lines, and married one of the sons of Max. The progeny of these five has been traced with more or less exactness through five generations, thus making total heredity which has been enrolled stretch over seven generations, if we count Max as the first. The number of descendants registered includes $\mathbf{5 4 0}$ individuals who are related by blood to the Jukes, and 169 by marriage or cohabitation; in all, 709 persons of all ages, alive and dead. The aggregate of this lineage reaches probably 1200 persons, but the dispersions that have occurred at different times have prevented the following up and enumeration of many of the lateral branches." 
Dugdale then proceeds to show that crime, pauperism, prostitution, vagrancy, illegitimacy, and all forms of social disorder arose in the descendants of these Jukes. Many of them he calls "idiotic" or "weak-minded," but the date of publication of the study tells us that Dugdale would be unlikely to have any clear ideas as to the real relationship between the behavior of the Jukes and their probable mental status. Dugdale's thesis was that forms of behavior, - criminal tendencies and pauperism, - are hereditary; that undesirable traits are "bred in the bone." His book was published in 1877 . He was a member of the Executive Committee of the Prison Association of New York, and it was as a student of crime that he undertook his investigations. The influence of his work has been very far-reaching, for it was, as previously said, a pioneer in its field. It was first published as a part of the thirtieth annual report of the Prison Association of New York. We are told by one of his associates that, " Like all men who think in advance of their fellows, Mr. Dugdale suffered from want of public support and approbation." Within recent years many scientific workers have followed the path he pointed out, and we now have studies of "The Nams," "The Pineys," "The Hill Folk," "The Zero Family," "The Family of Sam Sixty," and "The Kallikaks." These studies are all more or less closely modeled on "The Jukes." The method of investigation is to send out field 
workers, who trace out as many relatives of the stock being investigated as possible, and gather information as to their status and characteristics by questioning, interviewing the persons themselves, and making inquiries of neighbors, "oldest living inhabitants," and the like. In 1915 an investigator, Dr. Estabrook, brought "The Jukes" up to date, showing their descendants in this generation to have the same characteristics as those described in their ancestors by Dugdale in 1877.

"For the past 130 years they (the Jukes) have increased from five sisters to a family which numbers 2094 people, of whom 1258 were living in 1915. One half of the Jukes were and are feebleminded, mentally incapable of responding normally to the expectations of society, brought up under faulty environmental conditions, which they consider normal, satisfied with the fulfillment of natural passions and desires, and with no ambitions or ideals in life. The other half, perhaps normal mentally and emotionally, has become socially adequate or inadequate, depending on the chance of the individual reaching or failing to reach an environment, which would mold and stimulate his inherited social traits."

In a detailed estimate of crime, pauperism, disease, and debauchery, Estabrook estimates that the descendants of the five Juke sisters have cost the taxpayers of the communities where they have resided, about $\$ 2,516,685$ in money, aside from the trouble and contamination of which they have been the source.

One of the most widely known of similar studies is that of the Kallikaks, reported by Dr. Goddard. Martin Kallikak, a soldier in the Revolutionary war, 
had an illegitimate son by a feeble-minded girl, whom he met in a tavern. In 1912 there were 480 traceable descendants of this union, 143 of whom were known as feeble-minded, and many others of whom were of questionable mentality. The anti-social conduct of these descendants makes a long history.

After his return from the war, Martin Kallikak married a girl of good family. Of the descendants of this union 496 individuals were traced. No feeble-minded person was found among them. On the contrary, lawyers, educators, traders, physicians, and landowners predominated among them, and there were no criminals.

It detracts somewhat from the value of these studies that they rest upon the opinions of neighbors and field workers to so great an extent, and that mental deficiency has to be inferred from undesirable behavior. There still remains to be made a study - of equal scope, in which all relatives shall actually be measured intellectually, by the psychological method.

Mental Deficiency is Inherited. There is now no competent student of the heredity and transmission of mental traits who would dissent from the statement that feeble-mindedness is hereditary. Feebleminded and neuropathic parents produce feebleminded offspring. Heredity is the source of most of the mental deficiency with which the social order is burdened. This conclusion rests not only upon studies of the ancestry of subnormal children, but 
also upon studies of the ancestry of average and of superior persons, both children and adults. In a remoter sense it rests, furthermore, upon studies of the heredity of physical and motor characteristics of animals, and even upon the study of inheritance in plants. Throughout organic nature we find experimentally the operation of the law that "like produces like." Subnormal children are so, because they spring from the inferior germ-plasm of an inferior ancestry. Usually the parents themselves show the inferior mental traits, but occasionally the inferiority is found among grandparents, or other remote progenitors, the parents themselves being of normal ability.

The Nature of Heredity. This possibility of the inheritance of mental deficiency from an ancestor more remote than the parents exists because of the nature of inheritance. Persons who have made no close study of the subject usually assume that children spring from their parents' bodies and minds. The blood has been thought to be particularly involved, as is shown in such expressions as "He came of bad blood," "She came of such-and-such blood," "The blood of so-and-so flows in their veins." The science of biology has revealed, however, that children spring not from their parents' bodies and minds, nor from their blood, but from the germ-plasm of which their parents are merely the carriers. This germ-plasm, in the form of ova and spermatozoa, 


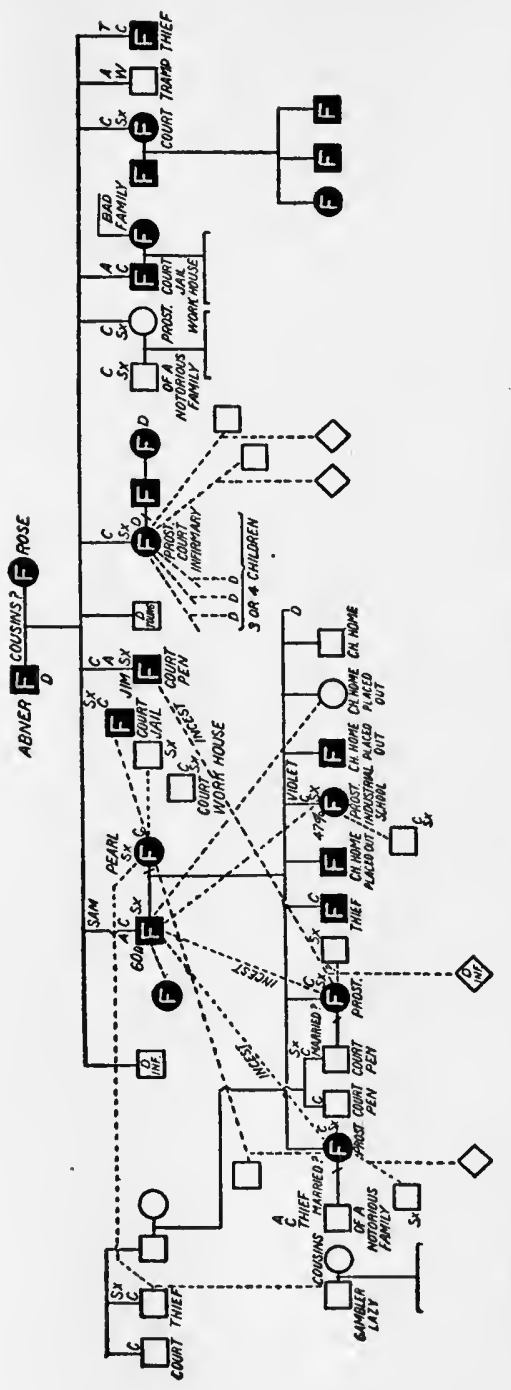

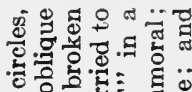

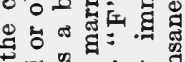

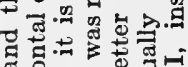

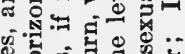

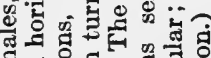
घ《.․․․․․

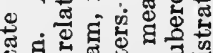
.

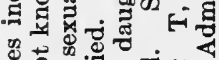

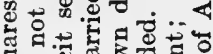

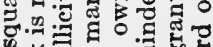

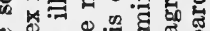
of

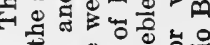

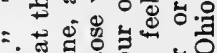

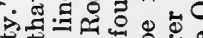
初 क ज्ञ

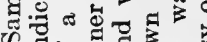

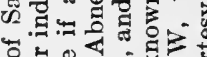
o 5 造

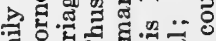
a 舟

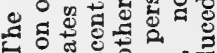

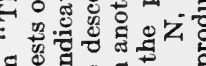

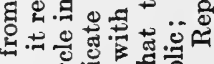

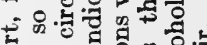
형 讨 等. 然

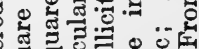
政 प्र 1 क

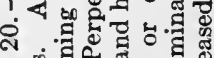

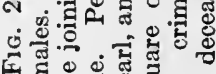

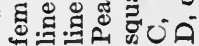


is continuous from generation to generation. The body of the adult organism does not manufacture germ cells, upon which it impresses various influences contributed by other cells, such as the nerve cells, the blood cells, the cells of the muscles, and so forth.

Conklin has stated these facts with admirable clarity as follows:

"Thus the problem which faces the student of heredity has been cut in two; he no longer inquires how the body produces the germ cells, for this does not happen, but merely how the latter produce the body and other germ cells. The germ is the undeveloped organism which forms the bond between successive generations; the body is the developed organism which arises from the germ under the influence of environmental conditions. The body develops and dies in each generation; the germ-plasm is the continuous stream of living substance which connects all generations. The body nourishes and protects the germ; it is the carrier of the germ-plasm, the mortal trustee of an immortal substance."

Our knowledge of these principles is due largely to the researches of the biologist Weismann. Since children are not in a fundamental sense the product - of their parents' bodies and minds, but of the germplasm which is continuous from generation to generation, and of which their parents are merely the temporary carriers, it follows that children may resemble remote ancestors, who were products of this same continuous germ-plasm. Which ancestors an unborn child will most resemble it is almost wholly impossible to predict in the present state of knowledge. 
Parents who are ill-informed concerning the principles which have just been stated, often undertake to determine the traits of unborn children by exercising their own minds and bodies in various ways. For example, the writer has among her acquaintances an intelligent, but uninformed woman, who read political dissertations throughout the months of pregnancy, because she and her husband desired a son who would have a political career. Another believes that her child was born with a red mark on his finger because she cut her own finger previous to his birth. Such beliefs have no foundation in fact. Pre-natal influences of this character do not exist. The only possible influence which the parental body, including the nervous system, can exercise upon the germ-plasm, or upon the developing embryo, is by interfering with its nourishment, or by poisoning it with chemical toxins.

There are many other complicated questions about the nature of heredity, which at present occupy much of the research time of scientific thinkers. All traits are not inherited according to the same laws. For instance, certain traits in human beings appear to be Mendelian, so called because they are inherited according to the laws which were discovered by Gregor Mendel to hold in the case of peas. Such a trait, apparently, is eye-color. If a member of a blue-eyed family mates with a member of a brown-eyed family, the descendants do not have eyes which are a mixture 
of blue and brown. Their eyes are either brown or blue, according to the combinations of eye-color found in subsequent matings from generation to generation, but they do not eventuate in a new bluebrown blend of eye-color. On the other hand, skincolor seems to follow a different law. If a member of a black-skinned race mates with a member of a whiteskinned race, the result is the brown skin of the mulatto. Here we have a blend of qualities, giving us an intermediate condition. Very much discussion has gone on among those best qualified to consider the question, as to whether mental deficiency is inherited according to the Mendelian law, according to the law of blending, or according to some still different law, at present not suspected. No agreement has been reached, for research is not yet sufficiently extensive. It is known that mental deficiency is transmissible through the germ-plasm, but according to what formula we do not know.

Alleged and Possible Causes of Deviation in the Direction of Subnormality. It has been stated that children are never identical with any ancestor. It is one of the marvelous facts about every human being that he is absolutely unique in the history of the race. There has never been another exactly like him, and there will never be another identical with him. It was also stated that we do not understand the laws governing these deviations, and cannot predict in what direction an unborn child will vary from the 
mental and physical status of his parents. Various theories have, however, been advanced in the attempt to explain mental deviations in the direction of subnormality as the result of influences external to the germ-plasm, acting either before or after the conception of the individual. Advocates of these theories believe that by removing the supposed external causes of subnormality, we might solve the problem of mental deficiency without becoming involved in the troublesome ethical and social considerations which arise with the question of preventing procreation by the unfit. It will be profitable to examine these theories at some length.

Alcoholism and Other Conditions in the Parents. It is possible that chemical changes in the bodies of human beings may affect the germ-plasm of which they are the carriers. Such conditions as lead-poisoning, alcoholism, chronic disease, partial starvation, might conceivably vitiate a potentially normal germplasm in such a way that mentally inferior children would be produced in consequence.

That such conditions actually. do have such consequences has never been scientifically demonstrated. It is impossible to experiment with human beings because they breed so slowly, and because there is a strong prejudice against biological experimentation on mankind. Thus, all we have that bears upon our question in the case of human beings is a collection of anecdotes, some of which show that a chronically 
ill, alcoholic, badly-nourished, or over-fatigued parent produced a feeble-minded child; others of which show that another parent, affected in the same manner, produced a superior child. No conclusions whatever can be drawn from such material.

Similarly valueless are the statistics which show that many parents of feeble-minded children are alcoholic. It is not permissible to conclude that one phenomenon is the cause of the other, simply because they accompany each other. Indeed, it is most reasonable to infer that feeble-mindedness causes alcoholism, and that the parents of feeble-minded children are alcoholic because they are mentally deficient, and unable to perceive or to appreciate the poverty, misery, and general ruin which drunkenness brings.

Experiments like those which Dr. Stockard has performed in the alcoholization of guinea-pigs are very suggestive in this connection. Here adult guinea-pigs of both sexes were subjected to the fumes of alcohol, and it was found that their offspring were greatly reduced in number, with many stillbirths, and were weak and sickly. Though it is a long leap from the physical life of guinea-pigs to the mental life of man, such experiments suggest that we may sometime find chemical properties of the parental body to be influences making for deviation in the direction of subnormality.

Sensory Defects. It is not very unusual to read 
that mental deficiency has been overcome in some child by the simple expedient of fitting him with glasses. What is meant in these cases is that the child was able to go forward in school, and improved in conduct after being fitted with glasses. School work and conduct are dependent upon eye-strain as well as upon innate intelligence, and may be modified by relieving the former, without reference to any change whatever in the latter. An inferior intelligence cannot be improved by correcting a sensory defect.

On the other hand, it is a question as to how much, if at all, a good intelligence may be hindered from developing by the lack of a means of contact with the objective world. Psychologists are gradually accumulating information about the intelligence of the blind and the deaf and dumb, but no systematic body of knowledge is as yet available. In general it appears in mental tests that children who suffer from severe sensory defects, total blindness or total deafness, are somewhat behind seeing and hearing children in their mental development; that total deprivation of a special sense is an influence making for subnormality in intelligence. Slight sensory defects probably have no effect, as they are found among children of all degrees of intelligence, among the very superior as well as among the very deficient. Dental Caries, and Defects of the Teeth. Bad teeth have been alleged as a possible cause of mental 
subnormality. As in the case of eye defects, it has been said that intellectual deficiency may be corrected by proper dental treatment, the statement resting on the fact that school work and conduct have been improved thereby. Since school work and conduct may be seriously interfered with by toothache, it follows that both may improve greatly after the teeth have been repaired, without reference to any modification of the intelligence.

In order to determine the effects of any physical condition on mental conditions, it is necessary to carry out systematic and carefully controlled experiments on children whose intelligence has been accurately measured, including always the precaution of the "control group," (as seen in the case of Woodrow's experiments on learning). The only actual experiments which have been made in the attempt to determine the influence of dental conditions upon mental subnormality have, unfortunately, neglected the check of the "control group," so that the results cannot be interpreted. These were experiments performed on twenty-seven children, who were suffering from disorders of the teeth and gums. Before treatment they were given five psychological tests. During the course of the treatment and after its termination, the same five tests were given four times, in only slightly modified form. The last trial showed very great improvement over the first trials, but we are by no means justified in concluding that 
the correction of dental disorders had an influence in bringing about this improvement. We know from the psychology of practice and learning that these children would have done much better on the last trial than on the first trial even if their teeth had never been treated. All of the improvement may well be due to practice.

This investigation should be repeated, using at the same time a. "control group" of children of equal ability, suffering to an equal extent from the same kind of dental disorders, who should take the tests exactly as the children who undergo treatment do, but who should not themselves be treated during the course of the experiment. If the treated group showed a reliably greater improvement than the " control group," we should be justified in concluding that the difference must be ascribed to the correction of dental conditions.

It is therefore an entirely open question whether carious teeth may exert an influence making for subnormality in intelligence, as children develop. That such is the case seems scarcely probable in view of the fact that a large percentage of children of very superior intelligence are found to be affected in this way.

Tonsils and Adenoids. Some' years ago the removal of tonsils and adenoids was advocated by certain enthusiastic persons as a remedy for mental deficiency. Many parents of feeble-minded children 
were led to believe that the removal of these portions of the anatomy would result in normal intellectual development, and the present writer has repeatedly been a witness to the bitter disappointment and resentment of parents, who for years had cherished the false belief that a deficient child would be "cured" by this operation.

The conduct and school work of a child are frequently improved by the excision of tonsils and adenoids, for a child will usually apply himself more effectually to tasks demanding effort if he is physically comfortable. But no scientific evidence exists to show that this operation ever has the slightest effect on the intelligence quotient. Any statement of value would necessarily be based on experiments conducted by the method suggested in the case of carious teeth, and such experiments have never been performed. The fact that adenoids and abnormal tonsils are found with as great frequency among average and superior children as among subnormal children gives a priori reason for supposing that experiment would reveal no connection between intelligence and tonsils and adenoids, although between school progress and the latter a connection might well exist.

Malnutrition. Malnutrition is frequently alleged as a cause of mental backwardness, and indeed malnutrition and anæmia are undoubtedly capable of producing a listlessness and inattention which conduce to poor school work, and hence to retardation 
in school status. However, here, as in the casc of other physical defects, we have no scientific experiments to guide our conclusions. We do not know as a scientific fact that malnutrition can affect the intelligence quotient of a child in the slightest degree.

The proponents of the theory that such an effect will be demonstrated, point out that all tissues of the body are susceptible to starvation, and it is only reasonable to suppose that the nervous system, being a tissue of the body, is no exception to the rule. Nothing is proved, however, by this kind of thinking, for it may well be that the tissues of the body nourish themselves selectively upon the available food; so that the nervous system might grow and function at the expense of other tissues.

Recently Dr. Blanton has made an attempt to approach this question scientifically. Among school children in Trier, Germany, who had suffered severely from malnutrition during the war, a decided increase in scholastic retardation was found. Upon inquiry a large number of children were considered by rektors or teachers as probably subnormal infellectually. The direct examination of intelligence by psychological methods is given for thirty children, who had suffered severely from lack of food, but from whose personal and family history a normal intelligence would be expected. It is not possible to base reliable statements upon thirty cases, in attempting to 
compare the distribution of these children with the normal curve. Nevertheless, it is of interest to know that so far as the figures go, the result showed no deviation from normal expectation. Of the thirty children selected as described, twenty-three fell within the norm; while three showed superior intelligence, and four showed intelligence below the average, falling between eighty IQ and ninety IQ. This is what we should expect among well-nourished children so selected, anywhere.

The investigator concludes that malnutrition extending over a period of two years causes decrease in nervous and physical energy, and changes in the attitude of children toward school work, but that children of superior or average intelligence can withstand malnutrition of even a serious degree, extending over more than two years, without any impairment of the intelligence. He adds that " children of poor or inferior intelligence suffer a general and sometimes permanent lowering of the whole intelligence level, from even a moderate degree of malnutrition." This latter statement does not, however, rest upon any acceptable objective evidence presented. The results from the thirty children objectively measured do not furnish a basis for the inference, since it would be quite as logical to attribute the superior intelligence unexpectedly found among them to malnutrition, as to attribute the inferior intelligence unexpectedly found to this cause. 
Of course a great many of the subnormal children who are examined in schools and on clinics are under-nourished, but it would be very unscientific to conclude from this fact that malnutrition caused the mental dullness. The most reasonable interpretation of such correlation as may exist between malnutrition and mental deficiency is that mentally inferior parents produce mentally inferior children, and at the same time are unable, on account of their inefficiency, to provide adequate food for them. We should expect, of course, that because of the laws of heredity stupid children will be ill-nourished more often than intelligent children. The same remarks would apply to the supposition that mental deficiency may be caused by poor home conditions.

Institutional Life. Another cause of low intelligence that is alleged repeatedly in diagnoses is institutional life. A child is said to be "retarded, due to institutional life." A prospective adoptive parent, seeking professional advice, is told that he will be doing well to take the child, for though he is one or two or three years below the norm in intelligence, this is "due to institutional life," and he will become "a bright child" once he is out of the institution.

Here obviously we have to deal with the familiar fallacy. We should expect that "institutional life" and mental subnormality will frequently occur together, not because orphanages produce deficiency in 
children, but because of the laws of heredity. Dull parents are unable to provide properly for their children, and they also feel less responsibility for their offspring than do intelligent parents. Hence their dull offspring are many times more likely to become the wards of charitable institutions than are the children of competent, intelligent parents.

By these remarks we do not, of course, understand that there are no normal and superior children in orphanages. There are many, for accident sometimes carries off very young parents, who have not yet had a chance to establish economic security, and whose relatives are in other lands. Sometimes illegitimate children are left at the doors of foundling asylums, whose parents are of good intelligence, but wish to avoid social disapprobation. A great disaster like a war or an epidemic operates to fill orphanages with children of good quality. Sometimes parents of good intelligence are physically weak, and for this reason are compelled to give their children over as public charges. Thus we do find children of all degrees of intelligence in institutions. The median for children in institutions is, however, distinctly below the median for children chosen at random, and the chances of finding subnormal children as dependent are very great.

In order to determine scientifically the effects of institutional life as contrasted with good home conditions upon the intelligence quotients of children, 
it would be necessary to take a large number of young children with high intelligence quotients, and subject them to institutional life for a term of years, to see whether they became reduced below their original status. Similarly it would be necessary to take a large number of young subnormal children from institutions, and subject them to the influences of good home conditions for a term of years, in order to see whether they would thus be raised toward normality. No one has ever performed this crucial experiment, although the latter half of it might easily be undertaken by a psychologist comnected with a bureau of child-welfare.

Hookworm and Malaria. In the case of hookworm and malaria among the children of the South in the United States, psychologists have carried out some experimental investigation. In 1916 the International Health Commission published the report of psychological investigations by Dr. E. K. Strong, $\mathrm{Jr}$., in which all the essentials of scientific method were carefully observed. Mental tests were given to four groups of school children, $(A)$ uninfected children, $(B)$ children infected and not treated, $(C)$ children treated and completely cured, and $(D)$ children treated but not completely cured.

These children were all tested psychologically before any treatment whatever was instituted, and were re-tested at the expiration of .3 of a year. The results of the study are difficult to interpret, as 
contradictory tendencies are shown in the various tests employed. In opposites, logical memory, memory span, and handwriting the infected, but not treated, (group $B$ ), were decidedly inferior to the treated and cured groups in the amount of improvement shown in .3 of a year. In calculation, formboard ability, and general intelligence the infected, but not treated, (group $B$ ), surpassed the treated and cured groups in amount of improvement during the interval. When the percentages of gain in all the tests given are tabulated, the result is as shown in the following table:

Showing the Gain in Each of Seven Mental Tests for the Four Grodps of Children

(Strong)

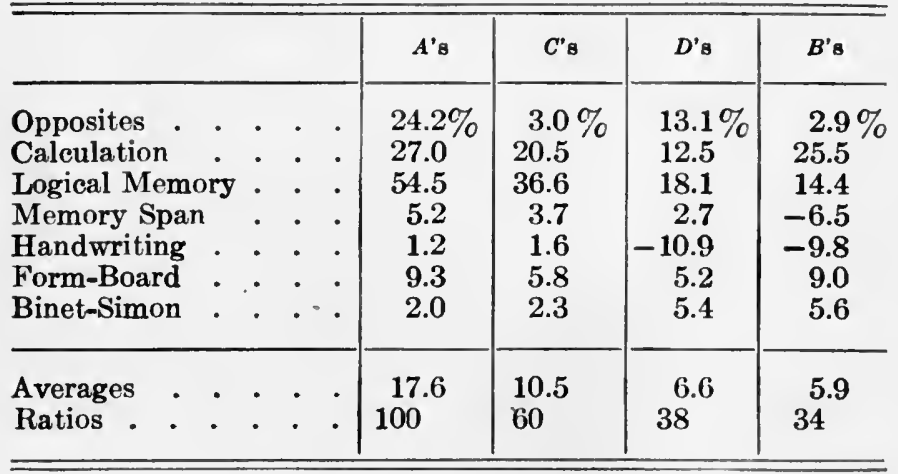

When the results from all the tests are combined as above, the average shows that the infected and not treated group (group $B$ ) is decidedly behind the treated and cured group (group $C$ ) in amount of im- 
provement over a period of .3 of a year. It is questionable, however, whether it is legitimate to combine the results from the Binet-Simon Measuring Scale for Intelligence in this manner with the other single tests, because it is not a test, but a combination of many tests, and the results from it are much more reliable for this reason than are the results of any single test.

On the Binet-Simon Measuring Scale the results were as follows:

The Average Age, both Actual and Mental, of Children Treated and Not Treated for Hookworm, Together with the Gain Made dering a Period of .3 of a Year

(Strong)

\begin{tabular}{|c|c|c|c|c|c|c|c|c|}
\hline GrodPs & \multicolumn{2}{|c|}{$A^{\prime}$ s } & \multicolumn{2}{|c|}{$C^{\prime} \mathrm{s}$} & \multicolumn{2}{|c|}{$D^{\prime s}$} & \multicolumn{2}{|c|}{$B^{\prime}$ s } \\
\hline Time of Exam. & before & after & b. & a. & b. & a. & b. & a. \\
\hline No. of Cases & 18 & 18 & 26 & 26 & 17 & 17 & 9 & 9 \\
\hline Av. Act. Age . & 11.1 & 11.4 & 10.9 & 11.2 & 11.1 & 11.4 & 10.6 & 10.9 \\
\hline Av. Ment. Age & 10.1 & 10.2 & 9.3 & 9.6 & 8.9 & 9.4 & 9.4 & 10.0 \\
\hline Gain Act. Age . & $\cdots$ & 0.3 & $\ldots$ & 0.3 & $\ldots$ & 0.3 & $1 .$. & 0.3 \\
\hline Gain Ment. Age & & 0.1 & .. & 0.3 & $\ldots$ & 0.5 & $\ldots$ & 0.6 \\
\hline
\end{tabular}

The figures show that the infected children who were not treated made a greater gain in the development of general intelligence than did those who were treated and cured.

It is true that this experiment extended over a very short time, and it is possible that the lapse of a year or of two years might show a more impressive 
gain in those treated and cured. Dr. T. L. Kelley made a similar experiment with school children in the State of Texas, using educational tests instead of mental tests. His experiment extended over six months, and he investigated the effects of malaria as well as the effects of hookworm. Unfortunately no group corresponding to group $B$ in Dr. Strong's experiment was used by Dr. Kelley, so that it cannot be stated in connection with his work what amount of gain would have been made in the educational tests by a group of children infected with malaria or with hookworm, but not treated. It can only be stated that children cured of disease gained in these tests slightly more than did children tested in the same manner and on the same occasions, who had not been infected at all with the diseases under investigation. From this it is suggested that hookworm and malaria are influences making for retardation in school subjects, since when they are removed there is a greater gain than with healthy children. The influence shown is not great, however, and not entirely consistent, as in the Courtis Tests in the fundamentals of arithmetic the cured-of-disease group showed less improvement than did children who had never had the diseases, and from whom no such handicap was therefore removed.

The Experimental Literature on the Relation between Physical and Mental Is Very Meager. The investigations of hookworm and malaria outlined 
above, have been considered at length because they are samples of the kind of laborious work that must be done before any body of truth can become available on the subject of the influence of physical conditions upon the development of intelligence. In no branch of child study is research more needed and at the same time more conspicuously lacking. General discussion, both printed and oral, abounds, but general discussion is of no value except in so far as it may be the preliminary to objective and controlled experimentation.

The subjective opinion of a physician who treats a physical disorder, as to the amount of mental development taking place in consequence, is not at all reliable. He is limited by the same laws which govern all human psychology. He will be almost certain to see improvement, where he is persuaded that it should and does exist. Nothing is reliable except objective measurements, made by trained persons, and these have been recorded in only a few instances.

The lack of data does not, of course, prevent a great number of positive statements from being made. Every specialist tends to believe that the remedy for mental subnormality lies in curing the physical or social conditions which lie within his own field. What we must demand from all who speak is not their opinion, however, but objective measurements made by competent experts. It is necessary 
for us all to bear continually in mind the nature of evidence, so that we may not be misled by anecdotes.

Children of Very Superior Intelligence Also Have Physical Defects. One fact which renders doubtful the hope that we shall be able to overcome mental subnormality to any very marked extent by the correction of physical defects is that we find these physical defects among children of the very highest intelligence, as well as among those who are the most inferior. Among twenty-five public school pupils chosen by mental tests to form a special class for gifted children, the following physical defects were subsequently found:

Physically perfect . . . . . 6

Carious teeth . . . . . . . . 9

Enlarged tonsils . . . . . . 5

Defective nasal breathing . . . . 2

Orthopedic defects . . . . . . 2

Malnutrition . . . . . . . 9

Overweight . . . . . . . . . 2

The intelligence quotients and the number of grades covered in one term by the children having these physical defects appear in the table on the following page. The median IQ is seen to be 137 . The median grade progress is 22 grades for the term.

One would be laughed out of court who would undertake to prove the very superior intelligence of these children to be due to their carious teeth, 
enlarged tonsils, malnutrition, and so forth. And yet the same array of data in the case of the subnormal has sometimes led to an inference as inadmissible. The fact is that we find physical defects scattered throughout the whole range of intelligence, and the relation between the two is almost wholly unknown, except in the case of neurological disorders.

Age, IQ's, and Grade Progress of Children Having the Physical Defects Listed Above

(Specht)

\begin{tabular}{l|c|c|c||c|c|c|c}
\hline \hline \multicolumn{1}{c|}{ B. } & AGE & IQ & G.P. & G. & AGE & IQ & G.P. \\
\cline { 5 - 7 } H.S. & $11^{8}$ & 150 & 2 & S.F. & $10^{4}$ & 161 & 3 \\
W.H. & $9^{5}$ & 149 & 2 & H.W. & $10^{2}$ & 154 & 3 \\
A.B. & $10^{4}$ & 147 & 2 & S.S. & $11^{3}$ & 144 & 2 \\
R.P. & $9^{7}$ & 146 & 3 & R.H. & $11^{5}$ & 141 & 2 \\
I.K. & $11^{1}$ & 146 & 3 & H.G. & $10^{2}$ & 130 & 2 \\
S.R. & $10^{2}$ & 143 & 2 & R.B. & $10^{5}$ & 137 & 3 \\
P.P. & $10^{6}$ & 138 & 2 & E.P. & $10^{8}$ & 137 & 3 \\
P.M. & $9^{8}$ & 137 & 3 & A.S. & 10 & 136 & 3 \\
E.R. & 10 & 133 & 4 & D.M. & $10^{5}$ & 132 & 1 \\
V.S. & $9^{10}$ & 131 & 2 & R.S. & $10^{7}$ & 133 & 3 \\
H.L. & $10^{1}$ & 127 & 2 & S.B. & $10^{2}$ & 122 & 2 \\
H.R. & $11^{2}$ & 123 & 2 & & & & \\
N.W. & $10^{5}$ & 122 & 2 & & & & \\
H.G. & $10^{10}$ & 117 & 2 & & & & \\
& & & & & & & \\
\hline \hline
\end{tabular}

Physical Defects Should Be Corrected for the Sake of General Health. It goes without saying that a child's teeth should be filled if any are decayed; that his sensory defects should be corrected, if they are corrigible; that any obstruction in the respiratory tract should be removed; that any and all diseases and 
disorders should be detected and treated. Every child should be kept at what is for him the maximum of physical health. Physical strength is one of the most important determinants of achievement, and should be conserved on its own merits. But we must guard against the supposition that by conserving physical health, and correcting anatomical defects, we shall be able to solve the problem of mental deficiency.

The Prevention of Mental Deficiency. The known fact that stands out most clearly in a consideration of the causes of mental deficiency is that it is hereditary. Feeble-mindedness is transmissible through the germ-plasm, and a large majority of the defective, variously estimated at from eighty-five to ninety-five percent, show " a bad family history," either maternal or paternal, or both. Since this is so, it follows that the prevention of mental deficiency in the population can be accomplished only by preventing defective persons from procreating.

Since this realization has dawned upon the informed public many so-named eugenic movements have been organized. These organizations have for their object the formulation of plans whereby the propagation of the inferior may be prevented. Now, it is apparent that this aim will be very difficult of attainment. Such plans run counter to one of the strongest of human instincts, which, as has been said, is well developed in the feeble-minded; namely, the 
sexual instinct. They also run counter to the firmly established principle that "all men are created equal; that they are endowed by their creator with certain inalienable rights." In a democracy no one feels fully qualified to "pass upon" the biological rights of another, even though that other may pilfer his goods, contaminate his children, and be supported at his expense in prison, almshouse, or refuge.

Two general schemes have been proposed for reducing the number of defectives born into the world: (1) the segregation of all mentally deficient adults during the reproductive period; (2) the artificial sterilization of mental defectives by surgical means. That there are serious practical objections to both plans is evidenced by the fact that neither of them is in operation, or seems likely to be put into operation soon. The objection to the first plan is that of the great expense involved. A conservative estimate of the number of defectives at present at liberty, as compared with the facilities now provided for their detention, indicates that expenditures on an enormous scale would be necessitated in order to segregate all of a state's defectives for the reproductive period of their lives.

The objections to the second plan, that of sterilization, are chiefly objections of sentiment. Here as elsewhere, there is a wide gap between the theory of what should be done, and actual realization in conduct. In states where sterilization is legalized it is 
carried out with relative infrequency. The law will have to make sterilization mandatory, not permissive only, before such measures will become effectual; and the consensus of opinion seems to be that knowledge should be much more extensive than it is at present, in order to justify such mandatory legislation.

\section{REFERENCES}

1. Bigelow, M. A., Contributions of Zoology to Human Welfare. Science. July 5, 1918.

2. Blanton, S., Mental and Nervous Changes in the Children of the Volksschulen of Trier, Germany, Caused by Malnutrition. Mental Hygiene. July, 1919.

3. Bryant, L. S., Unstable Diastolic Blood Pressure and Feeble-Mindedness. School and Society, Feb. 20, 1915.

4. Conklin, E. G., Heredity and Environment. Princeton University Press. 1917.

5. Courtis, S. A., Measurement of the Relation Between Physical and Mental Growth. American Physical Education Review. Nov., 1917.

6. Dawson, W. J. G., Results Obtained from the Removal of Tonsils and Adenoids in the Feeble-Minded. Journal of PsychoAsthenics. March and June, 1918.

7. Davenport, C. B., Heredity in Relation to Eugenics. Henry Holt and Company, New York. 1911.

8. Dugdale. R. L., The Jukes. G. P. Putnam's Sons. New York. 1877.

9. Estabrook, A. H., The Jukes in 1915. Carnegie Institution of Washington. Washington. 1916.

10. Estabrook, A. H., and Davenport, C. B., The Nam Family. Eugenics Record Office. Cold Spring Harbor, New York. 1912.

11. Foster, J. C., A Case of Intellectual Development Despite Enforced Seclusion. Journal of Applied Psychology. June, 1919.

12. Goddard, H. H., Feeble-Mindedness: Its Causes and Consequences. The Macmillan Co., New York. 1914.

13. Goddard, H. H., The Vineland Experience with Pineal Gland Extract. Journal of the American Medical Association. May 5, 1917. 
14. Haines, T. H., Wassermann Reactions of Juvenile Delinquents. Journal of the American Medical Association. Jan. 8, 1916.

15. Kelley, T. L., The Effect of Hookworm and Malaria upon Physical and Mental Development of School Children. Elementary School Journal. Sept., 1917.

16. Keyes, H. B.. Effect of Outdoor and Indoor School Life on the Physical and Mental Condition of Children. Fourth International Congress on School Hygiene. Buffalo. August, 1913.

17. Kite, E. S., "The Pineys." Survey. Vol. 31: 7-14. 1913.

18. Kostir, M. S., The Family of Sam Sixty. Ohio Board of Administration. Columbus. 1916.

19. Peters, A. W., Relation of Biochemistry to the Problems of Psychopathology. Journal of Psycho-Asthenics. 1912.

20. Pintner, R., and Paterson, D. G., The Form-Board Ability of Young Deaf and Hearing Children. Psychological Clinic. Jan., 1916.

21. Pintner, R., and Paterson, D. G., Learning Tests with Deaf Children. Psychological Monographs. Vol. XX, No. 4. Jan., 1916.

22. Pintner, R., and Paterson, D. G., A Measurement of the Language Ability of Deaf Children. Psychological Review. Nov., 1916.

23. Southard, E. E., The Correlation of Brain Anatomy, Mental Tests and School or Hospital Records in a Series of FeebleMinded Subjects. Journal of Nervous and Mental Disease. 1916.

24. Specht, L. F., A Terman Class in Public School No. 64, Manhattan. School and Society. March 29, 1919.

25. Strong, E. K., Effects of Hookworm Disease on the Mental and Physical Development of Children. International Health Commission. Bulletin No. 3. Rockefeller Foundation. New York. 1916.

26. Thomson, J. A., Darwinism and Human Life. Henry Holt and Company, New York. 1910.

27. Wallin, J. E. W., Experimental Oral Euthenics. Dental Cosmos. 1912.

28. Wallin, J. E. W., Experimental Oral Orthogenics. Journal of Philosophy, Psychology and Scientific Methods. 1912.

29. Weismann, A., The Germ Plasm. Walter Scott. London. 1893. 


\section{CHAPTER XIII}

\section{SECONDARY CASES}

A Small Percentage of Mental Deficiency is Due to Disease of the Nervous System. As we have already stated, research points to the conclusion that approximately 90 percent of the mentally subnormal are the products of inferior germ-plasm. The remainder are the victims of organic causes, and are in a true sense pathological cases. In such cases the mental deficiency is said to be secondary, meaning that it depends on and is a consequence of some underlying misfortune to the nervous tissue, but for which the child would have been of normal intelligence. Since the nervous system is the physiological mechanism fundamental to the psychological life, destruction or disease of its elements may result in psychological abnormalities. In the case of young children, disease of the nervous system may result in failure to develop intellectually. These are the true cases of arrested development, previously mentioned, and to be described here in some detail.

Syphilis. This disease is directly responsible for a smaller proportion of mental deficiency in children than was formerly supposed. No doubt this is due 
to the fact that syphilis causes sterility, abortion, and infant mortality, so that few offspring of syphilitic parents live to show mental deficiency. Syphilis is an organic disease, to which various tissues of the body are susceptible, the nervous tissue among them. If it attacks the nervous tissue of a young child, the typical result is mental deficiency. If it attacks the nervous tissue of an adult, the typical results are ataxia, intellectual deterioration, general paresis.

Many children whose mental deficiency is due to syphilis deteriorate as they grow older, and follow the ordinary course of general paresis. They are then classified under the concept of juvenile paresis. The mental condition is not recoverable, though treatment ordinarily given in cases of syphilis is often effective in allaying active physical symptoms.

There are certain typical clinical features which characterize these children. The bridge of the nose is often lacking, there being merely a flat space between the eyes. In many cases the incisors are pegshaped, and notched on the edge, being termed "Hutchinson's teeth." The reflexes are in the majority of cases disturbed. There is a positive reaction in the Wassermann test of the blood.

Ductless Glands. It is well known that mental deficiency may result from malfunctioning of the thyroid gland. If during the years of growth this gland does not secrete its product into the system, the result is a child showing the following character- 
istics: stunted physical growth, spade-shaped hands and feet, legs short and bowed, a broad nose, a thick, coarse tongue, and a sallow, parchment-colored skin, which is dry, rough, and so redundant that it wrinkles on the face and scalp. The tout ensemble gives us a gnome-like little creature, easily recognized for what he is by one who has seen many cases so affected.

These children are called cretins. The specific medicinal treatment is thyroid extract, and if the case is diagnosed in the first year of life, and treated regularly and persistently during life, the individual may in some cases approximate normal development. In other cases no effect of the treatment can be noted. What the result of treatment will be in any given case is, therefore, unpredictable. The most common result seems to be that there ensues improvement in both mental and physical condition, even in cases neglected beyond infancy. Treatment is sometimes conducted surgically, by the transplantation of a thyroid gland from the neck of an animal to the body of the affected child. Favorable results have been reported from such operations, but in any given case the outcome is unpredictable.

Cretins differ widely with respect to intelligence. Some never develop above a mental level of three years. Others approximate normality, both mentally and physically. The present writer knows of one case, that of a girl of seventeen, who was suffi- 
ciently intelligent to hold a position at simple, routine clerical work in an office, and yet in whose case a diagnosis of cretinism was made after consultation among several competent specialists, on the basis of the clinical features presented. The symptoms were mild but typical. The physique was stunted, the extremities were blunt and spade-like, the skin was sallow, with a tendency to be redundant, there was a history of slow development, and the physiological changes normal at adolescence had not taken place. This case illustrates the range of severity in cretinism.

The principles underlying the education of cretins are the same as in mental deficiency in general, except for the fact that they are especially characterized by poor motor control. Their gait is ungainly, they manage their bodies poorly, and are not as near the norms as are ordinary feeble-minded children in ability to make eye-hand coördinations. Thus on the whole they will not be very well adapted to manual training.

The discovery of the fact that cretinism is due to malfunctioning or absence of the thyroid gland has led to the expectation that other cases of mental deficiency may finally be traced to abnormalities of various ductless glands. There have been attempts to treat mentally subnormal children with extract from the pituitary gland, from the thymus gland, and with other endocrine substances. No convincing 
results of such treatment have been reported. Such reports as have been scientifically made give the result of experimentation as negative.

Experimentation in the matter of the influence of the ductless glands upon anatomical and physical anomalies is, however, making progress. It is well established that malfunctioning of the pituitary gland affects physical growth. Dr. Walter H. Eddy has recently established in experiments carried out at the New York Hospital, that substances extracted from the pancreas of a sheep very clearly affect the physical development of rats when administered to them. Thus within the next century there may come about a much closer contact between endocrinology and psychology than has existed hitherto.

Abnormal Growths in the Brain. Tuberous or nodular growths in the brain tissue may cause a child to be mentally defective. If these are present, convulsions, headache, twitching, tremor, paralysis, and progressive deterioration, one or all, are symptomatic. The treatment is surgical, but a favorable outcome is to be expected in rare cases only.

Hydrocephalus. Hydrocephalus is a condition in which there is an accumulation of cerebro-spinal fluid within the ventricles of the brain, sometimes amounting to several pints. This fluid exerts pressure upon the brain tissue, and also upon the skull, the sutures of which often become quite widely spread. These children, therefore, usually have very 
large heads, though in rare instances where the bones of the skull have united prematurely, expansion of the cranium may not be possible, in which case convulsions are frequent, followed by early death.

The course of hydrocephalus is unpredictable. It may progress, and end in death during childhood; it may become arrested spontaneously; or it may be amenable to periodic surgical treatment, which consists in drawing off the excess fluid. In nearly all cases there is some degree of mental deficiency. Mild cases are occasionally seen in school, though the majority are easily recognized as proper subjects for hospital or institutional care.

Encephalitis and Meningitis. Acute inflammation affecting the nervous tissue in a growing child may be the cause of mental subnormality. Usually such infections occur in the early years of childhood, and the mortality from them is very great. Of children who do not succumb by death, a very few recover completely, but in most cases the intelligence is impaired, and paralysis and sensory defects, especially deafness, are commonly present.

A minute description of the onset, course, and pathology of these conditions is irrelevant to the purposes of a treatise on educational psychology. It is furthermore true that very few of the children so afflicted ever appear in the schools. This is so for various reasons. In the first place, there are very few of them in existence. In the second place, they 
are usually of very low grade mentally, too low for attendance upon the public schools. In the third place, they are often physically crippled in such a way as to render attendance upon school impossible.

Of the rare cases attending schools, it will often be found that they profit less by instruction than do ordinary defectives. Apparently the lesions which are produced by the disease interfere with the association processes, in a manner which is not seen in those who have never suffered from any pathological condition, but are simply of inferior quality.

Epilepsy. Frequently repeated convulsions, which are epileptic in character, have a deleterious effect upon the mental life. In persons who have reached the limits of mental growth before the onset of the seizures, deterioration in mental prucesses is a common phenomenon. When the attacks begin in a growing child, in whom the development of the neurones is still incomplete, growth may be arrested by the disorder, and mental deficiency results. Here again the degree of deficiency varies from mild inferiority to the condition of idiocy.

Epileptics of whatever degree of intelligence tend always to deterioration, so that instruction is carried on in their case with a maximum amount of effort and a minimum amount of reward. The prospects of improvement by training, and the outlook in general for these cases is most unfavorable. Retention seems to be especially impaired by epilepsy, so that 
the child forgets what seemed to have been well learned on a previous occasion. It is much more difficult to build up a system of specific habits in them, than in children simply inferior by nature. Moreover, epileptics in general are characterized by irritability and other unfortunate traits of temperament, and feeble-minded epileptics are no exception to this rule.

The seizures producing the mental deficiency may be of any of the classic types. They may be of the Grand Mal type, in which the whole body is convulsed; they may be of the Petit Mal type, in which there is convulsive twitching, without falling; they may be Jacksonian in character, in which case only a part of the body is involved; or they may belong to the type called Psychic Epilepsy, in which case there are no motor phenomena, the consciousness alone being interrupted.

It has been found that the epileptic respond best to manual training, and to occupations which can be carried on in the open air. It has always to be borne in mind that dangerous machinery, sharp implements, and hot objects like boilers and stoves, must be avoided in the occupation of the epileptic, as he may injure himself in an attack. Thus cooking, running elevators, and similar simple work for which high-grade defectives are and can be trained, are not appropriate in these cases, although clinical examiners constantly find epileptics so engaged. 
Infantile Cerebral Degeneration. From a cause unknown it sometimes happens that cerebral degeneration begins in an infant or young child, progressing through a course in which total blindness supervenes, and at the end of which the child dies. The disorder is always fatal, and the victim of it does not, of course, develop normal intelligence, as degeneration of the cortical neurones is one of the chief pathological features of the condition. These children rarely live to attain school age, and even if one so afflicted should survive to such age, he would be unfit to attend school. Thus teachers are very little concerned with such cases. Since the course of the disease is progressive deterioration to inevitable early death, the cases are subjects for nursing rather than for teaching.

Because of the fact that more than one child in a family is usually affected, the disease is often called Amaurotic Family Idiocy, the word amaurotic referring to the atrophy of the optic nerve, which leads to blindness.

Injury to the Cranium, Involving the Brain. Severe injury to the head, in which the skull is fractured, and the brain is involved, may result in arrest of mental development, if it occurs in a young child. Even though the skull remain intact, it is possible to bring about the catastrophe if the injury is of such a nature as to produce hemorrhage within the brain.

Prolonged pressure on the head during the process 
of birth may work such injury. Paralysis of one or more limbs is a very common feature of such cases. Motor control is poor, and not infrequently the child grows up subject to convulsions. Such condition due to pressure during birth is called Little's Disease, for the physician who originally described it. Mental deficiency may, but does not invariably, accompany the paralysis, and other manifestations. Since the child suffering from Little's Disease is a cripple, his instruction is often carried on privately, rather than as a member of a school group.

Injury to the head sustained after birth, during the years of childhood, may also interfere with mental growth. Only very severe accidents are, however, to be considered here, such as are followed by hemorrhage from nose or mouth, loss of consciousness, fracture, vomiting, a change in temperature, convulsions, or paralysis. Nearly all children "bump their heads," yet continue to follow out the course of normal development.

It is true that children who are mentally deficient by original nature fall more frequently and have more accidents than do normal children, simply because they are not so able to guard against common dangers. Thus "falling down," "hitting the head," and such accidents are very often alleged by parents to be the cause of their offspring's defects. In the majority of cases it will be found that where a fall is the cause given, cause and effect have been confused; 
that the child is not defective because he fell, but fell because he is defective.

These Causes May Act on Any Degree of Native Intelligence. Accident and disease, such as we have touched upon here, may degrade to a lower level any degree of intelligence. They may degrade a genius, a mediocrity, or a moron to the status of an idiot or an imbecile. They may also attack children originally idiotic or imbecile. They occur without reference to the degree of intelligence potential in the germ-plasm. The-opinion has been put forth by a few specialists in the field that children of neuropathic ancestry are more likely to suffer from organic diseases of the nervous system than are children in whose ancestry there is no neuropathic strain. This has never been established by figures scientifically collected. If true, it might mean that the number of really secondary cases is even smaller than at present estimated.

Mental Deficiency Due to Accident and Disease is not Hereditary. In cases where a child of potentially good intelligence becomes the victim of any of the organic misfortunes which have been mentioned in this chapter, and is mentally deficient as a result, this mental deficiency is not hereditary. The nature of the germ-plasm is such that it cannot be affected by injuries to the nervous tissues, any more than it can be affected by the amputation of an arm from the body, or by dyeing the hair of the head. The chances are small that any child affected in the manner which 
has been described will have direct descendants, so that the question of heredity has a practical bearing only in the case of his relatives. The hereditary background is not impaired in the least by the presence of a truly secondary case of feeble-mindedness in the family, since this is a matter of external influences, and not a matter of the constitution of the germ-plasm. Whether a given case is secondary or not can be determined only by a competent specialist. Parental and popular prejudice would, of course, tend to find some external cause for all mental defect, would tend to regard all cases as secondary; whereas very few cases really fall into this category.

Teachers Do Not Often Find Secondary Cases in School. It is clear that accident and disease sufficiently severe to produce mental deficiency will, as a matter of fact, be survived by few children. The mortality among children afflicted with syphilis, abnormal growths in the brain, hydrocephalus, encephalitis, meningitis, cerebral degeneration, and fracture of the skull is very great. Since no great proportion of children are ever afflicted with these misfortunes in the first place, and since only a few of those afflicted survive, it follows that among children of school age, few exist. Of the few who do exist, most are reduced to the status of idiocy or imbecility, and many are crippled, so that they are obviously not "physically and mentally able to attend school." 
Those who are able to receive instruction, are often taught privately at home.

The secondary cases of mental deficiency which are oftenest met in the elementary school, and in special classes, are the epileptics and the cretins. Teachers should, therefore, be able to recognize these conditions when confronted by them. In mental ability they are on the whole much more uneven than the feeble-minded, whose deficiency is primary. Secondary cases are characterized by irregularity of performance in tests of intelligence.

\section{REFERENCES}

1. Baldwin, B. T., A Study in Mental Retardation in Kelation to Etiology. Medical Record. Jan. 27, 1917.

2. Barr, M. W., Mental Defectives. P. Blakiston's Son and Company. Philadelphia. 1913.

3. Eddy, W. H., The Isolation of a Growth-Producing Substance from Sheep Pancreas. Journal of Biological Chemistry. Oct., 1916.

4. Jelliffe, S. E., and White, W. A., Diseases of the Nervous System. Lea and Febiger. Philadelphia. Second Edition. 1917.

5. Shuttleworth, G. E., and Potts, W. A., Mentally Deficient Children. P. Blakiston's Son and Company. Philadelphia. 1916.

6. Tredgold, A. F., Mental Deficiency. William Wood and Company. New York. Second Edition. 1915. 


\section{CHAPTER XIV}

NERVOUS AND MENTAL DISORDERS WHICH MAY COMPLICATE MENTAL DEFICIENCY

The Mentally Deficient are Subject to Mental and Nervous Disorders Which may Affect Children in General. A low grade of intelligence is no insurance against mental and nervous disorders, to which children in general may be subject. Just as the feebleminded may contract any organic disease, so they may be affected by disorders of the mind and nerves. In such cases the disease or disorder is the accompaniment of the mental subnormality, there being no causal relation.

In addition to the organic diseases and traumata of the nervous system, which have already been mentioned, and which may affect the originally feebleminded to reduce them further in mental status, it is necessary to consider briefly certain other nervous and mental disorders, which occasionally complicate mental deficiency in children.

Speech Defects. Speech defects are much more common among subnormal children than among children chosen at random. The power of learning to formulate words rests upon a basis of various complex 
abilities which we have called general intelligence. Individuals below a certain mental age are incapable of using language', in the sense that they cannot learn to express their ideas or trends by the use of articulate sounds.

It has already been noted that lateness in talking is characteristic of those who are subnormal in gencral intelligence. As speech develops in the subnormal it often tends to be defective in some respect, most commonly in respect to distinctness of articulation. Dr. Wallin found that in the classes for mentally deficient children in St. Louis about a fourth of the children were defective in speech. "In general the lower the grade of intelligence of the group, the greater the prevalence of speech defects." All forms of speech defect except stuttering were more prevalent among mentally deficient than among normal children. Other investigations have led to similar conclusions, except that all have not agreed that stuttering is more common among children of normal intelligence.

As Dr. Wallin observes: "It is not at all surprising that there should be a close correlation between speech defects and mental defect, in view of the fact that the mechanism of speech is highly complicated, involving the harmonious integrative action of a number of delicate anatomical, physiological, and mental adjustments. The above facts indicate how necessary it is that teachers of feeble-minded and 
backward children should be capable of correcting at least the simpler types of faulty articulation."

Two peculiarly interesting anomalies of speech met with in low-grade institutional cases are echolalia and coprolalia. Echolalia is a curious tendency found in defectives, who are mentally at what Binet calls " the dawn of speech," to repeat or echo what is said to them or in their hearing. Individuals who have not sufficient intelligence to originate remarks of their own, may be able to "echo" quite well. They show no understanding of the question-response situation, but imitate words and inflections which they hear. Sometimes they repeat gestures as well. The same phenomena are observable in young children who are at "the dawn of speech," but are not so noticeable in them as they quickly pass beyond this mental level, - may pass it in a week or a month, perhaps, - whereas the defective who reaches his ultimate intellectual level just at this point shows the phenomenon all his life.

Binet gives an interesting account of the imbecile, Denise, who could echo quite well, though she was forever incapable of developing the complete use of spoken language. Denise was twenty-five years old, an inmate of an institution in Paris. Binet gives the following description of her.

"She is affected with echolalia and mimicry accompanied by all kinds of comical actions. If one coughs, she coughs; if one blows his nose, she blows hers; if one laughs, she laughs. She repeats the last word of a sentence which is said, or else says yes 
in acquiescence, even when one is paying no attention to her. At the same time she imitates whatever one does. If one writes, she takes on a mischievous air and pretends to write with her finger on the table; if one scratches himself she scratches herself; if one crosses his arms she does the same; if one twirls his moustache, she imitates the action. The imitation by gesture or voice is done quickly, accompanied by a laugh and mocking air, but the imitation does not continue long. Very quickly her attention fails; Denise thinks of other things, looks about her, then after a time comes back to us and if we continue to write she resumes her imitative gestures. . . Before a witness whom she does not know Denise is intimidated, remains shy, and shows no evidence of echolalia or mimicry. It is, therefore, something different from reflex echolalia, since it is under the influence of psychic causes and is exercised only under certain easily determined conditions. Neither is it a voluntary echolalia, the art of imitation as practiced by a comedian who gives himself to this effort as others give themselves to any sort of work. It is an intermediate form which is at the same time partly reflex and partly voluntary, and which very clearly expresses the childish character of Denise."

Coprolalia is the tendency to utter certain words or phrases spontaneously, without any appropriate external stimulus having been applied. The individual bursts forth suddenly at intervals with his expression. For example one imbecile repeated at intervals, "I want to know," and another was accustomed to utter explosively, "Get out! Get out!" Both echolalia and coprolalia occur generally among defectives who are too low-grade to develop language, and who are therefore not school cases.

Occasionally a subnormal child is found who has developed a language of his own. Being unable to articulate the word which he hears applied to that of 
which he wishes to speak, he approximates it with some utterance of his own, and by repetition makes the association permanent; and he continues to use these improvised words even after he reaches a higher level of intelligence, at which the correct expressions could be learned. To re-educate such a child in speech is a long and tedious task.

There has been a considerable amount of discussion bearing on the relation of "handedness" to speech. It has been indicated by investigation of the relation of speech defects to "handedness" that attempts to " change over" a right-handed child to the left, or a left-handed child to the right, frequently result in stuttering. That there is some connection between the speech mechanism and the mechanisms controlling the hands is further indicated by data bearing upon right hemiplegia and left hemiplegia (paralysis of right and of left sides, respectively), and the disturbances of spoken and written speech attendant thereupon. On the whole, it would seem to be the wisest policy not to try to " change over" a child who is decidedly left-handed, or decidedly right-handed.

The correction of serious speech defects can be successfully undertaken only by teachers who have made a special study of the subject. In some cases the condition calls for surgical or dental treatment, as in tied-tongue, cleft palate, and malformation of the teeth. Treatment should be prescribed by a specialist, wherever the services of a specialist are available. 
Chorea (St. Vitus Dance). This disorder is named from the Greek word which means to dance.

and like tar felling well.

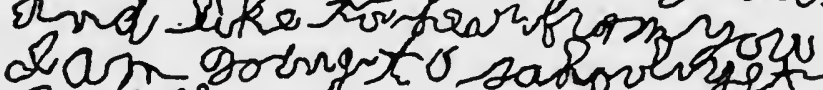
and there chas class and she tored Yce That afe knoy you seanze zovalwaryogras Fo the-fictor a nol ols

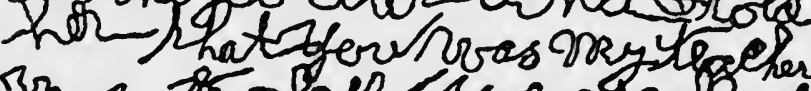

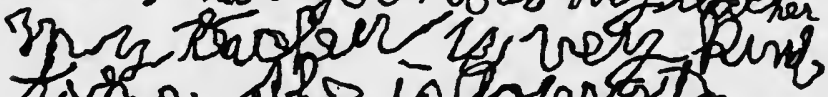
toshe. Ala is Goursto Inake arparly to morrow

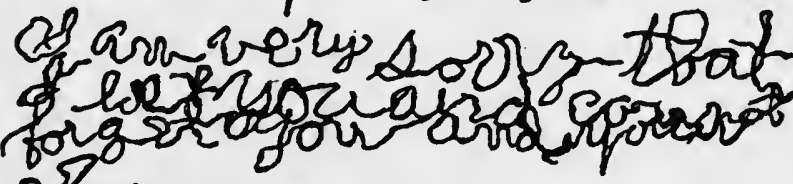

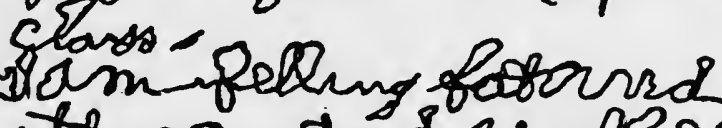
ottong ond urbergor

Fig. 21. - Facsimile of a letter written by a feeble-minded child with chorea.

Dancing is suggested by the gait of the child affected, as in the more pronounced cases there is great difficulty in coördinating the movements of the grosser 
muscles. The outstanding feature is impairment of motor control, which ranges in severity from mere twitching of the finer muscles, so slight that it can be detected only by instruments of precision, to a condition in which the child is in constant motion, jerking and twitching in all his muscles. The movements are arhythmical in character, - not like that rhythmical nodding of the head, which is sometimes seen in old people.

The extreme interference with voluntary movement is well illustrated in Figure 21, which shows a letter written by a feeble-minded child with chorea. It is also illustrated by the motor test reproduced in Figure 22, which shows the condition of a boy of normal intelligence, suffering from chorea in severe degree. In these children often the first symptom noted is that handwriting is poor. Of course all manual work is a strain upon them. They "drop things," spill ink, stumble, speak indistinctly, and "cannot keep still" in school. Any child exhibiting these symptoms in noticeable degree should become an object of concern to the psychological clinic.

That mental symptoms may be present in chorea is seen in the case of the child whose motor test is shown in Figure 22. Fred F- was seen in 1916, on the Psychopathic Wards at Bellevue Hospital. He was 11 years 3 months old, and had been in school up to the very day of his appearance at the hospital. Motor symptoms were very marked, speech was 
indistinct, and there were delusions of grandeur. These delusions were fairly stable, remaining approximately the same from day to day. He said on examination: "I have seven million dollars. I sold

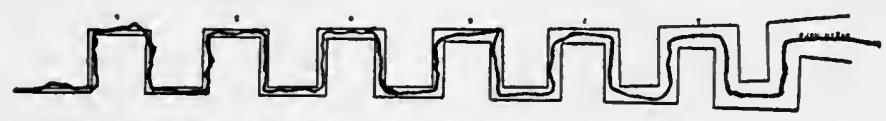

g see a digy in the br.

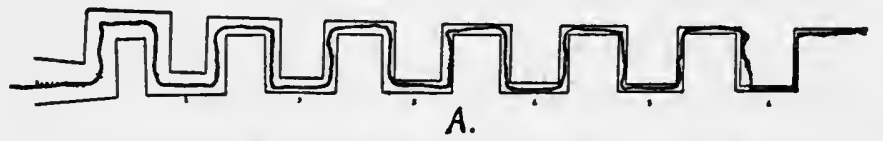

FIG. 22 (A). - Motor test and handwriting of a normal child.
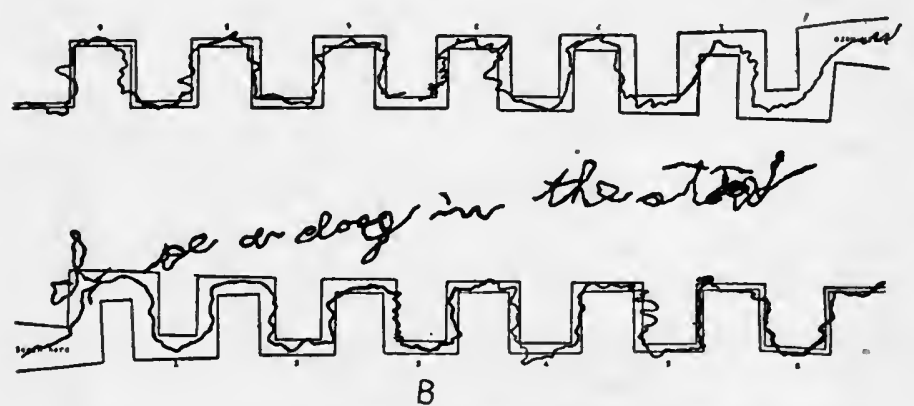

FIG. 22 (B). - Motor test and handwriting of a child suffering from chorea.

diamonds and got it. I have a big house on Fifth Avenue. Big white house. When I get out of here I'm going down to Texas to be a cowboy. . . . At night I see big faces on the walls. Big horns on them. In the day I see little things flyin' around me. 
They scare me. I knock 'em, - like that! I hear ladies talkin' underneath the pillow. They say, 'Catch him. Bring him down here.' They're going to eat me. When I hear them, I get up quick and try to find a book to read, so I'll fool 'em."

At night this child cried out, and frequently he rose and walked out of his room in his night clothes.

The mental symptoms are usually, however, not of this bizarre character, consisting rather in a general apathy and dullness of attitude. Pulse is accelerated, and temperature may be high. A child suffering from well-defined chorea has no place in school, and should be removed for medical treatment until he recovers.

Hysteria, and Other Functional Disorders. Among the soldiers of the recent war who showed hysterical symptoms, and who were incapacitated by functional neuroses, were many of subnormal intelligence. Hundreds of men of very low grade intellectually were inducted into the service at the beginning of the war, before the psychological methods of examination had been put into use. In this way it came about that men as low in the scale of intelligence as the six-year level were found among those suffering from hysteria in the hospitals. It has thus been shown that very low orders of intelligence are capable of taking refuge in hysteria, when faced by an unavoidable environment from which they shrink instinctively. 
In many cases histories of these soldiers were obtained, showing that they had evinced hysterical symptoms in childhood and adolescence. Mental deficiency may be complicated by hysterical attacks, just as mental mediocrity, and mental superiority may be so affected.

Dementia Praecox. The relation between intelligence level and the occurrence of various forms of insanity is practically unknown. No research exists to show whether there is an increase or a decrease in liability to insane states as we go downward in the scale of intelligence. It may be that a stupid man is more likely to become insane than a mediocre man or a gifted man; or there may be no relation whatever between degree of intelligence and the liability to become mentally unbalanced; or the relation may vary greatly with the different psychoses.

It is certain that adolescents of subnormal intelligence may and do develop the type of psychosis called dementia praecox. On the other hand there is probably a limit to the intellectual level at which this may occur. Certainly no one has ever reported an idiot or a low-grade imbecile as having developed dementia praecox. Evidently a certain amount of mental life is necessary as a basis for the disorder, which argues in favor of the theory that dementia praecox is psychological in character, and not of organic origin.

The forms of abnormal behavior subsumed under 
the concept of dementia praecox are numerous and varied, and will not be discussed in detail here. Detailed information on the subject is to be found in the references appended. In general it may be stated that the disorder is characterized by emotional inadequacy, pathological indifference to surroundings, and phantasy. False beliefs (delusions), and false percepts (hallucinations) are usually present. The child or adolescent expresses absurd ideas, hears voices, sees visions, and otherwise conducts himself strangely. The age of onset is most frequently between fifteen and twenty-five years, though it has been reported as early as ten years. Dementia praecox is not a recoverable condition, and the individual suffering from this psychosis is a menace to himself and others, and has no place in school.

Manic-Depressive Insanity. This mental disorder occasionally occurs among children, and among subnormal children as well as among others. In the manic phase the child is abnormally elated, active, flighty, incoherent, and shows other psychological and neurological symptoms. In the depressed phase he is indifferent and inactive, often will not even make the effort to eat, or attend to other personal needs, sits with bowed head, does not answer when spoken to, or else answers very slowly, and presents in general the picture of extreme woe. Sometimes melancholy delusions are present, and the patient hears voices, sees visions, and so forth. 
In these cases one phase follows the other, in various combinations. There may be first a period of depression followed by a period of excitement; or a

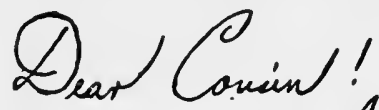

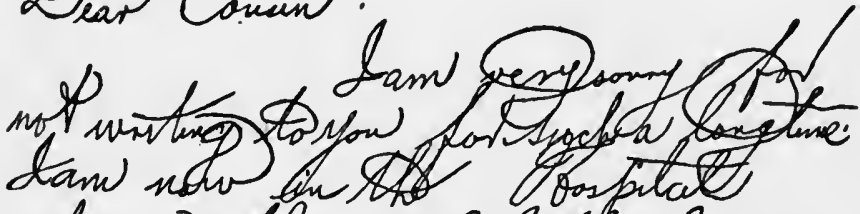
and anv all prelleg thinkt will go home torday. Lravemade wh

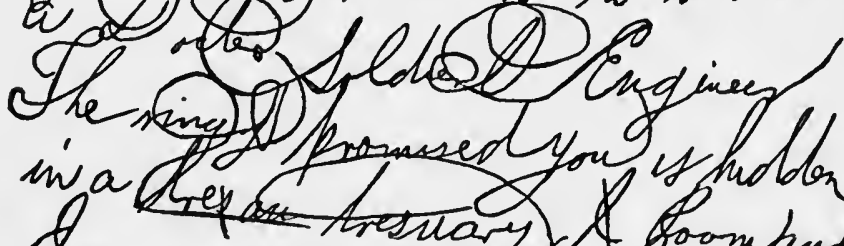

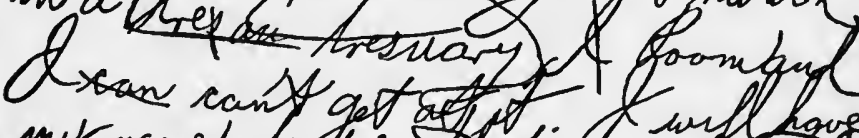

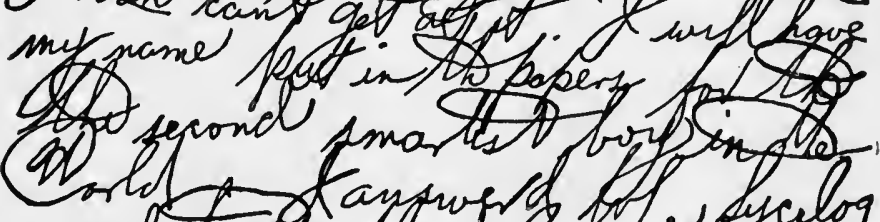

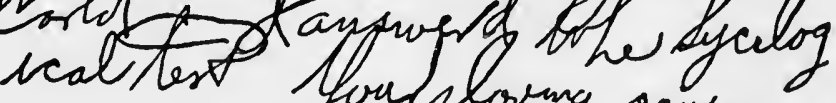

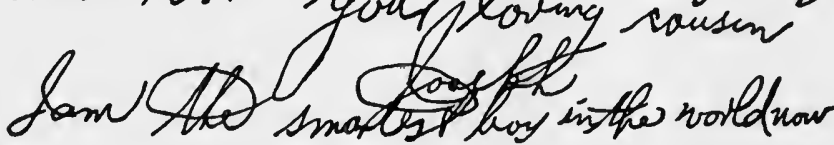

FIo. 23. - Facsimile of a letter written by a child in the manic phase of manic-depressive insanity. 
period of excitement followed by depression; or either may be followed by a period of normal behavior, which is in turn followed by the opposite mood. The chances of recovery from any single attack are

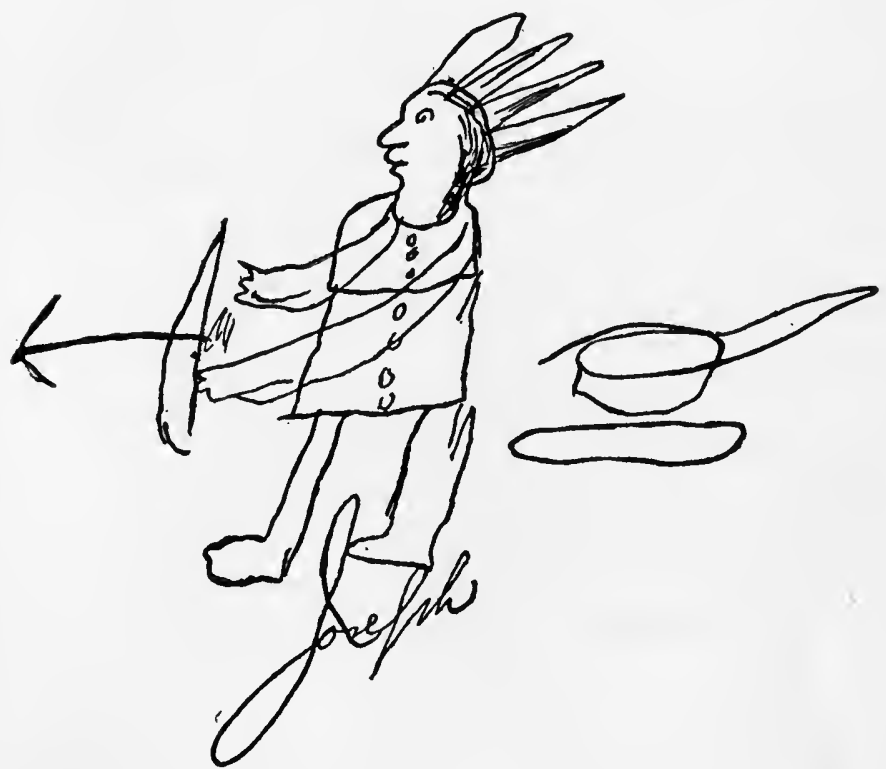

Fig. 24. - Drawing by a child in the manic phase of manic-depressive insanity.

very good, always, however, with liability to recurrence.

Figure 23 and Figure 24 show respectively a letter and some drawings produced by a child eleven years of age, who was brought to the Psychopathic Wards of Bellevue Hospital in a typical manic state. This letter and these drawings were produced at the height 
of the attack, spontaneously. The child was in the $7 \Lambda$ grade in school, and was slightly superior to the average in general intelligence, showing on examination after recovery a mental age of thirteen years, two months.

That a similar condition may occur in a child of subnormal intelligence is shown by the following case: Rachel M-, a child of twelve years, was brought for mental examination at the request of a society interested in child welfare. The child had been observed performing peculiar antics in a street car, and upon being spoken to would tell neither her name nor her address, but loudly demanded a nickel. Upon examination she showed well-marked flight of ideas, as follows: "Crazy - they say - crazy. Mendelsohn - whoop-ee! Mendelsohn comes my mother is crazy - ha! ha! blood - blood in the eye - blood in your eye - the children - where's my penny? - jail - gone to jail. So many children are lost - go to $\mathrm{H}-$ ! go to $\mathrm{H}-$ ! No, I don't say you go to $\mathrm{H}-$, I say. Mendelsohn go to $\mathrm{H}$ Where is my penny? and there goes teacher" . . .

This string of incoherencies was continuous. The child was placed in the hospital, where she was extremely mischievous and garrulous, and where she answered hallucinatory voices. After six days the symptoms subsided, and at the end of the tenth day she was in condition to be discharged to the custody of her parents, who had located her. An intelligence 
examination, conducted after all symptoms had subsided, gave her a mental level of five years, two months. This was in entire agreement with the facts of her developmental history, and her school history. At the age of twelve years she was still in the first grade at school, though she had attended since the age of six years. She had never learned to write even her own name legibly, and could recognize only a few simple monosyllables when asked to read. Her family knew that she had " never been bright," but stated that this was her first attack of this nature. She had "never acted in this way before," and had never before wandered away from home.

A case of depression in a feeble-minded child is the following: Walter $S$ - , a boy of fourteen years, was sent for mental examination, accompanied by the following statement from a physician, in the Department of Education: "The Bureau of Attendance of the Department of Education requested me to examine a boy fourteen years of age, named Walter S-, who has behaved abnormally only since last Monday, at which time he left home at 7:40 A.M., for the early session at a parochial school. He returned at 10 A.M., and could give no account of himself. He is afraid to leave the home premises unaccompanied by his parents. He can answer only simple questions, and them with great difficulty. He has a slight contusion above the left ear. No paralysis. No history of nose-bleed. Has not been 
unconscious, so far as known. He was delirious last night. I telephoned this P.M., and was directed to send him for observation."

The boy was brought by his father who stated that he had always been backward in school. He knew the child was " not bright," for he had been "left back" five times, and had attained only grade $5 \mathrm{~A}$ at the age of fourteen years. He had, however, never acted in this peculiar manner before.

Upon examination the boy was very much depressed. There was no mobility of facial expression, and reaction time was abnormally long. He responded to questions with wholly irrelevant remarks, such as, "He will go to hell," "They will sin if they eat meat on Friday," "They must pray for him." He was afflicted with self-accusatory ideas. He declared that the whole world hated him. This was because he was ruptured as a baby, on account of his mother holding him too much. He reiterated the statement that he would go to hell, because he had been so bad. When he wept he said it was because he had cursed at the teacher. This was a very wicked thing to do. God spoke to him. There was a band of iron about his head, and people gazed at him on account of his sins.

In about a week the symptoms subsided in the case of Walter $\mathrm{S} \longrightarrow$, and he became cheerful, and normal in behavior. Intelligence examination revealed a 
mental level of eight years. This finding was entirely consistent with the developmental history of the boy, and with his school status. His case illustrates very well the occurrence of a psychotic episode in a child of subnormal intelligence.

Other Forms of Mental and Nervous Disorder in the Subnormal. We have now mentioned briefly the nervous and mental disorders which are most commonly found among children, - among mentally deficient children as well as among others. Every teacher should know of the existence of these disorders. Many a case regarded as disciplinary, over which the teacher wears out her energies, really belongs to one or another of the conditions described here. Our discussion has been by no means exhaustive, but only such as will enable teachers to be intelligently on the lookout for symptoms of real mental and nervous disturbance in children who present special problems of discipline. When such symptoms are noted by a teacher, the child should be reported at once to the psychological clinic, or to whatever person is in a position to make a diagnosis of the case.

In addition to the disorders specifically mentioned here, it must be stated that the adult feeble-minded may suffer from any organic disease of the nervous system which may affect persons in general; and that they may develop any psychosis, except such psychoses as require a well developed intellectual life as 
a basis. It is possible that paranoia (sometimes formerly called "reasoning insanity") cannot develop in feeble-minded persons, and that they may be exempt from certain other forms of insanity by virtue of their inability to formulate and entertain ethical ideals, or strenuous personal ambitions. The lower the intelligence, the simpler is the mental life, and hence the fewer are the mental conflicts which arise. Thus it is possible, though not known to be a fact, that low intelligence may constitute an exemption from certain mental disorders which are psychological in character.

\section{REFERENCES}

1. Gordon, A., Psychoses in Mental Defects. American Journal of Insanity. April, 1919.

2. Hollingworth, L. S., Echolalia in Idiots. Journal of Educational Psychology. April, 1917.

3. Richards, E. L., Psychopathological Observations in a Group of Feeble-Minded. American Journal of Insanity. March, 1919.

4. Tredgold, A. F., Insane Aments. (Mental Deficiency.) William Wood and Company. New York. Second Edition. 1915.

5. Wallin, J. E. W., Report on Speech Defectives in the St. I.ouis Public Schools. Board of Education. St. Louis. 1915-16.

6. Walsh, E. A., A Study of the Speech Defects of Ninety-One Ungraded Class Children. Master's Essay. Columbia University. 1917.

7. White, W., Outlines of Psychiatry. Nervous and Mental Disease Publishing Company. Washington. Sixth Edition. 1918. 


\section{CHAPTER XV}

SPECIAL CLASSES AND SPECIAL SCHOOLS

Why Have Special Classes Been Established? Before the enactment of compulsory education laws, those children who did not "fit" into the system suitable for the majority failed to attend school, or were excluded by act of the school itself. Subnormal children have always existed, doubtless in about the same proportion as they now exist, but the school did not become acutely aware of them until the law decreed that every child must receive an education, "if physically and mentally able to attend school." The state then hired truant officers to bring in those who of their own volition failed to attend, and the school was prohibited from "expelling" children. Thus the subnormal child and the school were forced into a reluctant mutual recognition of each other.

The recognition on the part of the school was reluctant because "an education" meant that which constituted the curriculum for the great average, and "education" in this sense these "misfits" were unable to assimilate. The teachers in the elementary school labored long and diligently with them, not recognizing the true source of difficulty. It reflects 


\section{PSYCHOLOGY OF SUBNORMAL CHILDREN}

unfavorably upon a teacher's ability when many of her pupils are unpromotable. Thus the problem of instructing and disciplining these children has been a great drain upon the time and energies of teachers, who were conscientious in the belief that all are created equal, and that all can learn equally if a sufficient effort is made. Nor is it correct to speak of this situation in the past tense, for it still exists in the majority of our public schools to-day. The cities are taking the lead, but towns, villages, and rural districts have, in most cases, still to face the problem in the light of scientific fact.

The same increasing interest in public education which led to the enactment of compulsory school laws, also led to the professional training of teachers. In the professional training of teachers psychology is of fundamental importance, and one of the chief interests of educational psychology for the past twenty years has been the study of individual differences. Gradually those facts which we have summarized in the first chapter of this book were recognized by progressive educators. It was learned that children differ by original nature over a very wide range of ability; that what constitutes education for one, may not constitute education for another; that the schools must offer a widely differentiated curriculum if compulsory education is to succeed. Thus special classes began to appear here and there over the country, as part of the school system. 
These have been established not only for the children who are subnormal in general intelligence, but for children who for various reasons do not fit into the regular classes. In 1915 the city of Cleveland had special classes, separately conducted, for truants, for the deaf, for the blind, for the epileptic, for the crippled, for the tubercular, for the foreign born and recently immigrated, for the dull and backward (not so low in the scale as the feeble-minded), and for the mentally defective. In addition to these various kinds of special classes, provision is being made here and there for the very superior children, who can easily cover two or three years' work while the average child is covering one year's work.

The History of Special Classes for the Subnormal in the United States. As long ago as 1872 Dr. William T. Harris, then United States Commissioner of Education, called attention to what he designated the "pedagogical misfits" in St. Louis, but the educational world was not roused to any effective interest in the matter at that time. The idea of the actual establishment of special classes for deficient children in the public schools seems to have been first introduced publicly to American teachers as a professional group by August Schenck, of Detroit, in 1878, in an address before the American Teachers' Association. Acting on the suggestions there made, Dr. Andrew Rickoff, Superintendent of Schools for the city of Cleveland, established two special classes in Cleve- 
land, limiting them to children who presented disciplinary problems. The second special class was established in Chicago, in 1892. This has since been expanded into the Department of Child Study and of Special Classes, for which Chicago has long been noted.

New York established its first special class in 1895, under the direction of Miss Elizabeth Farrell. Under Miss Farrell's direction, this work has grown until now there are over two hundred and fifty special classes for subnormal children in New York City. From 1895 up to the present time the movement for special classes has grown apace, so that in 1911, according to the Bulletin of the United States Bureau of Education, a total of ninety-nine cities had public classes for mentally defective pupils, and two hundred and twenty had classes for what was called "mentally backward" children. Since 1911 this number has greatly increased.

The first city to plan for a complete organization of these classes directly under the school administration was Providence, Rhode Island, which had six classes for truants and disciplinary cases, and a separate class for backward children, by 1896 . Springfield, Massachusetts, followed with special classes in 1898, and Boston in 1899.

At the present time school reports show that certain states are very far ahead of others in provision for subnormal children. California, Illinois, New 
Jersey, Wisconsin, Ohio, New York, Minnesota, Iowa, Missouri, and Massachusetts are among the leaders.

Organization of Special Classes. In cities where the school population is sufficient to call for the establishment of several classes for the subnormal, it is usual to consider them as a department, and to place this department under a supervisor, especially trained to administer it. The curriculum is planned by the supervisor, in consultation with the teachers, and others who may be concerned. The work is thus coördinated under a responsible head. Examples of this organization are seen in New York, St. Louis, Duluth, Richmond, and in many other large cities.

For rural districts and small towns the state may provide the administration of special classes, in cooperation with the local authorities. For example, the State of New York provides a supervisor of special classes in the state department of education, in accordance with a law passed in 1918. The first report of the state supervisor of special classes in Wisconsin has recently been issued. Michigan has conducted a mental survey during the months just passed, with the object of ascertaining what provisions are needed, and Virginia is engaged in a similar enterprise.

Special Schools. Usually the special class occupies a room in the building where the regular classes are held, but in certain communities the special classes of a large section are all placed in a building 
by themselves, which is then called a special school. This plan has the advantage of rendering possible the more exact grading of the children by mental age. On the other hand, it has the disadvantage of bringing the children a greater distance from home than does the special class which is maintained in the regular school building. Each plan, in fact, has its advantages, and hence its staunch advocates.

In this connection it should be noted that the state institutions for the feeble-minded are now called schools,' where laws pertaining to their maintenance have recently been re-formulated. Formerly, when intellectual subnormality was considered a mental disease, the institutions for the feeble-minded were called asylums, and were maintained as custodial institutions, on a medical basis. With the passing of this concept of intellectual subnormality, and with the recognition of the fact that children sent to these institutions are continuous in ability and kind with children in general, the word "asylum" is disappearing, and the institutions are being placed on an educational basis, under the designation school. These then become special schools, belonging under the supervision of the state department of education. Of course in these institutions there will always be a number of cases where mental development cannot rise above the level of infancy, and these will need nurses rather than teachers, as infants do. The majority of inmates are improvable by education, just 
as other children are, though in lesser degree. Of these state schools the most widely known are the Training School for the Feeble-minded at Waverly, Massachusetts; the Training School for the Feebleminded and Epileptic, at Faribault, Minnesota; the Whittier State School, at Whittier, California; and the Sonoma State Home at Eldridge, California. The Training School for the Feeble-minded at Vineland, New Jersey, which is perhaps better known here and abroad than any other special school of its kind in this country, is not strictly a state institution, being supported to a great extent privately. All these schools have become famous through their educational system, and through the research which they have carried on in the psychology and treatment of the mentally defective.

State institutions for the feeble-minded began to be established in the United States about the middle of the nineteenth century. The first institution of the kind in the United States was built at Syracuse, New York, in 1854. It is interesting to note that it was built as a school, and has always been maintained as a school. At the present time there are only a few states which are without provision for the feebleminded.

Training of Teachers for Special Classes. In order to render efficient service in special classes, a teacher must have a firm grasp on the psychological and social problems presented by her pupils. This 
means special training, beyond that which is prescribed for teachers generally, though this special training need not be elaborate or greatly prolonged. Within the past ten years departments of psychology and education, in universities and normal schools, have organized courses for teachers of special classes. Training is given in industrial arts, methods of teaching, hygiene, correction of speech, the psychology of subnormal children, corrective gymnastics, and sociology. The demand for teachers who have had the prescribed preparation for teaching in special classes far exceeds the supply at present.

An increasing number of teachers in the regular grades of the elementary school elect these courses, as they realize that they themselves have to deal with the subnormal children in communities where no special classes have been organized. To teachers of the regular grades it is especially interesting to know how the feeble-minded are distributed through the school, where no attempts at segregation have been made.

Distribution of Subnormal Children in the Grades. Idiots seldom enter the public schools, so that teachers do not have to deal with such children very frequently, unless their work is in a special school, such as those maintained by the states. If an idiot enters public school at all, it is only for a short time in kindergarten or first grade. Idiots are institutional cases, and are nearly always recognized as such by 
parents, and by administrative authorities in the school. Defectives of IQ lower than 30 seldom appear at school. Defectives between 50 and 70 IQ are those who attend the public school, as distinguished from the state institution. In addition the public school has, of course, all the degrees of subnormality which range from $70 \mathrm{IQ}$, up to normal, but which are not technically rated as " defective." Our question is, what is the distribution of the technically defective in the grades of the public school?

Investigation has shown that there are mentally defective children in all grades of the elementary school, but that the number found above the sixth grade is very small. High-grade defectives may occasionally reach the seventh or eighth grade in communities where there is a rule requiring that no child shall repeat a grade more than once. Under such a rule, promotion becomes automatic, and presence in a given grade loses much of the significance it should have in relation to mental capacity. Very little study has been made of the intelligence of high school pupils, but the indication is that adolescents with an IQ as low as 70 practically never enter public high school. It cannot be said that adolescents as low in the scale as $70 \mathrm{IQ}$ absolutely never enter high school, for an instance is known to the present writer where a girl of intelligence nearly as low as this actually did enter a public high school, and was retained there for several weeks. However, the 
high school teacher has little concern with the technically defective, though the subnormal who lie between 80 and 90 IQ very often complicate high school problems.

It is true, then, that the teachers of kindergarten, first grade, second grade, third grade, fourth grade, fifth grade, and sixth grade will have charge of the mentally defective, in school systems which make no provision for special classes. Teachers of kindergarten and first grade commonly have to deal with all defective children in the community, who are above the status of idiocy. A typical example of this was seen in a Nebraska town of about four thousand inhabitants. The teacher of the first grade had two rows of pupils far beyond first-grade age, sitting in the first-grade room. The true nature of the difficulties experienced with these children was not well understood. The complaint was that they had not yet been able to learn to read or write a single word, and since they could not proceed to the next grade until these arts had been mastered to some extent, they were "kept back." Some of them had spent three or four years in this room, taking the time of the teacher from the other pupils, and disturbing the discipline of the class, held there to tasks which were irrelevant to their needs.

Teachers of second grade also have to deal with nearly all of the defective children of a community, for they seldom pass beyond the compulsory school 
age without visiting the second grade. Scarcely ever would a child be kept for eight or ten years in the first grade. He would be promoted at least once, if for no weightier reason than that a change might be thought to be beneficial.

Teachers of third and fourth grade have at any given time more defectives than any others, because there is a strong tendency for those of the status of moron to collect there. It is necessary to bear in mind the fact that as the degree of defect becomes milder, the numbers become greater. There are many more morons than imbeciles, and the former practically always reach the third or fourth grade before they pass the compulsory school age, even in schools where promotion is not regulated by artificial rules. They are able to perform the work of the third or fourth grade by the time they are fifteen or sixteen years old, because their mental level is then eight or nine years, and thus they really "reach" these grades.

In school systems where the rule is that a pupil may repeat a grade only once, the defective reaches the fifth or sixth grade, before the compulsory school age is passed. In many states the limit of compulsory attendance is sixteen years, for all who have not by that age passed successfully beyond the sixth grade. Under such circumstances, where no provision has been made for the scientific selection of the deficient, the defective child enters 
school at about the age of six years. If he repeats every grade once on his scholastic journey, he reaches the third grade and remains in it during the years ten to twelve, he is in the fourth grade during the years twelve to fourteen, and is in the fifth grade from fourteen to sixteen. Thereafter he is above the age of compulsory attendance, and drops out of school. This is the typical career of many a feeble-minded boy and girl, who have dragged on through the elementary grades in this fashion, a burden to their teachers, to the administrative officers, and to themselves, never being recognized for what they really are. At the end of such a course, time, money, and effort have all been spent, and the boy or girl has learned almost nothing that is useful to one of such limited capacity. A feebleminded boy after spending several months in a grade beyond his mental age was asked to tell what he had learned during the term. All he could say was that, "An interrogative sentence begins with a capital letter." Asked to illustrate by giving an interrogative sentence, he was unable to respond. He had no conception of what he was talking about. The work of the year had been a meaningless verbal jumble to him, in no sense training him, or preparing him for social participation. The state, having the intention of training him, had in reality forcibly deprived him of an education, by compelling him to attend on the work of the regular grades. 
The Relation between the Special Classes and the Psychological Clinic. The first step in the proper training of the subnormal is identification. When special classes were first started, there was no technique for the scientific identification of the intellectually subnormal. Children were entered in the special classes largely on the basis of general conduct. In this way children of all degrees of intelligence were collected, in a heterogeneous group, with nothing in common except unsatisfactory conduct, or backwardness in school work. Educators were not slow to see that the success of the special class is directly dependent upon the accurate identification of the pupils who really belong in it. As psychologists developed a scientific technique for identifying the subnormal, educators called them into service, and the psychological clinic developed, as we have already seen in a previous chapter. The chief function of the psychological clinic is identification; the diagnosis of conduct. It therefore bears an essential relation to the special class. In follow-up work the clinic is also an important agency, as it keeps the records pertaining to each child, and can keep and furnish subsequent history.

Follow-up Work. It is not infrequently supposed by those who have made no systematic study of the subject, that the school will permanently solve the whole problem of mental deficiency, by administering training suited to the mental level of each child. 
The training plays, however, only a part (though a large part), in the solution of the problem. No training can ever provide intelligence, the ability to meet new situations adequately, to make adaptations in emergencies, to perceive the remote consequences of present acts. Thus the defective if left to his own supervision is much more likely than is the average person to fall into trouble, to "lose his job," and to become dependent in spite of the specific skills which he has acquired by training.

In order to reduce these dangers to a minimum some system of follow-up work is necessary. Just what this system shall be is a question at present much discussed by social workers, educators, and citizens interested in the welfare of the state. We need especially to know the subsequent histories of the graduates of special classes. We need to know what their success is, socially and industrially. A few preliminary studies have been published by inspectors of ungraded classes, and the indication is that the graduates of special classes are able to maintain themselves industrially to a surprising degree. The findings are somewhat complicated, to be sure, by the fact that labor has been very scarce during the years of the war, and wages have been high. Whether the subnormal will make as good a showing in more normal times remains to be seen.

As a final word, let it be said that the school alone cannot solve the problem of mental deficiency. All 
the agencies and agents of social welfare must enlist in an intelligent coöperation, to the end that the subnormal may find social adjustment and cease to be a menace and a burden to the state, and to themselves.

\section{REFERENCES}

1. Farrell, E. E., A Preliminary Report on the Careers of 350 Children who Have Left Ungraded Classes. Journal of PsychoAsthenics. Sept. and Dec., 1915.

2. Fitts, A. M., Mental Defectives in Industry. Ungraded. May, 1919.

3. Maxfield, F. N., The Present Status of the Subnormal Class. State Council of Education. New Jersey. Oct., 1918.

4. Michigan, State of, Backward and Deficient Children. Department of Public Instruction. Lansing. 1918.

5. Mitchell, D., Schools and Classes for Exceptional Children. Cleveland Foundation. Cleveland, Ohio. 1916.

6. New York City, Reports on Special Classes. Department of Education. 1916-17.

7. Oakland, California, Annual Report of The Superintendent of Public Schools. Board of Education. 1917-18.

8. Richmond, Va., Report of the Work of Special Classes. City School Board. Sept., 1918.

9. St. Louis, Missouri, The Psycho-Educational Clinic and Special Schools. Annual Report of the Superintendent of Instruction. 1916-17.

10. Wisconsin, State of, The Exceptional Child in the Public Schools. Biennial Report. State Department of Public Instruction. Madison. 1919. 
$\checkmark$ 


\section{INDEX}

Abilities, special, 125, 126

Adenoids, 223

Alcoholism, 19, 219

Arithmetic, 126, 127

Bellevue Hospital, 259, 265

Birth-rate of feeble-minded, 146

Boston, special classes of, 274

California, expenditures for erime, 21; School of Industry, 33; Juvenile Court, 33

Chicago, special classes of, 274

Chorea, 258

Classification of mental defectives, 52

Cleveland, special classes of, 273

Cranium, 135

Cretinism, 242

Crimes of feeble-minded, 155

Criteria, social-economic, 43 ; pedagogical, 44; medical, 45; psychological, 48

Curriculum, differentiated, 25 ; for feeble-minded, 187

Delinquency, 18; among children, 32

Dementia, 49 ; præcox, 262

Detroit, prevocational classes, 127

Development, "arrested," 94 ; physical, 96; mental, 99; limits of, 98 ; in mental defectives, 100,105

Diagnosis, how made, 70 ; early diagnosis important, 200

Disabilities, special, 125, 126

Drawings of feeble-minded, 183, 184

Echolalia, 255

Education, implications for, 90, Intelligence, 116, 117 $129,168,187$; physical, 145 ; Intelligence quotient, 67

Emotion, 153

Encephalitis, 245 mindedness, 15

Epilepsy, 246

Eugenics, 236 284

Fighting, 159

Follow-up work, 283

Glands, 241

Habit, 167, 198 209 ; nature of, 214

Hookworm, 229

Hydrocephalus, 244

Hysteria, 261

Idiots-savants, 127

Imbeciles, moral, 167

Improvement, nature of, 197

Individual differences, 5

Inferiority, constitutional, 54

Injury to the brain, 248 154

moral, 167; first experiment in education of a defective, 203

Environment, as related to feeble-

Experimentation, 63, 85, 86, 88, 97, $98,101,105,111,112,113,118$, $125,126,127,137,138,139,161$, $173,175,176,177,179,180,182$, $183,184,199,203,220,222,223$, $225,229,230,231,232,235,244$,

Growth, physical, 95 ; mental, 97

Heredity, 208; of mental defeet,

Infantile cerebral degeneration, 248

Instinct, general consideration of, 150 ; in the feeble-minded, 120 , 
Jukes Family, 209

Kallikak Family, 212

Learning process, 170 ; of feebleminded, 171 ; curves, 173, 177; mental age in, 181

Legislation, 237, 271

Malaria, 229

Malnutrition, 224

Manic-depressive insanity, in mental defectives, 263

Manual arts, 115

Meningitis, 245

Mental age, $64,181,178$

Mental defectives, classification of, 52 ; scientific study of, 17 ; identification of, 55; education of, 271

Mental deficiency, definition of, 38 ; criteria of, 42

Mental tests, $62,64,66,69,70$

Microcephalus, 145

Minnesota, State School for FeebleMinded, 125

Mongolians, 144

Mortality among feeble-minded, 146

Mothers, unmarricd, 20

Nervous system, growth of, 97 ; diseases of, 240

New Jersey, Newark, clinic of, 71

New York, expenditures for crime, 21 ; Clearing House for Mental Defectives, 34; Department of Ungraded Classes, 125; Municipal Lodging House, 202

Pennsylvania, University, clinic of, 75

Perception, 120

Practice curves, 173, 177

Prenatal influences, 217
Prevention of mental defieiency, 206, 236

Prostitutes, mental status of, 20

Providence, special classes of, 274.

Psychographic methods, 69

Psychologist, 73

Psychological clinics, 74, 76

Race, as related to feeble-mindedness, 14

Reading, 126, 127

Responsibility, legal, 165

Retardation, in the schools, 24; causes of, 26

Secondary cases, 240

Sensory capacity, 110; defects, 220

Sex, 9, 11, 158

Special classes, 271, 273, 277

Special schools, 271, 275

Speech, 253

Springficld, special classes of, 274

Stigmata, 133, 139

Suggestibility, 160

Superior ehildren, 8, 234, 235

Surveys, mental, 27

Syphilis, 240

Syracuse, State School, 277

Teeth, defects of, 221

Texas, State Reformatory, 33

Ties, 114

Tonsils, 223

Training, transfer of, 179 ; industrial, 130; physical, 146; moral, 167 ; in speeific habits, 195

Unemployment, 20

Variability, 1; physical, 3, 138; mental, 5, 6, 7; in school attainment of children with identical mental ages, 125

Variation, 208

Vineland, 136

Vital capacity, 137 


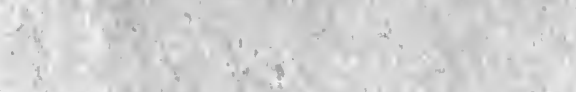

1.

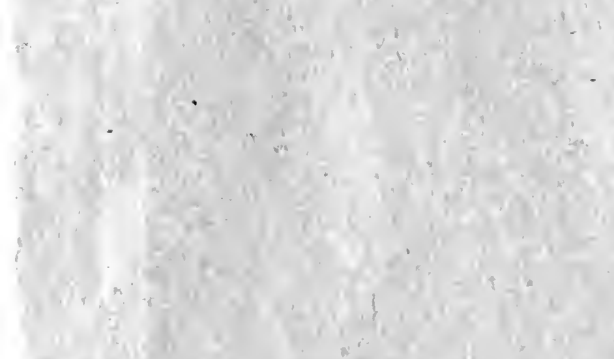


UNIVERSITY OF CALIFORNIA LIBRARY, LOS ANGELES EDUCATION AND PSYCHOLOGY LIBRARY

This book is DUE on the last date stamped below.

\section{SEP 19 19S?}

RET \& DCT 231972

RECEIVED

OCT 251912

EDU.IPSYCH. LBRARY

NOY 211974

PECEIVED

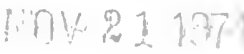

Form L9-10m-9,'65 (F7203s8) 4939A 

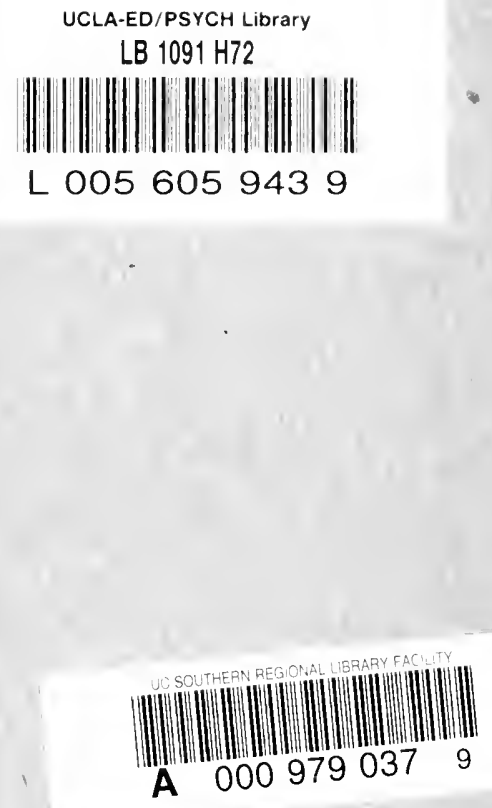
